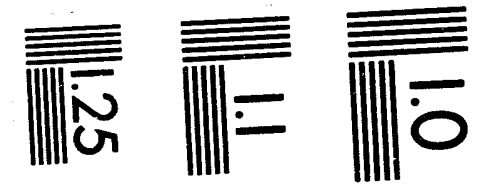

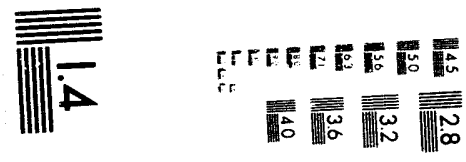

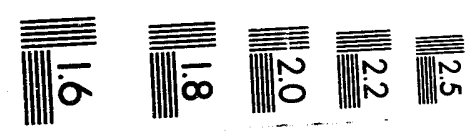




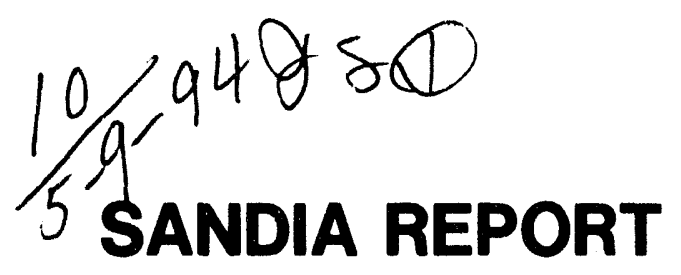

SAND93-3884 - UC- 902

Unlimited Release

Printed March 1994

Interim Report for SNL/NM

Environmental Drilling Project

R. P. Wemple, R. D. Meyer, R. R. Layne

Propared by

Sandla National Laboratories

Albuquerque, Now Mexlco 87185 and Llvermore, Callfornia 94550

for the Unlied statos Dopartmont of Enorgy

under Contrect DE-ACO4-O4AL85000

Approved for public release; dietribution is unlimited.
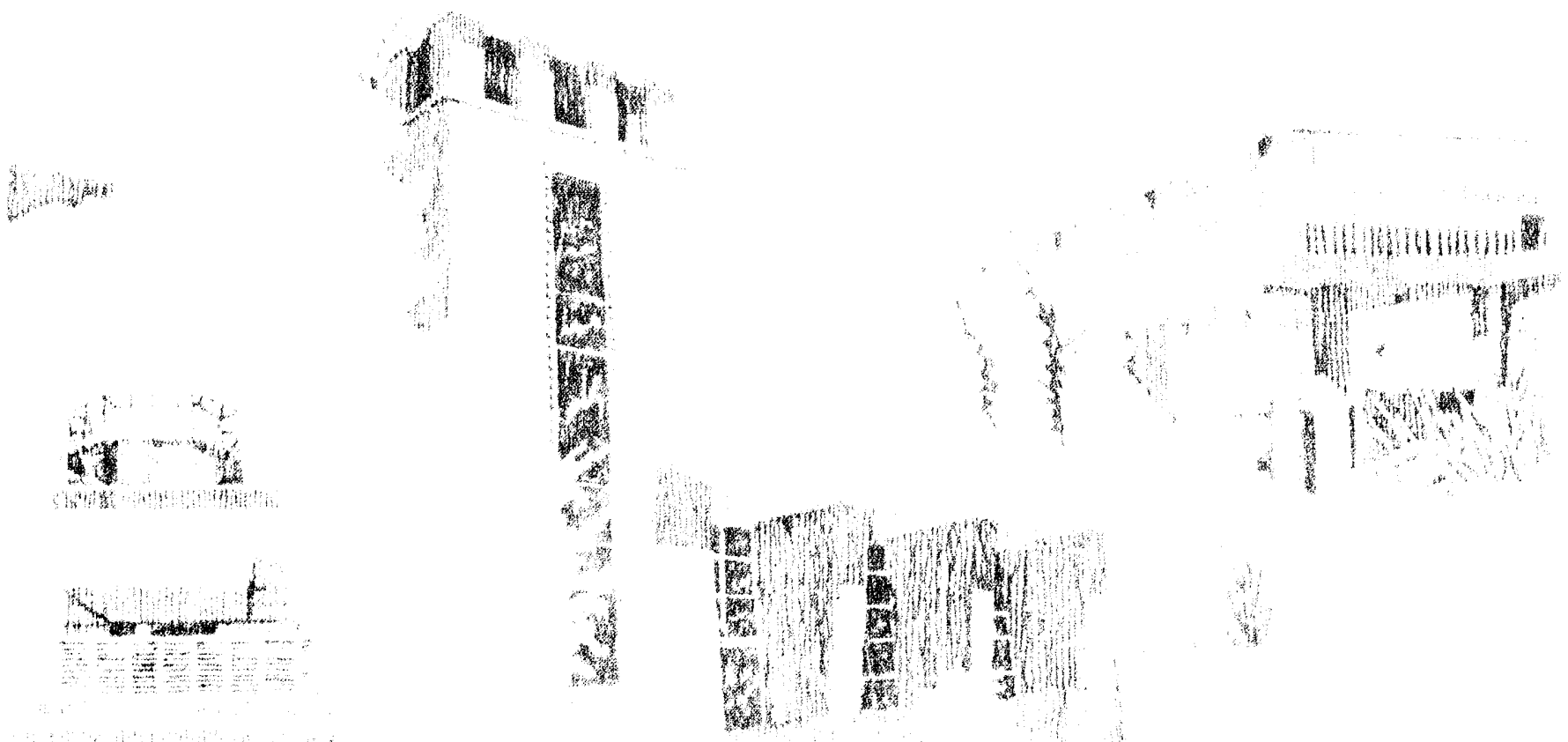

max 
Issued by Sandia National Laboratories, operated for the United States Department of Energy by Sandia Corporation.

NOTICE: This report was prepared as an account of work sponsored by an agency of the United States Government. Neither the United States Government nor any agency thereof, nor any of their employees, nor any of their contractors, subcontractors, or their employees, makes any warranty, express or implied, or assumes any legal liability or responsibility for the accuracy, completeness, or usefulness of any information, apparatus, product, or process disclosed, or represents that its use would not infringe privately owned rights. Reference herein to any specific commercial product, process, or service by trade name, trademark, manufacturer, or otherwise, does not necessarily constitute or imply its endorsement, recommendation, or favoring by the United States Government, any agency thereof or any of their contractors or subcontractors. The views and opinions expressed herein do not necessarily state or reflect those of the United States Government, any agency thereof or any of their contractors.

Printed in the United States of America. This report has been reproduced directly from the best available copy.

Available to DOE and DOE contractors from

$O$ ffice of Scientific and Technical Information

PO Box 62

Oak Ridge, TN 37831

Prices available from (615) 576-8401, FTS 626-8401

Available to the public from

National Technical Information Service

US Department of Commerce

5285 Port Royal Rd

Springfield, VA 22161

NTIS price codes

Printed copy: A06

Microfiche copy: A01 


\title{
INTERIM REPORT FOR SNL/NM ENVIRONMENTAL DRILLING PROJECT
}

\author{
R. P. Wemple, R. D. Meyer \\ Sandia National Laboratories \\ Albuquerque, NM 87185-5800 \\ R. R. Layne \\ Charles Machine Works, Inc. \\ P.O. Box 66 \\ Perry, OK 73077-0066
}

\begin{abstract}
Concern for the environment and cost reduction are the driving forces for a broad effort in government and the private sector to develop new, more cost-effective technologies for characterizing, monitoring and remediating environmental sites. Secondary goals of the characterization, monitoring and remediation (CMR) activity are: minimize secondary waste generation, minimize site impact, protect water tables, and develop methods/strategies to apply new technologies. The Sandia National Laboratories (SNL) project in directional boring for CMR of waste sites with enhanced machinery from the underground utility installation industry was initiated in 1990. Preliminary activities included surveying the directional drilling access needs of various DOE sites, identifying an existing class of machinery that could be enhanced for environmental work through development, and establishing a mutually beneficial working relationship with an industry partner. Since that time the project has tested a variety of prototype machinery and hardware built by the industrial partner, Charles Machine Works (CMW), and SNL at several sites (Savannah River Site (SRS), Hanford, SNL, Kirtland AFB (KAFB), CMW), successfully installed usable horizontal environmental test wells at SRS and SNL/KAFB, and functioned as a clearing house for information regarding application of existing commercial machinery to a variety of governmental and commercial sites. The project continues to test and develop the machinery and technique refinements needed for future applications at DOE, DOD, and private sector sites. The original goal of cost-effectiveness is being met through innovation, adaptation, and application of fundamental concepts. Secondary goals are being met via a basic philosophy of "cut/thrust and compact cuttings without adding large quantities of fluid" to an environmental problem site. This technology will not be universally applicable to all geologies, but will be very cost-effective where applicable. The industry partnership has been extended through FY 94. Technology transfer to the private sector is ongoing and ultimately should result in commercial availability of the machinery. Education of regulatory agencies resulting in restructuring appropriate regulatory standards for specification of the horizontal drilling techniques will be a final project goal.
\end{abstract}




\section{ACKNOWLEDGEMENTS}

The authors wish to thank several individuals at Sandia National Laboratories for their contributions to this project: R.D. Jacobson for his technical support, continuing participation, and technical innovations; J.J. Westmoreland for carrying out the drill cuttings containment system acquisition and testing; and J. Gabaldon for his logistical support of field operations, and J.M. Phelan for his vision and providing seed money for a new project.

The authors also wish to thank their industry partner, Charles Machine Works; the Integrated Demonstrations team for Mixed Waste at SNL; the staff at the Non-Arid Site, Savannah River; and staff at the Arid Site, Hanford.

The Sandia National Laboratories authors welcome any feedback on this report. Please contact R.P. Wemple at (505) 844-2230 or R.D. Meyer at (505) 844-4181. Author R.R. Layne, the Charles Machine Works project manager, can also be contacted at (405) 336-3591 for additional information. 


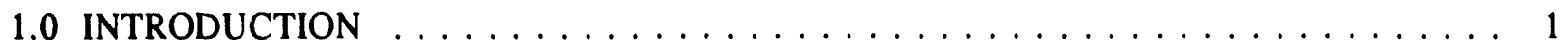

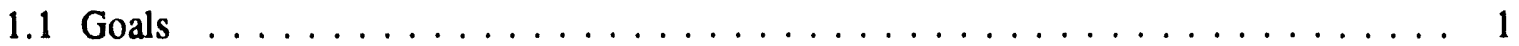

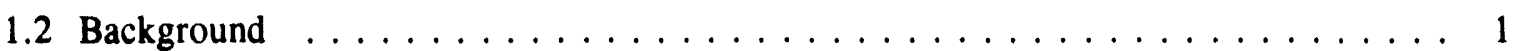

1.3 Technical Approach $\ldots \ldots \ldots \ldots \ldots \ldots \ldots \ldots$

2.0 TECHNICAL DEVELOPMENT AND ACHIEVEMENTS BY FY $\ldots \ldots \ldots \ldots \ldots$

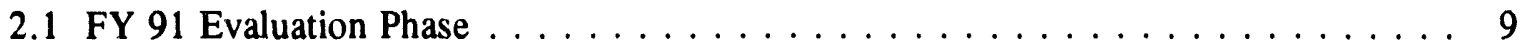

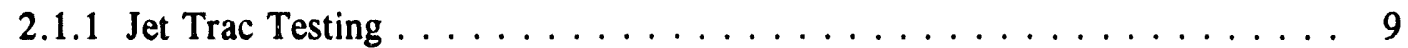

2.1 .2 True Trac Testing . . . . . . . . . . . . . . . . . 13

2.1.3 P-80 Rod Pusher Testing . . . . . . . . . . . . . . . . 13

2.1.4 Pierce-Airrow Pneumatic Hammer Testing . . . . . . . . . . . . . . . 15

2.1.5 FY 91 Development Activity Conclusions . . . . . . . . . . . 15

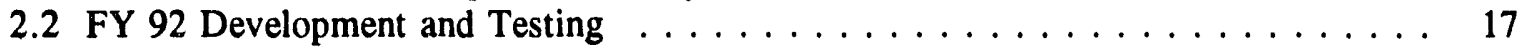

2.2.1 Construction of Test Bed Boring Machine . . . . . . . . . . . 17

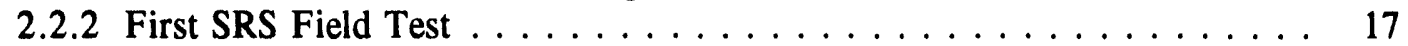

2.2 .3 Second SRS Field Test $\ldots \ldots \ldots \ldots \ldots$

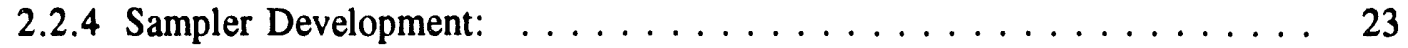

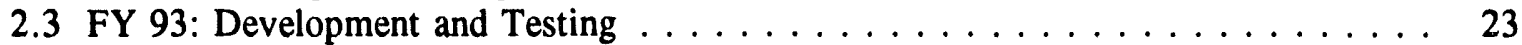

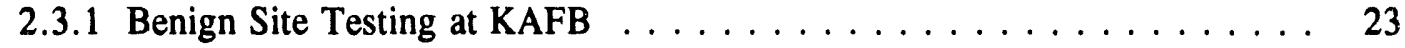

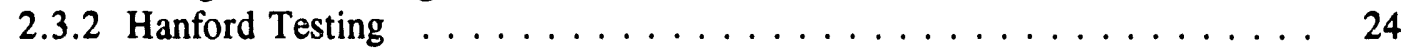

2.3.3 RB-11 Environmental Site Testing at KAFB . . . . . . . . . . . . . . 28

2.3.4 Cuttings Containment System Development . . . . . . . . . . . . . 29

2.3.5 Sampler Development Activity . . . . . . . . . . . . . . . 30

3.0 PROBLEM AREAS $\ldots \ldots \ldots \ldots \ldots \ldots \ldots \ldots \ldots \ldots \ldots \ldots \ldots \ldots \ldots \ldots \ldots$

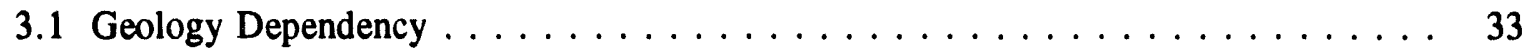

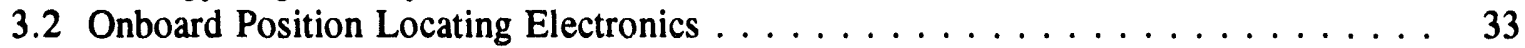

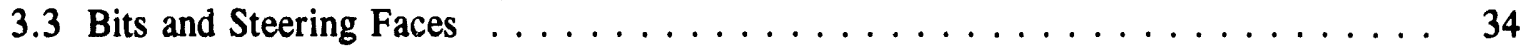

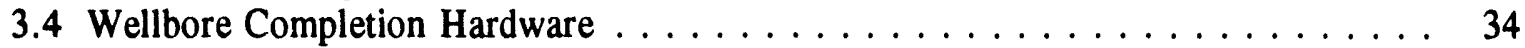

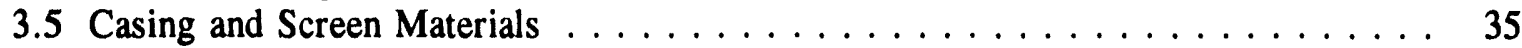

4.0 TECHNOLOGY TRANSFER TO USER INDUSTRIES AND REGULATORS $\ldots \ldots \ldots$

5.0 TYPICAL GOVERNMENT, COMMERCIAL AND PRIVATE SECTOR

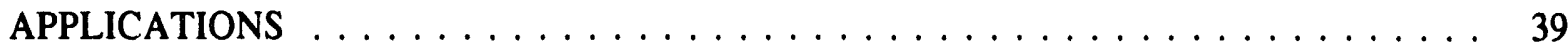

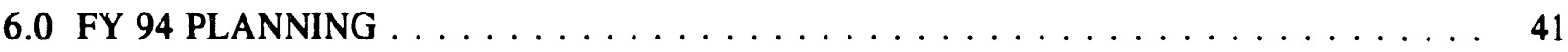

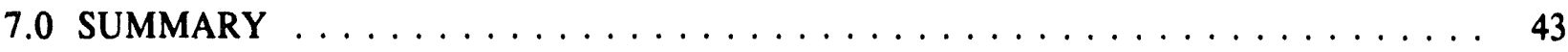

Appendix A: Test Plans, Trajectory Plots, and Edited Field Notes . . . . . . . . . . . A-1

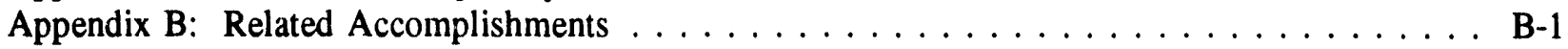




\section{FIGURES}

Figure 1. Waste pit, directionally-drilled borehole grid. $\ldots \ldots \ldots \ldots \ldots \ldots \ldots$

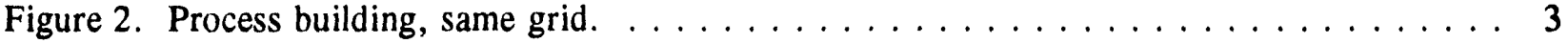

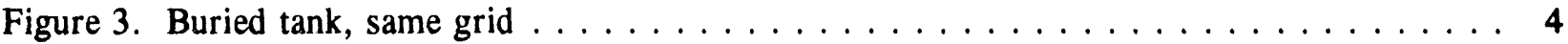

Figure 4. Typical utilities industry directional boring machinery $\ldots \ldots \ldots \ldots \ldots \ldots \ldots$

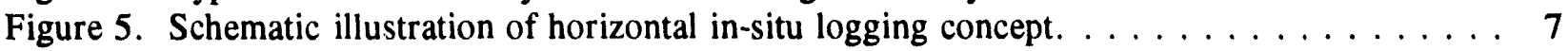

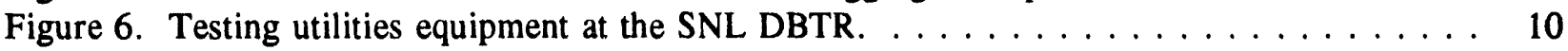

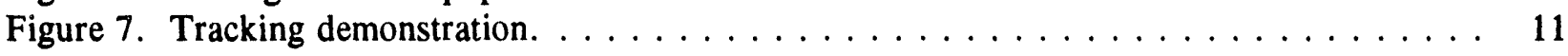

Figure 8. Typical downhole hardware for different drilling phases. $\ldots \ldots \ldots \ldots \ldots \ldots$

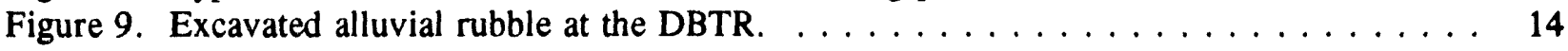

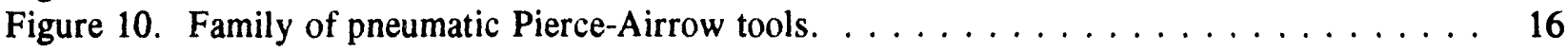

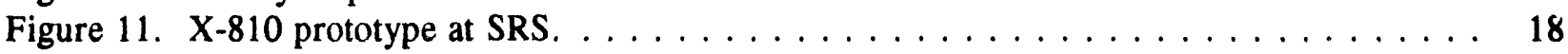

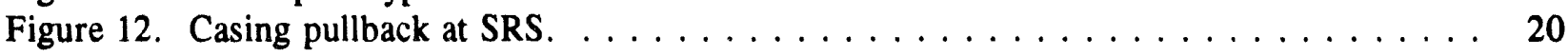

Figure 13. Teflon casing remnant and new fiberglass casing at SRS $\ldots \ldots \ldots \ldots \ldots$

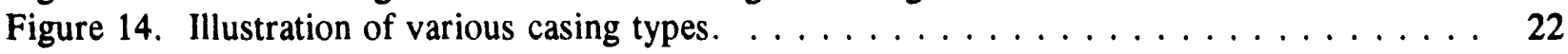

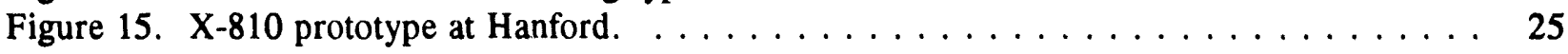

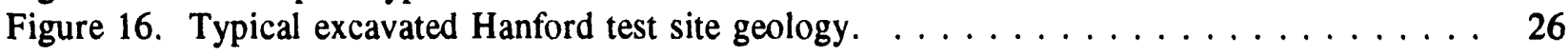

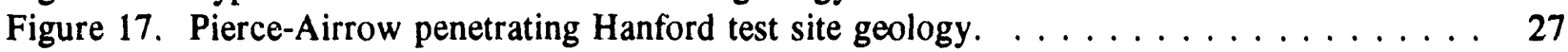

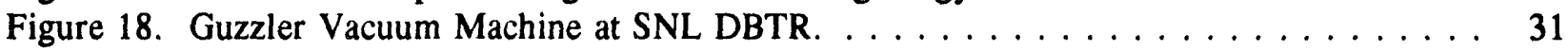

\section{TABLES}

Table 1. Project Funding History in $\mathbf{K} \$ \ldots \ldots \ldots \ldots \ldots \ldots \ldots$

Table 2. Typical Candidate Hardware for Hybrid Systems $\ldots \ldots \ldots \ldots \ldots \ldots \ldots$

Table 3. Four Test Phases for the Drill Cuttings Containment System . . . . . . . . . . 32 


\subsection{INTRODUCTION}

\subsection{Goals}

The original goals of the project were established early on to: 1) minimize environmental impact by the boring/drilling/thrusting method, 2) provide a low cost and yet a high quality alternative to more expensive directional drilling methods for certain geologies, and 3) provide high quality horizontal access as an alternative to vertical drilling at the site periphery. Technology development activities to address Goal 1 were: minimizing the amount of fluid (typically potable water) used in the drilling process, minimizing site impact by the drilling process, and minimizing the amount of secondary waste generated at the borehole entrance by the drilling process. Goal 2 was addressed by identifying existing machinery in various industries that could be enhanced for use at environmental sites, adapting existing methods of underground installation of pipes, cables, and conduits, and developing new technology only as needed to bridge technology gaps. Goal 3 was to be addressed by developing and applying innovative strategies and methods.

Involving an established, world class machinery manufacturer as an industry partner with SNL in the project would help to assure that the project would stay on course and ultimately might result in the generation of a new hybrid machinery class that could be applicable to a variety of environmental problem sites. A subtask of this safeguard would directly involve the ultimate users of the equipment in the hands-on testing and evaluation of the hybrid machinery.

Figures 1, 2, and 3 illustrate the drilling concept.

\subsection{Background}

The project was initiated after some of the experienced SNL staff associated with the DOE Geoscience Research Drilling Office (GRDO) were asked to observe and comment on the installation of a typical vertical monitoring well at SNL. This well was being emplaced to comply with EPA requirements that require several monitoring wells to be drilled to the water table (typically 500' at the site), located both up and down the hydraulic gradient, and completed with grout and casing/screen for continuing use in the future. The GRDO personnel realized that if a drilling company was not extremely careful in drilling and grouting this type of vertical well the immediate potential risk to the deep water table, particularly in arid regions like Albuquerque, could be greater than the original risk associated with landfill disposal of hazardous materials, with the resulting contaminant plume slowly migrating downward over many years.

A less risky way to interrogate a site would be to directionally drill beneath these sites at several depths to sample any leakage plumes migrating beneath the site. Even better, if a grid of surface-tosurface boreholes having entrance and exit portals could be formed in a basket shape, the geometry of the grid could be used for a variety of characterization, monitoring and remediation scenarios for the site. This observation was fundamental to initiating the relatively shallow directional boring development project at SNL. Seed money for the project came from the Environmental Restoration (ER) group at SNL and the SNL Chemical Waste Landfill was identified as a candidate site for 


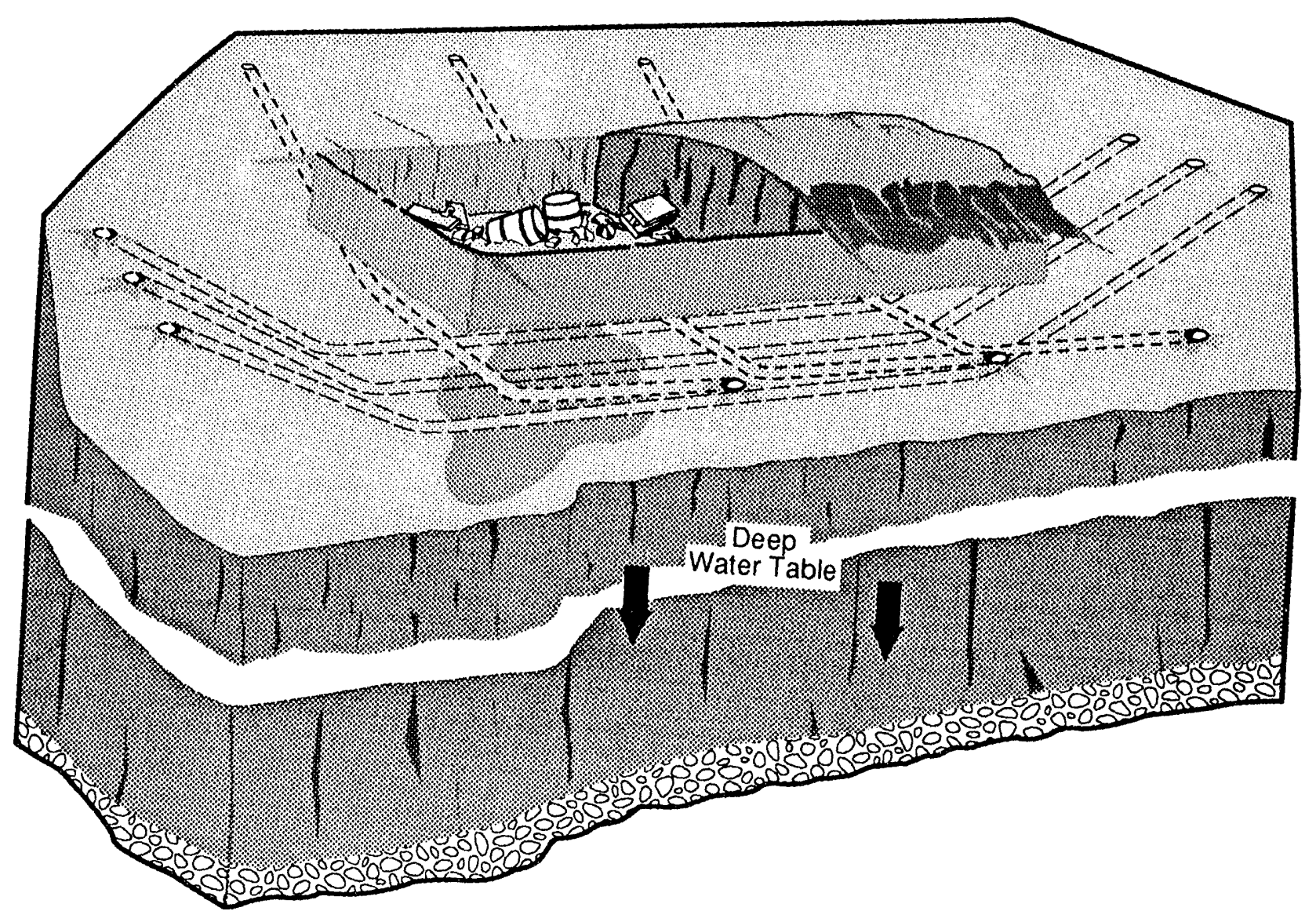

Figure 1. Waste pit, directionally-drilled borehole grid. 


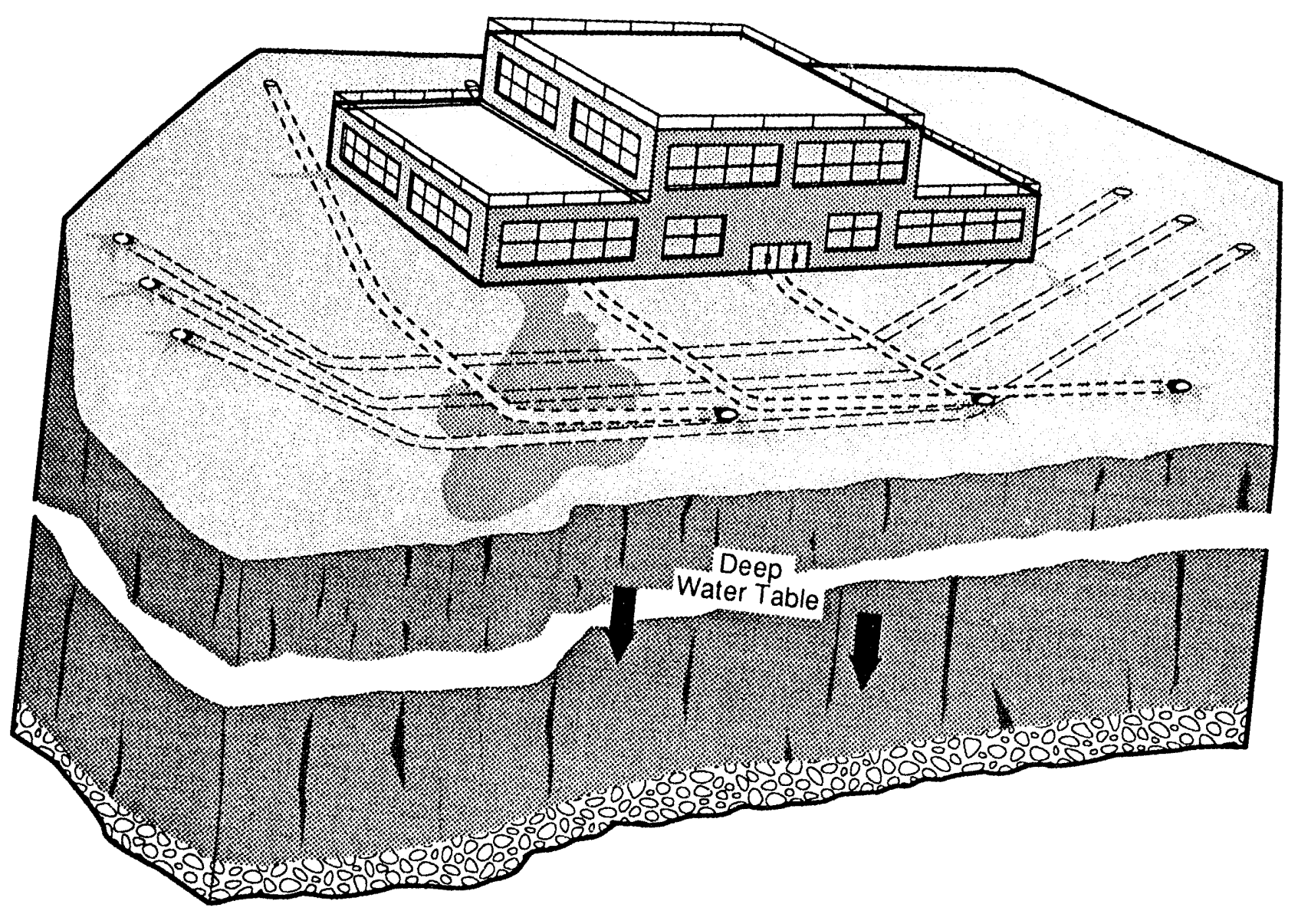

Figure 2. Process building, same grid. 


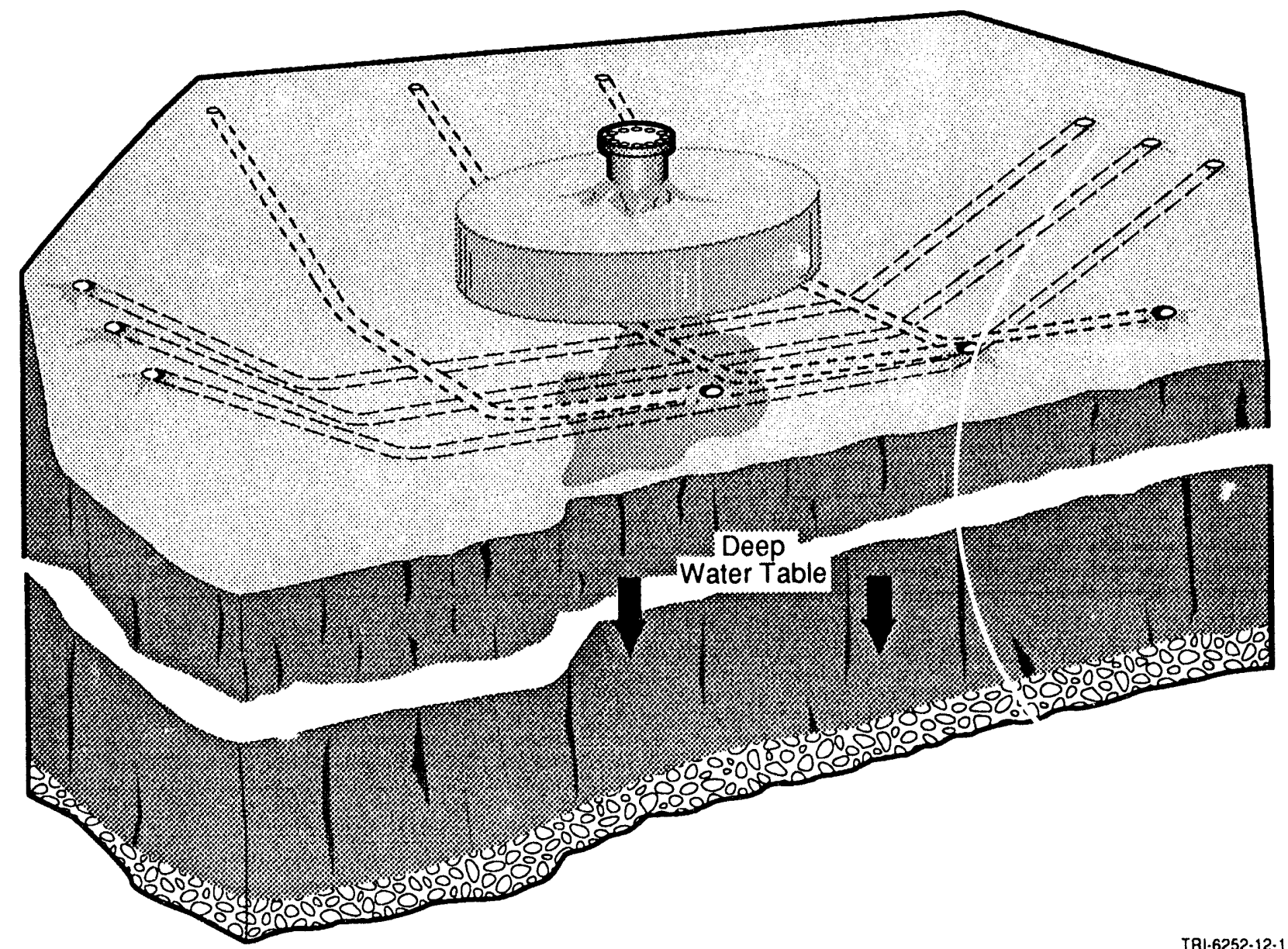

Figure 3. Buried tank, same grid. 
technology development. An adjacent vacant, benign site of six acres was obtained for test purposes with the idea that the geology would be similar.

A no-cost industrial partnership with the Charles Machine Works, makers of Ditch Witch ${ }^{\text {Tu }}$ products, was established and several existing types of machinery used in the shallow underground utilities industry were tested at the SNL Directional Boring Test Range (DBTR) and at the CMW test range in Perry, OK. This partnership was a significant turning point for the project because CMW provided private capital for their share of the development activity and solid industrial judgement about the project direction.

The second year of the project was funded by continuation of small amounts of ER funding, by a supplemental contribution from the COE-OTD Non-Arid Site Integrated Demonstration at SRS, and the continuation of private capital contribution by CMW. The supplemental funding permitted the project scope to expand and trips were made to other DOE facilities to gather information on technology needs. These needs can be summarized as follows: access to greater depths, improved steering and locating techniques, drill cuttings containment through a "cut and compact" method, modification or development of sampling hardware, lower cost when compared to large rigs, and competitive costs when compared to installation of traditional vertical monitoring wells.

Third and fourth year funding was continued by CMW and DOE-OTD and permitted expansion of development activity and refinement to the needs of government and the private sector. However, the DOE-OTD funding was severely reduced by general cost reduction guidelines for FY 94 and will affect completion of the project as originally envisioned. The industry partner continues to provide funding and is developing plans for commercialization. Table 1 provides the detailed funding history.

Additional development of well completion hardware (casing, reamers, and casing pulling mechanisms) could result in commercial equipment better suited to the more difficult geologic formations found at several DOE sites (SNL, Hanford, INEL, and LANL). DOE investment of project funding to improve this hardware should pay significant dividends through reduced drilling costs in the future. Figures 4 and 5 illustrate typical machinery use.

Table 1. Project Funding History in $\mathbf{K} \$$

\begin{tabular}{lccccc}
\multicolumn{1}{c}{ Source } & FY 90 & FY 91 & FY 92 & FY 93 & FY 94 \\
\hline SNL ER & 50 & 75 & 0 & 0 & 0 \\
SRS ID & 0 & 100 & 300 & 300 & 0 \\
SNL ID & 0 & 0 & 300 & 450 & 200 \\
Hanford & 0 & 0 & 0 & 30 & $80^{*}$ \\
DOE Total & 50 & 175 & 600 & 780 & 280 \\
Industry Total & 0 & 300 & 300 & 300 & 300 \\
Proj. Total & 50 & 475 & 900 & 1080 & 580 \\
\hline \hline
\end{tabular}

- For cuttings containment testing at Hanford 

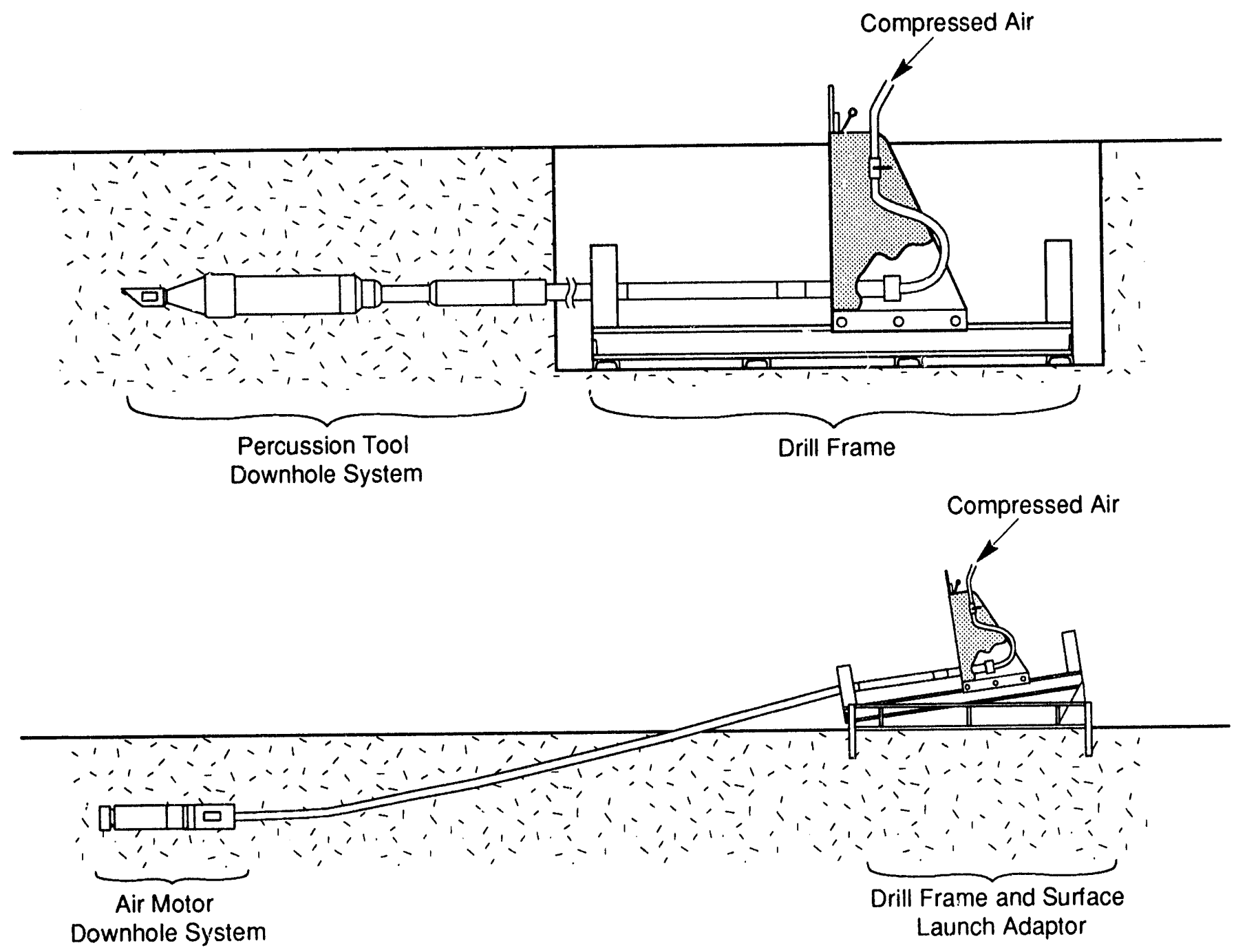

TRl.6252-20.1

Figure 4. Typical utilities industry directional boring machinery. 


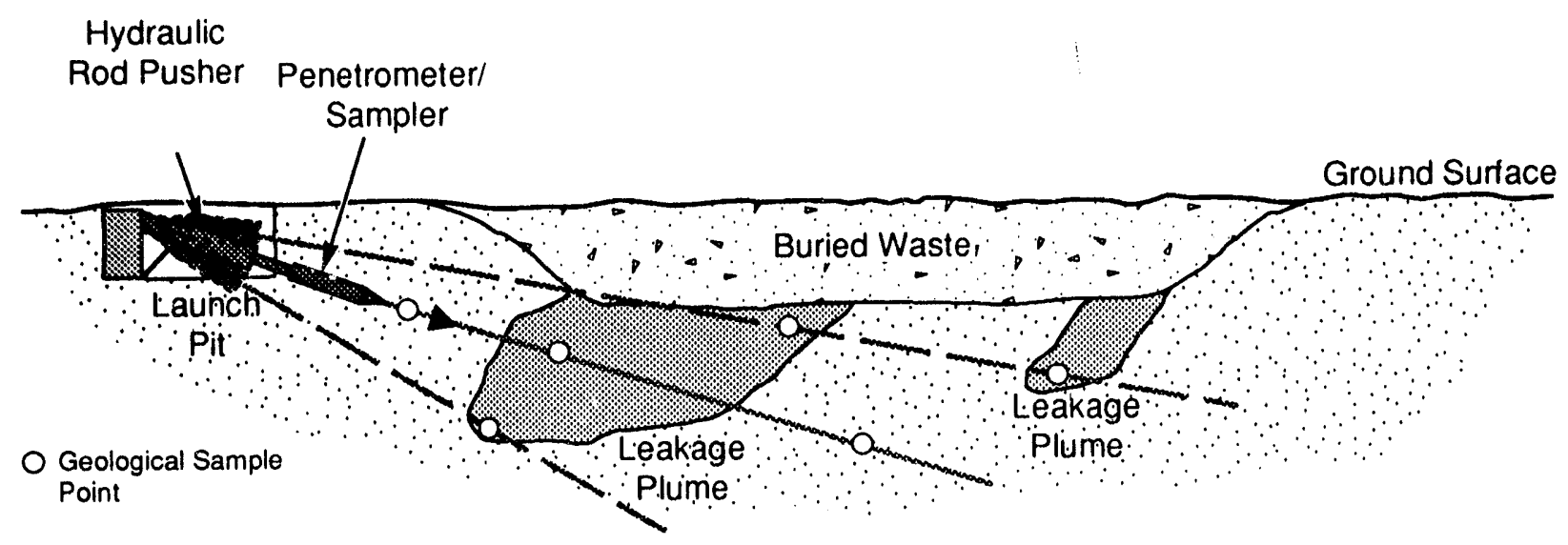

TRI.6252.5.3

Figure 5. Schematic illustration of horizontal in-situ logging concept. 


\subsection{Technical Approach}

The technical approach chosen for this project was to survey a variety of industries where proven geotechnical hardware was being used, determine/test the limits of the machinery, determine if a set of machinery from one industry could be combined with a set from other industries, adapt the interfaces where necessary, develop new machinery and/or hardware only as necessary to improve the capabilities of the resulting hybrid, and then test the hybrid in a variety of soil types under field conditions while continuing to identify environmental industry needs and regulatory constraints so that the project could remain on a reasonable course.

Some of the industries surveyed for equipment were: underground utilities installation, soil mechanics, hard rock drilling, river crossing drilling, oil/gas, geothermal and environmental. These industries contributed steering control, position location, sampling hardware as well as bit/reamer design, and contamination containment protocols for testing the environmental directional boring equipment. Table 2 lists some of the hardware considered for hybridization.

As mentioned previously in the Goals section, cost was a major consideration. A goal of $\$ 25$ to $\$ 75 / \mathrm{ft}$. was established. This per foot cost compares to $\$ 5$ to $\$ 15$ for underground utilities, $\$ 75$ to $\$ 150$ for river crossing, approximately $\$ 200$ for oil/gas, $\$ 350$ fol geothermal, and $\$ 300$ to $\$ 500$ for previous directional environmental work with large rigs. Some specialized vertical hammer rigs used in the northwestern states have costs approaching $\$ 2000 / \mathrm{ft}$.

It was anticipated that a major factor in the success of the hybrid machinery would be the soil conditions. The hybrid machinery was not expected to function properly in all soil types or in all regions of the country; however, it was expected that the machinery would be very cost effective where the soil conditions were appropriate. Cost effectiveness encompasses many variables: time necessary to drill and complete a borehole with appropriate casing/screen; the crew size necessary to operate the rig effectively and safely; transportation costs to the site for the machinery; the field support needed by cranes, excavators, backhoes, welders, etc; completed borehole dimensions (length, depth, diameter); the type of casing/screen required for completion, and the sophistication/cost of steering tools are a few of the variables.

Table 2. Typical Candidate Hardware for Hybrid Systems

* Hydraulic Thrusting Systems

* Tracking/Steering/Locating Hardware

* Cone Penetrometers

* Fluid/Moisture, Temperature, Pressure Sensors

* Sidewall Coring Apparatus

* Various Geophysical Source/Sensing Equipment

* Various Soil, Fluid, and Volatile Samplers

* Push Coring Systems

* Pneumatic Sleeve Emplacement Equipment

* Soil Fluorescence Apparatus

* Many Technologies in the Soil Analysis and Environmental Characterization Industries 


\subsection{TECHNICAL DEVELOPMENT AND ACHIEVEMENTS BY FY}

\subsection{FY 91 Evaluation Phase}

The industrial partnership with CMW began in early FY 91. After several meetings to discuss the correct approach to defining environmental drilling problems and possible solutions, SNL project personnel and their counterparts at CMW arranged to visit SNL-CA, LLNL, Westinghouse-Hanford, and INEL. The visit to INEL was cancelled by INEL at that time and was not rescheduled. Also, numerous phone conversations with drilling companies such as Harcro Inc., Eastman Environmental Corp., Cherrington Inc., etc, and visits to a Harcro river crossing operation near Shreveport, La. and the Westinghouse-SRS site in SC added to the information base. A search of the literatu:e on environmental underground access issues, equipment and techniques used in sister industries, concerns about specific environmental problem sites, and typical geologies for those sites was initiated.

The information gained by these visits and phone conversations was invaluable. Information on the type of contaminants, exposure limits, requirements for decontamination of equipment, type and spacing of underground tanks, EPA regulations applicable to sites, physical constraints on site access, ER philosophies at various sites, proximity of groundwater, impact of soil types with wide differences such as glacial deposits versus sedimentary coastal plain deposits, current methods of vertical drilling to characterize sites, problem magnitude, and the very high cost associated with nationwide clean up was obtained.

When all of the above information was considered and reduced to fundamental needs and problems, it was obvious that there was a gap in the type of available equipment to economically do what was needed at a significant percentage of government and private sector environmental sites.

Several pieces of commercial machinery manufactured by CMW for the underground utilities installation industry were tested and evaluated at the CMW test range in Perry, OK and also at the SNL Directional Boring Test Range (DBTR) in Albuquerque, NM. These are shown in Figure 6. The walk-over method of tracking the underground boring head position of this equipment is limited to approximately 20'. These machines were the water-assisted Jet $\operatorname{Trac}^{\mathrm{Tu}}$, the air-assisted True $\mathrm{Trac}^{\mathrm{Tu}}$, the P-80 ${ }^{\text {th }}$ rod pusher and the Pierce-Airrow ${ }^{\text {th }}$ pneumatic hammer tool. Results of the scoping tests at these locations varied due to the geology. The soil in Perry is basically clay to about $14^{\prime}$ depth, underlain by a $5^{\prime}$ zone of shale, and then a deeper zone of more dense clay with some sand and small gravel. The geology at SNL is alluvial in origin and thus contains debris from the decomposition of nearby mountains; i.e., caliche, sands, gravels, cobbles and boulders distributed somewhat randomly, except that some cobbles are concentrated in several layers of old river beds to at least a 50' depth.

Figure 7 shows a tracking demonstration test at the DBTR. Figure 8 shows the typical downhole hardware for various phases of well emplacement.

\subsubsection{Jet Trac Testing}

The Jet Trac, as mentioned previously, uses water for cooling of onboard electronics, cooling of the bit and to assist compaction of drill cuttings in the hole. This machine is normally used to create a borehole with entry and exit portals. The position of the boring head (depth and tool face) is determined by the signal from an RF transmitter mounted behind the bit being detected on the surface 


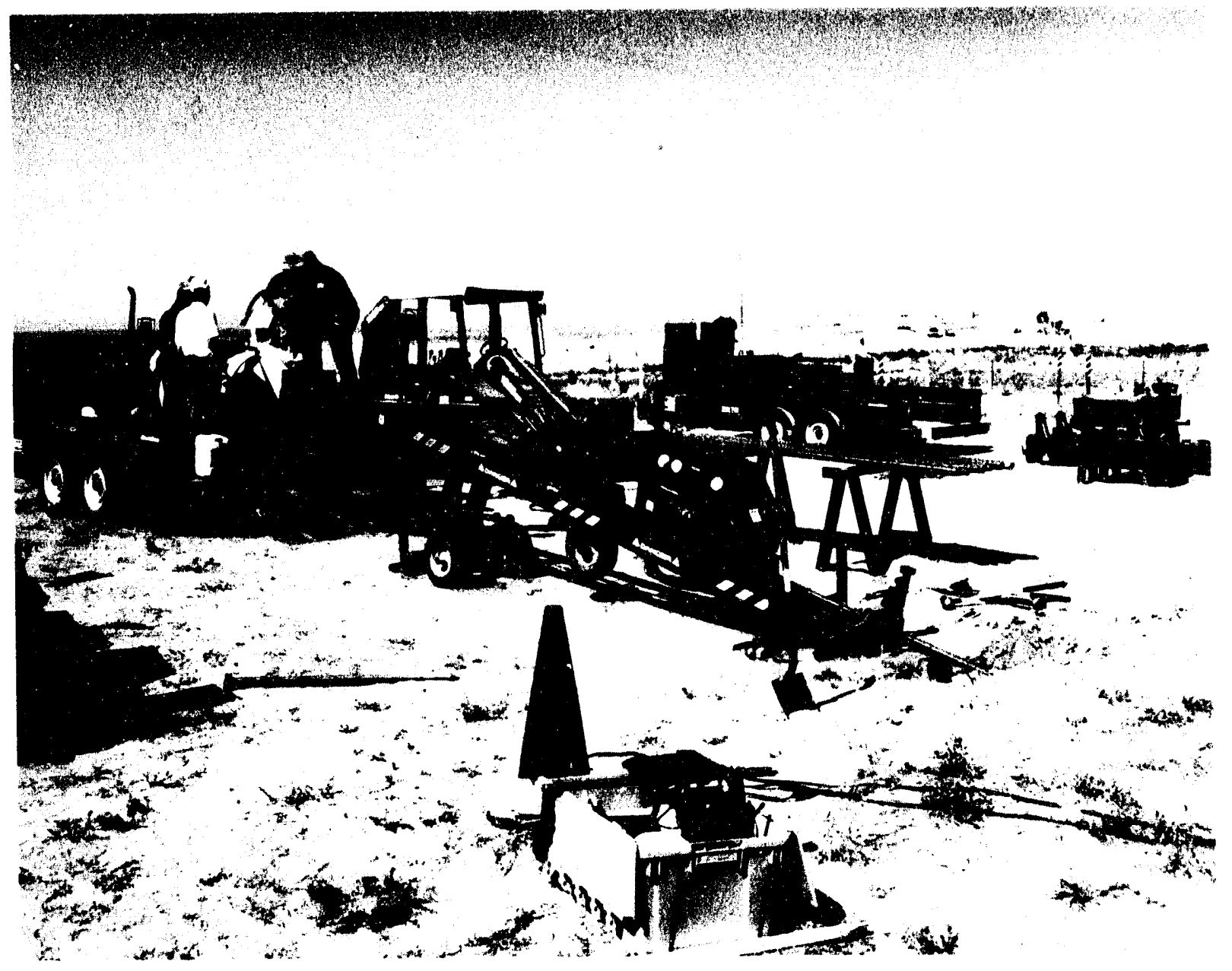

Figure 6. Testing utilities equipment at the SNL DBTR. 



\section{Drilling Assembly}

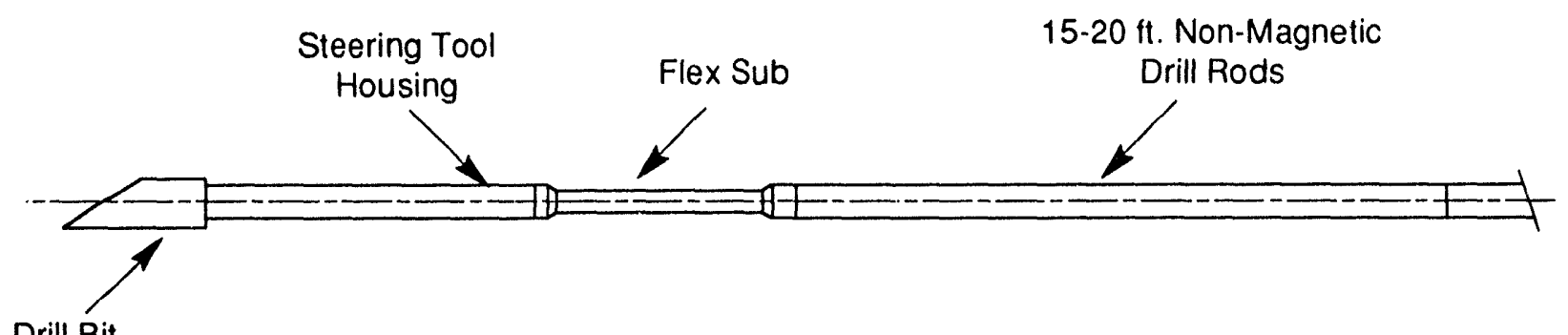

Drill Bit

\section{Reaming Assembly}

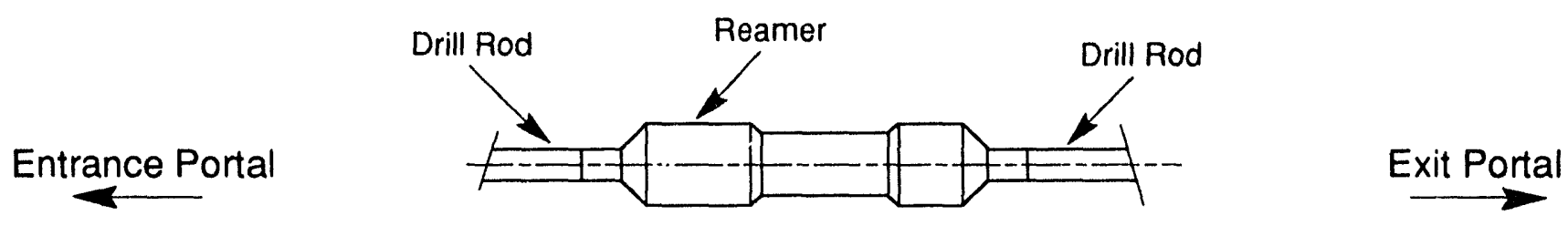

\section{Reaming and Casing Pullback Assembly}

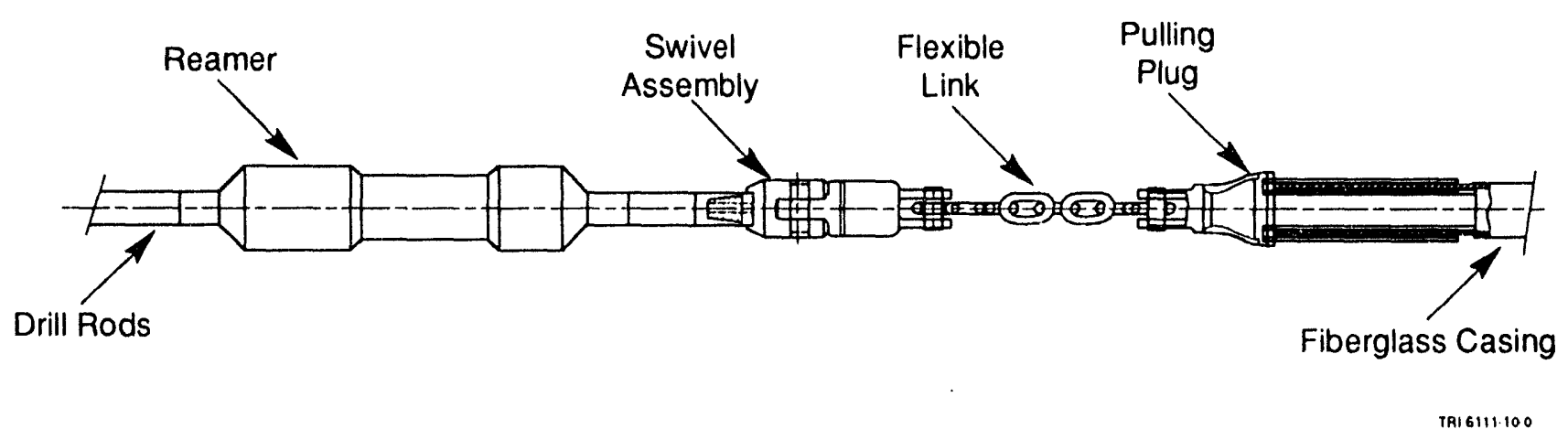

Figure 8. Typical downhole hardware for different drilling phases. 
by walk-over tracking electronics. The machine uses $1.75^{\prime \prime}$ diameter drill rod in $10^{\prime}$ lengths. The torque and thrust capabilities of the machinery are adequate for most utility applications, but for the Albuquerque geology, penetration of the cobble zones was not possible when the zones were intercepted at a necessarily shallow angle. Steering with this machine requires co-alignment of the vertical reference of the tracking electronics and the wedge face of the bit. The bit travels forward in a straight path while rotating. If a course correction is necessary, the bit is oriented in such a way to use the wedge shape to set the new direction while the drill string is thrusted, but not rotated, for some distance. Once this new direction is confirmed by the electronics, the boring head is again rotated. The inability to maintain positive steering control and to reverse in the borehole without key locking was encountered. Several attempts to bore to 20' depths at the SNL DBTR were unsuccessful and the downhole hardware had to be retrieved with a backhoe; however, several surface-to-surface boreholes up to $300^{\prime}$ in length were completed with casing at 10' depths in coarse sands and caliche.

\subsubsection{True Trac Testing}

The True Trac air-assisted boring machine tested at the DBTR used air to turn a downhole air motor that then vented the air to the borehole with the result that the cuttings were swept to the surface entry portal by the air stream. The tracking electronics were the same as used on the Jet Trac. Directional control of the boring head was different than the Jet Trac in that a bent sub was used behind the air motor and its angle was co-aligned with the vertical reference of the tracking electronics. The downhole motor/bit assembly performed the cutting function and the drill string was thrusted forward and back to alternately provide cutting and hole clearing of chips. This machine uses a $2.875^{\prime \prime}$ diameter drill rod in 5 ' lengths. While this machine had the capability to cut through cobbles and boulders, it also was subject to key locking in the old riverbed zones and it was difficult to keep the hole clear of cuttings. This hardware also had to be retrieved by excavation on several occasions. One early borehole, however, was completed at a 6' depth with the air motor and cased with High Density Polyethylene (HDPE) tubing. Figure 9 shows some of the excavated alluvial rubble encountered at the DBTR.

Another entry-to-exit borehole approximately $200^{\prime}$ in length was completed with this machine at a depth of approximately 8' using a downhole air hammer option on the machine. It was obvious that if this machine or a similar air-assisted drilling machine were to be used in hazardous waste environments, a capability to contain the airborne drill cuttings exiting the entry portal would be mandatory. A large vacuum system with appropriate separation chambers and absolute and organic vapor filters, operated at a negative pressure with high flow requirements was envisioned.

\subsubsection{P-80 Rod Pusher Testing}

The P-80 hydraulic rod pusher was evaluated at the DBTR. This high thrust force machine with the capability to rotate one revolution in one rod length (4') uses the same principles of wedge face steering control as the Jet Trac. Thrusting and compacting the displaced earth without adding fluid is the method of penetration. A variety of bit face wedge angles can be chosen to match steering control to soil conditions to maintain appropriate bend radii for the borehole. This machine also is intended to create entry and exit portals for the borehole. While the Jet Trac is normally launched from the surface, the True Trac can be launched from the surface or a shallow pit. The P-80 is normally launched from a shallow pit or trench to assure solid control of thrust reaction forces.

There was mixed success at the DBTR with this machine. Several pushes were performed and due to the small diameter (1.75") solid push rod, the flexibility of the rod, and a small frontal area of the boring head, penetration of cobble zones was sometimes easier than with larger diameter drill strings. 


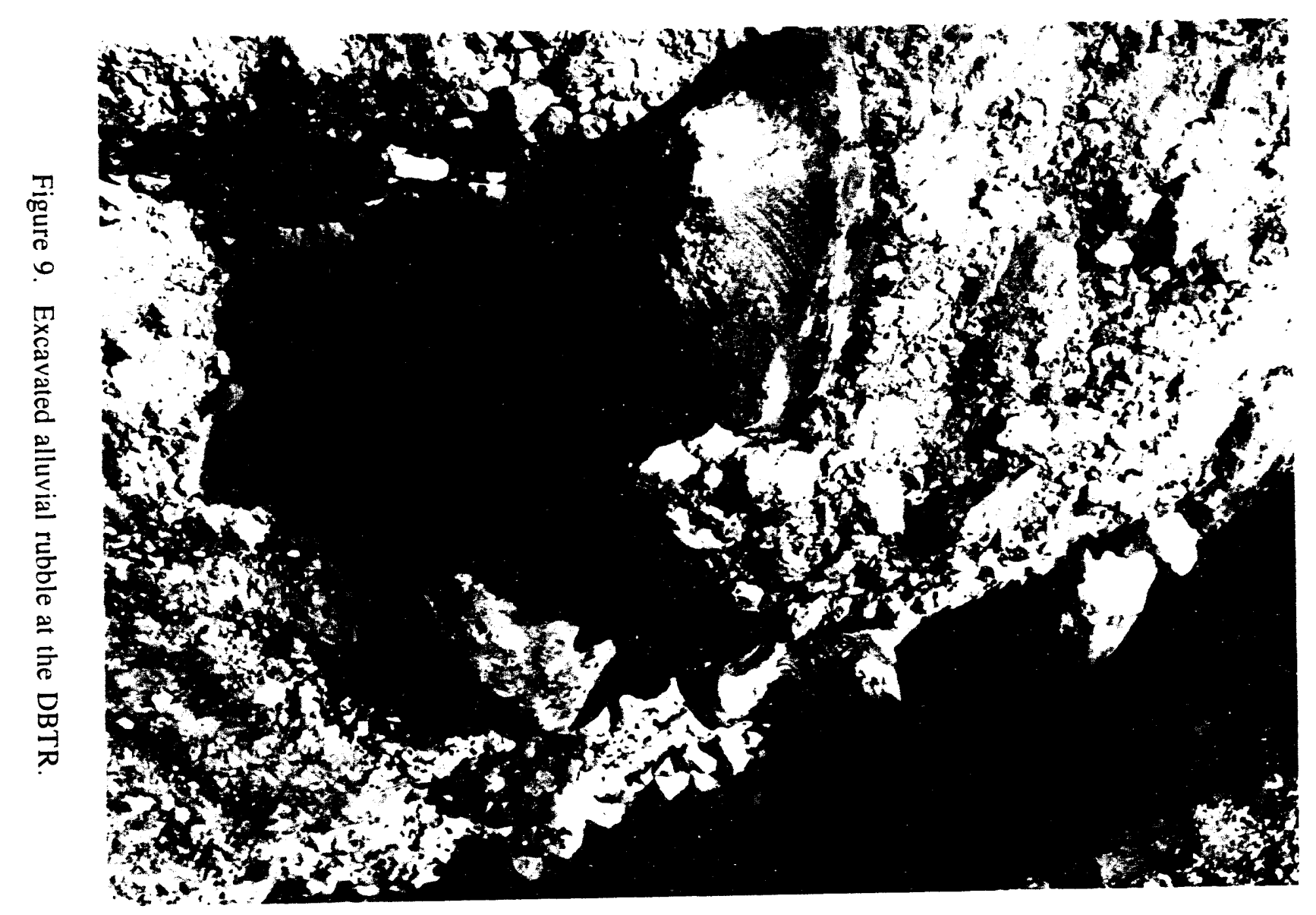


The $80,000 \mathrm{lb}$. hydraulic thrust capability also contributed to these successful penetrations. Some cobble zones encountered at the DBTR were impenetrable at shallow angles (up to $15^{\circ}$ off horizontal) with this machine. The same walk-over tracking method was used as was used in the Jet Trac and True Trac tests.

Several successful tests were performed with the P-80 being used as a vehicle to emplace soil samplers and instrumentation packages. Adapting the hardware for these tests was relatively straightforward. Several soil samples and data from a cone penetrometer measuring soil density were obtained at the SNL DBTR.

\subsubsection{Pierce-Airrow Pneumatic Hammer Testing}

A 3" diameter Pierce-Airrow pneumatic hammer tool was also launched horizontally from a pit wall in the DBTR soil. In the caliche zone, the tool would pierce and compact for a short distance and then stall. The tool could be backed out of the hole. One test involved a piece of 1" diameter pipe approximately 5' long attached to the front of the P-A as a simulated coring tube. When this assembly was run back into a hole where the P-A had previously stalled, the pipe removed a core of soil. The P-A without the core pipe attached was then placed back into the hole and was able to continue to the end of the core hole, demonstrating that when some portion of the cross section of the hole is removed, the tool can then compact the remainder and continue normally. Figure 10 shows a family of hammer tools with various hardware configurations.

This tool was also tested as a means of inserting steel pipe into the ground by pulling the pipe instead of pushing it. This test was successful in penetrating downward at a 45 degree angle only until the cobble zone was encountered. Another problem with this test was breakage of the pipe due to mechanical vibration at the threaded connection at the rear of the tool where the pipe was attached. Overall, this tool was deemed to have some potential as a carrier to insert instrument packages into an environmental site and even be sacrificed in place if its removal would create a decontamination or secondary waste disposal problem.

\subsubsection{FY 91 Development Activity Conclusions}

After gathering information regarding hazards, access, soil type, operational constraints, etc., from various sources and scoping out the capabilities of a variety of shallow underground equipment, the SNL/CMW project team met to plan a course of action for out-year development and testing. Issues of penetration force, steering control, onboard locating electronics, minimizing secondary waste, minimizing site impact, ease of decontamination, casing advancing techniques, field support logistics, optional equipment for characterization, monitoring and remediation, operational crew size, etc. were considered.

CMW then took the initiative to begin design and construction of a prototype machine that was expected to meet most of the criteria and serve as a test bed for development work. The machine was expected to reach 80' depths and lateral distances of 1000'. This machine was built entirely with private funding from CMW, with SNL contributing technical input, duplicate electronics packages for spares, and other miscellaneous hardware for testing with the prototype. Under the industry partnership, both SNL and CMW were free to go to third party companies and bring technology to the project.

Another field support issue addressed in FY 91 was boring crew safety. Potentially hazardous vapors or materials could be encountered at the borehole entry portal. This potential problem was discussed 


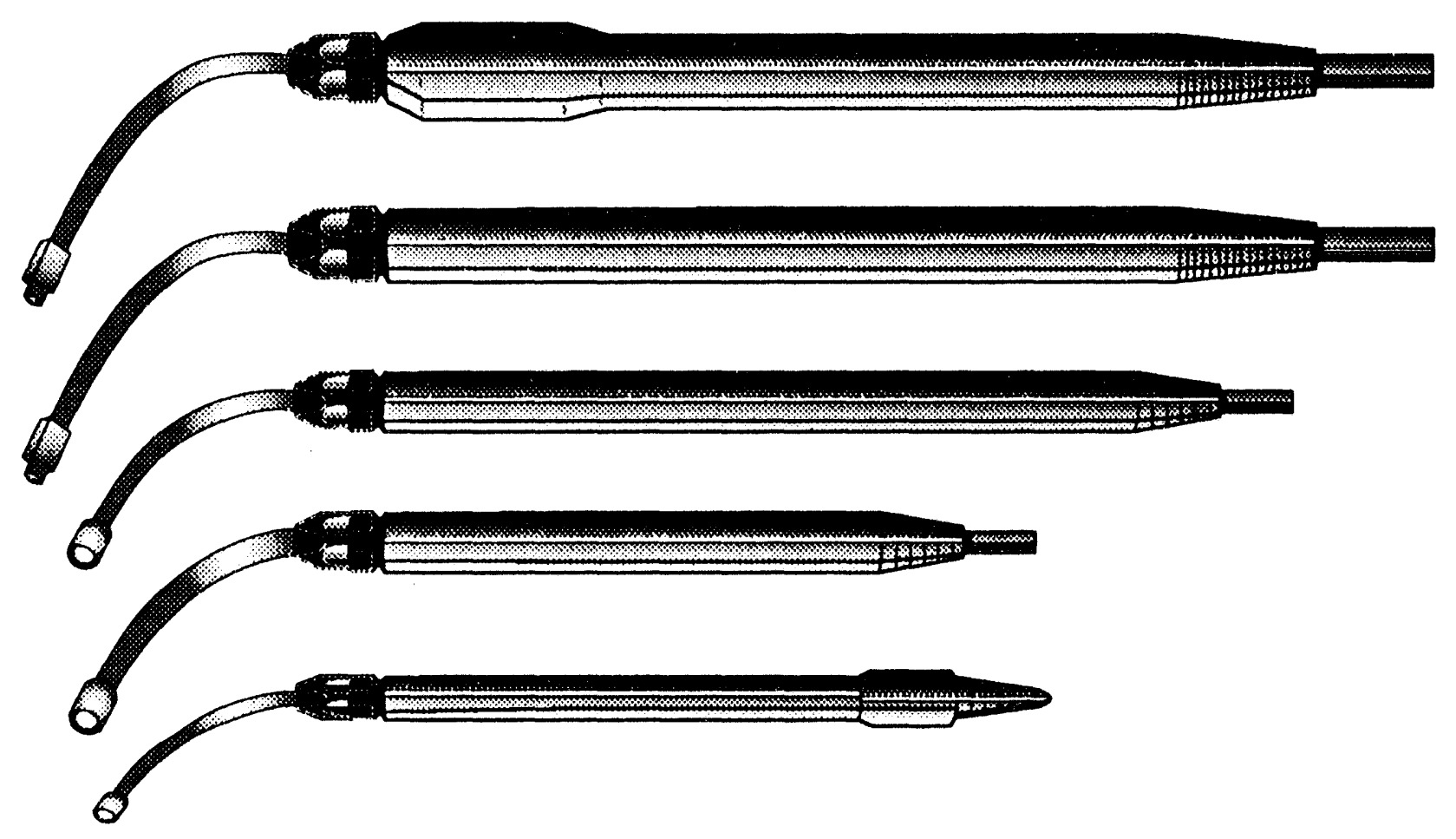

TRI.6111.17.0

Figure 10. Family of pneumatic Pierce-Airrow tools. 
with the mass spectrometer development staff in the Materials Center at SNL and they tested some of the portable mass spectrometer (MS) devices during the field testing of the boring machinery. These tests were performed at environmentally benign sites and at VOC Sites at SRS and SNL, assuring that the MS systems could operate on field power under widely varying weather and operational conditions.

\subsection{FY 92 Development and Testing}

\subsubsection{Construction of Test Bed Boring Machine}

Construction of the prototype test bed machine was completed in the second quarter of the FY. This machine was designated the X-810. Shakedown testing at the CMW test range in OK and several iterations of modification and improvement of the X-810 were completed by June 1992 .

\subsubsection{First SRS Field Test}

The machine was then shipped to the Westinghouse-SRS site in SC for field testing at the M-Area drilling test field where significant quantities of TCE had leaked into the ground in past years. The SRS stafi in charge of this area had previously contracted with Eastman Environmental to emplace four blind directional wells at the site at depths ranging from 90' to 150' with relatively large 10" diameters. The drilling machines used for these wells, emplaced in pairs above and below the contaminated zone, were first a standard vertical oil field rig and secondly, a modified oil field rig laid over at a shallow angle. Approximately one year separated the first and second series of large rig directional well installations.

The test borehole to be attempted by SNL/CMW was to be emplaced in a TCE contaminated clay layer at a target depth of 40' with the entry and exit portals separated approximately 600'. The well would be used by SRS experimenters for RF heating experiments to see if TCE vapor extraction could be enhanced parallel to and above the primary extraction wells previously emplaced by Eastman Environmental. The soil at the site is coastal plain sediments that have formed very tight clays with some sand and small gravels. The X-810 was surface launched for this operation as it had been at CMW for the shakedown testing. Drilling of this borehole took approximately one week. Several problems with rig stability using surface tiedown anchors, uncertainty of directional measurements with the electronics, uncertainty regarding magnetic field influence of nearby large metallic equipment, etc. were encountered, but were overcome with perseverance. The borehole exited within approximately 15' of the desired exit point and well within the boundaries of the general target area. Refer to Appendix A for more detailed information regarding this test.

Casing for this well, specified and designed by SRS, was to be Teflon in the heated zone and polyvinylchloride (PVC) in the approach zones. With the X-810 pullback reamer leading a downhole hardware string composed of a pulling plug and casing, the first casing attempt was started. The Teflon did not have the strength in either the threaded joint nor in the wall thickness to survive the pullback force and combined stresses and it separated in the borehole after less than 100' of pullback. Some of the casing was removed from the hole, but some could not be removed. A second attempt to case the hole, this time using standard 3" diameter PVC monitoring well, slotted/solid screen/casing, was also a failure when the PVC broke at the plane in the first pipe joint where thread roots, a mating shoulder and an O-ring seal groove combined to provide the maximum stress concentration. This drilling/borehole completion test at SRS was then terminated and the machinery returned to CMW. Trajectory planning, tracking and plotting for this test was accomplished with the use of a hand 
calculator and manually plotting the trajectory. The field mass spectrometer was used by SNL Materials Center personnel to monitor entry portal vapors during this drilling and casing activity. Even though the M-Area site had measurable levels of TCE in the soil at the depths being drilled, no detectable levels above background were detected at the entry portal.

An additional test was performed at the TNX Facility at SRS. This facility is located on a low bluff along the Savannah River, separated from the river by a marsh area which is a protected wetland. Concern about possible TCE subsurface contamination at the wetland area was the driving force for this test. A Jet Trac machine was used to attempt a shallow bore of approximately 300 ' length. This test was not successful for several reasons; first, machinery problems and second, the geologic formation that consisted of fine, wet, running sand that was not compactable. The borehole could not be stabilized.

\subsubsection{Second SRS Field Test}

During the fourth quarter of FY 92, the machinery and project personnel from SNL and CMW returned to SRS for a second attempt to emplace a usable well for the RF soil heating experiment. This time the X-810 was launched from a shallow pit prepared by SRS approximately 5' (but later determined to be 2') off line from the first borehole. This launch configuration is shown in Figure 11. The test plan was to bore a second hole parallel to the first and pullback fiberglass casing provided by SRS that was environmentally and thermally compatible with the RF heating goals and also had greater tensile strength than the Teflon and PVC tried in the first hole.

Drill rig stability was greatly improved by using the pit launch technique. As mentioned above, the location of the new borehole entry portal was not offset from the previous borehole as far as originally intended. This positional error was due to uncertainty in the exact location of the first borehole entry, caused by post-test excavation at the site. The result of mispositioning the new hole was that the boring head and drill string soon drifted into the old borehole. A decision was made to continue in the old hole and then try to redrill to the exit end and bypass the broken casing remaining in the old borehole from the first attempts to complete the well. This strategy paid off and redrilling the exit end resulted in the exit portal being slightly offset from the first exit portal. The X-810 was again configured with a reamer, pulling plug and the 3" diameter casing. The entire string of the new fiberglass casing was successfully installed in approximately four hours. This casing proved to be strong enough to sustain the drag and bending forces in this installation. The fact that the clay was wet and slick from the water added during boring/reaming also contributed to the successful installation. Figures 12 and 13 show the casing installation activities at SRS. Figure 14 shows various types of casing.

Software newly developed at SNL was used to plan, track, and plot the trajectory for this wellbore and to make real time corrections to the trajectory while drilling.

Completion of the well for use by SRS included adding a riser section of casing at the entry and exit portals to bring the casing to the desired above ground level, swabbing the well to clear out water and formation mud that had entered the casing during installation via the screen slots, and finally, an independent survey logging by Sharewell Inc. and SNL to verify the well geometry. This survey basically confirmed that the data from the less sophisticated onboard steering tool used to guide the boring head during boring was reasonably accurate. Refer to Appendix A for more detailed information regarding this test. 


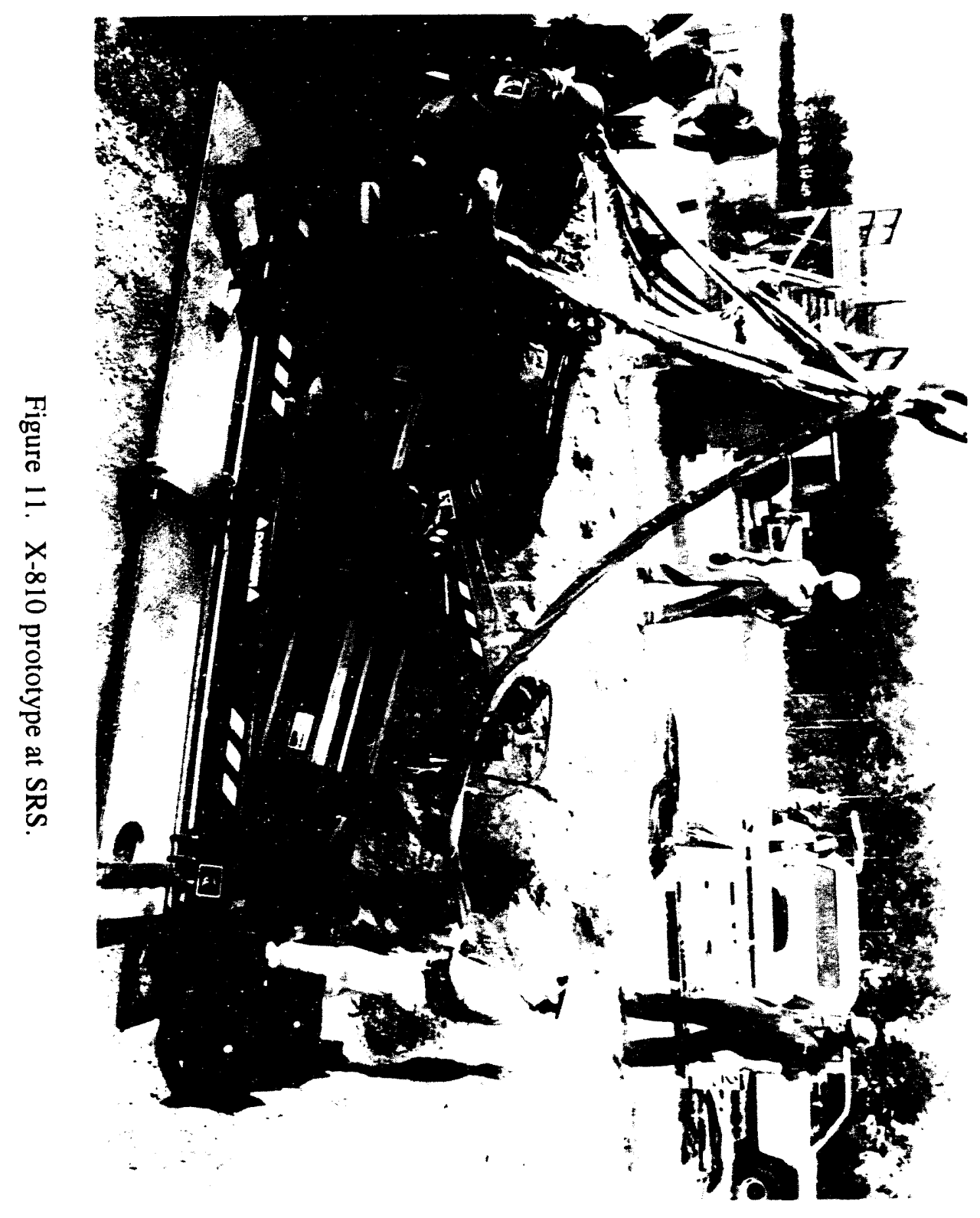




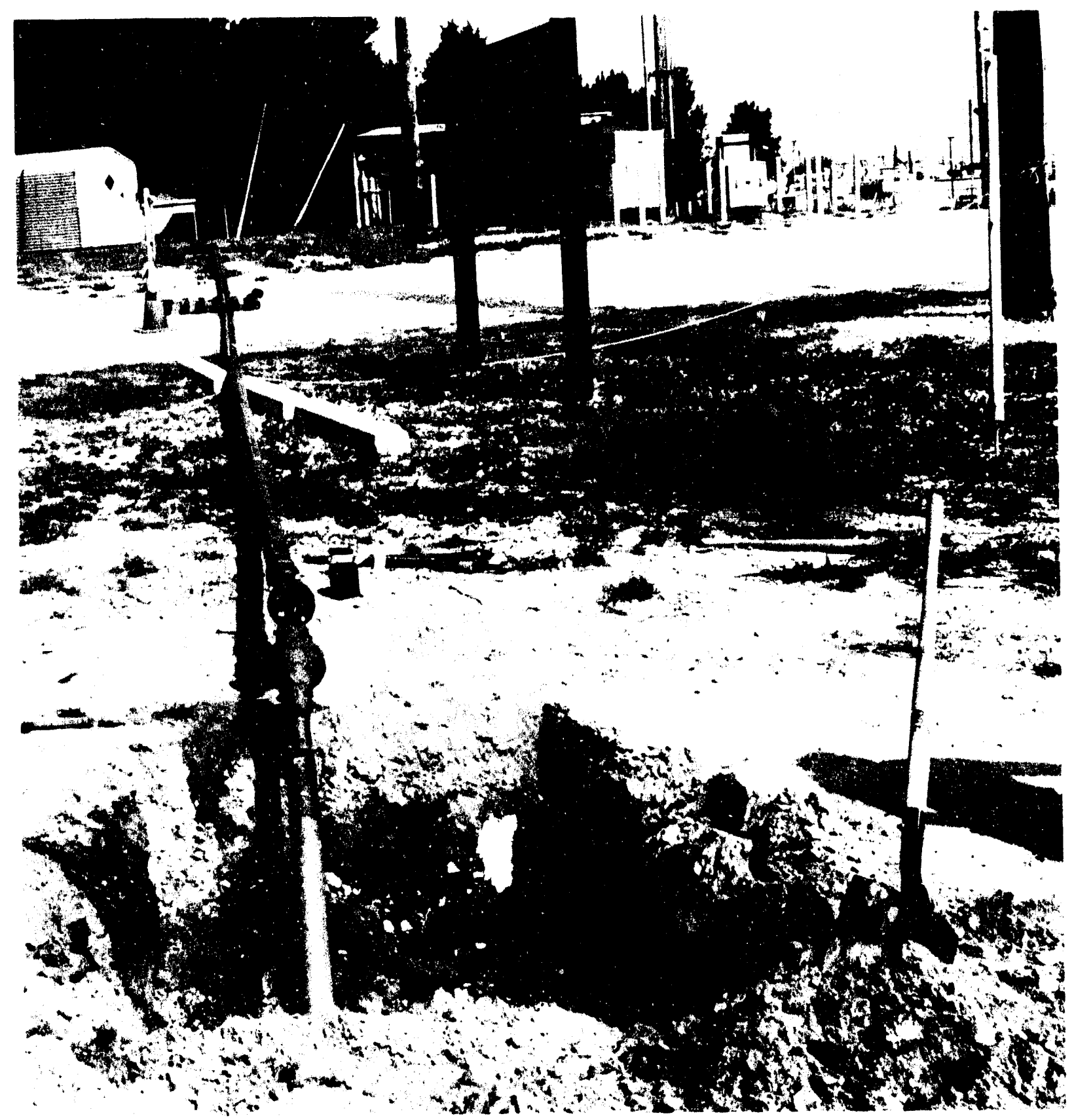

Figure 12. Casing pullback at SRS. 


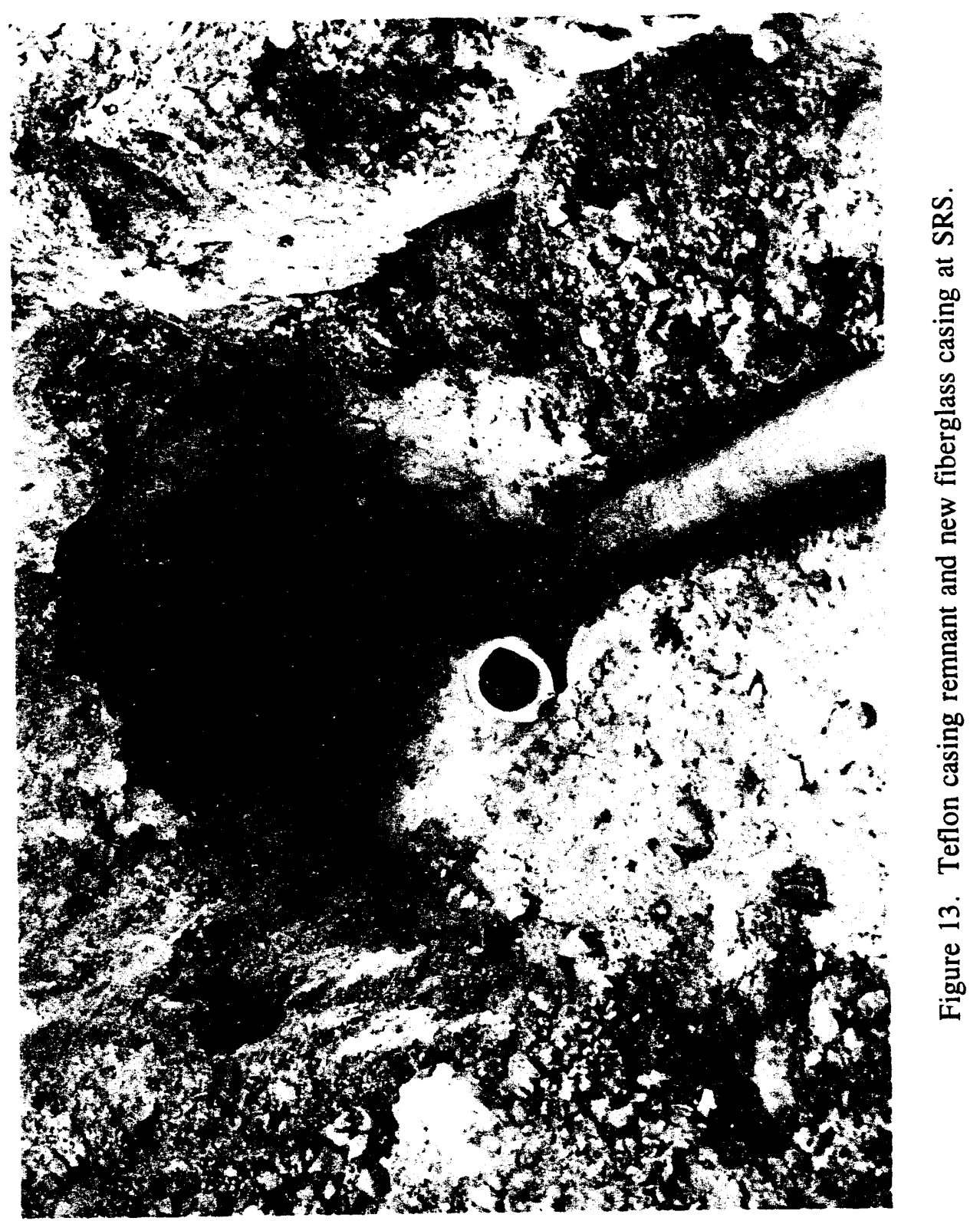


PVC Pipe and PVC Well Screen

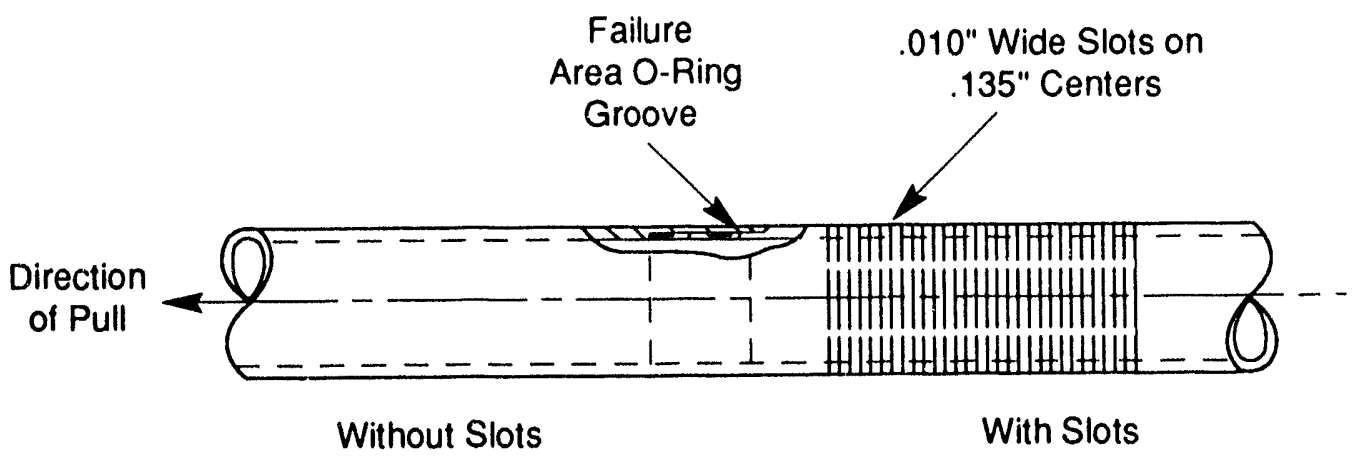

Fiberglass Epoxy integral Joint Line Pipe

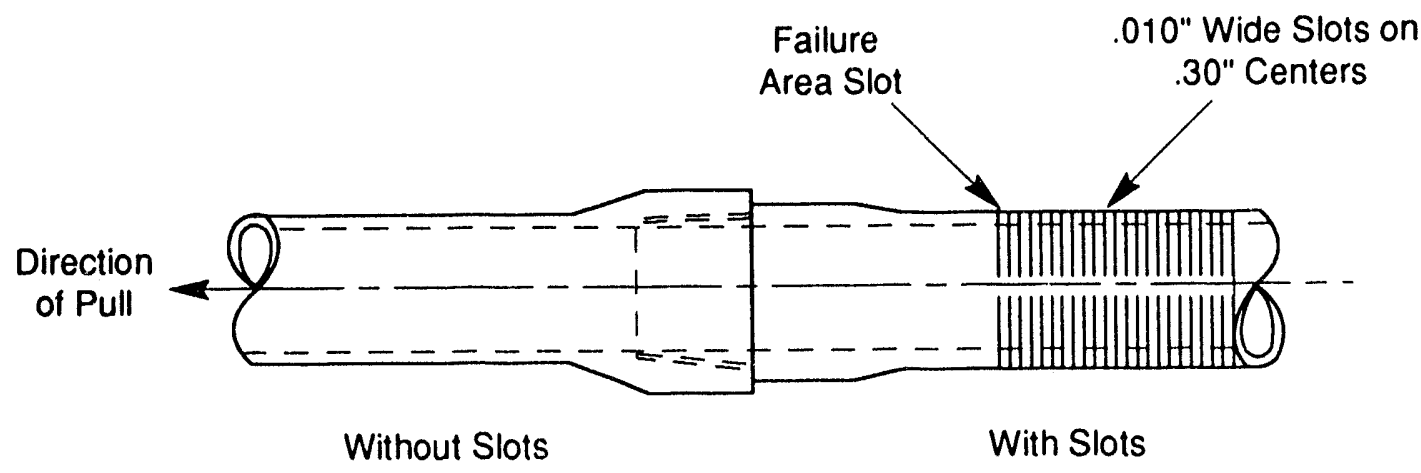

Fiberglass Epoxy Integral Joint Line Tubing

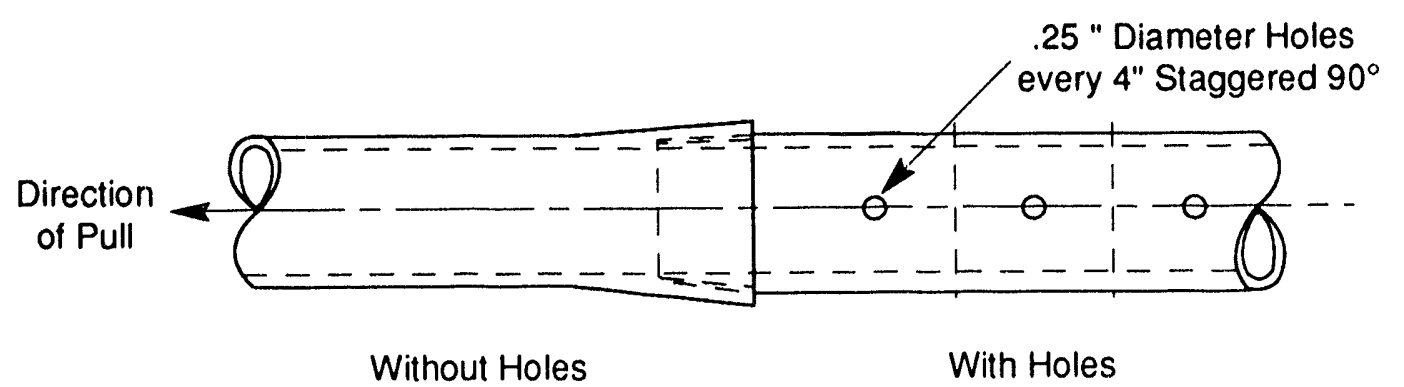

TRI.6111-12.0

Figure 14. Illustration of various casing types. 
The X-810 was returned to CMW for maintenance and then shipped to SNL for additional testing during the first quarter of FY 93.

\subsubsection{Sampler Development}

Sampler testing and development continued at SNL with modification and testing of commercial samplers in combination with the P-80 at the DBTR. Mechanical latching of these samplers, normally used in vertical configurations by the soil mechanics industry, depends on gravity to assure that the latch is engaged. When these samplers were used horizontally, the latch mechanism had to be redesigned to work without the gravity assist. A reliable latch was designed, tested, and a patent disclosure was made.

Also, a concept to permit several soil samples to be taken simultaneously was developed. This concept of sampler modules, distributed in a push rod string, connected and operated by common hardware, resulted in early prototype hardware being designed, fabricated and tested at the DBTR. Further work would be needed to carry this concept to practical hardware for environmental applications.

\subsection{FY 93: Development and Testing}

Early FY 93 testing at the SNL DBTR involved new bit hardware and improved software for planning and tracking wellbore trajectories. After approximately two weeks of testing, the X-810 was moved to the Kirtland Air Force Base RB-11 site. This site was used for radiation effects testing during the 1950s and 60s. Several shallow open trenches were filled with low level contaminated post-test debris. These trenches were covered with soil when they were used. This site is now being used by the SNL Mixed Waste Landfill-ID as a site for testing emerging environmental site characterization technologies. The site belongs to KAFB and characterization of the site to meet EPA requirements and evaluate new technologies was needed.

\subsubsection{Benign Site Testing at KAFB}

A test borehole was completed with the X-810 at this site in a benign area in December of this FY. This hole was approximately $300^{\prime}$ in length and approximately 33' deep in the horizontal section. Difficulty was encountered in drilling the rocky formation at a 20' depth near the exit portal. An excavator was used to create a trench above the downhole boring assembly thus relieving the overburden confinement and allowing the hardware to follow the trench to the surface. The open trench remained while the reaming and casing attempts were made. The hole was reamed in one pass and a PVC casing (the available casing provided by the SNL sponsor staff) was prepared for pullback. The casing broke approximately $90^{\prime}$ from the exit portal, near the first major bend in the borehole. The remaining downhole hardware was then pulled toward the entry portal. Another breakage occurred, this time in the connection between the swivel assembly and the pulling plug. As a result, the pulling plug remained in the ground and was not recovered. Refer to Appendix $A$ (see RB_TST2.XLS and Fig. A-5) for more detailed information regarding this test.

After this test, some confidence was gained that this site could be drilled, but many questions remained unanswered about whether a casing could be installed due to the severe stresses and external abuse caused by the rocky soil. Planning for a test under the potentially contaminated burial trenches was initiated and an investigation to find stronger casing material was begun. Also, new stronger downhole hardware was designed to increase the chances of a successful test. Two horizontal test 
wells were planned for the site. The wells were planned to cross at different depths, each trajectory approximately bisecting a different group of trenches at midpoint. Both wells would be drilled with the X-810 launched from a $5^{\prime}$ deep pit.

\subsubsection{Hanford Testing}

In March, FY 93 the X-810 was shipped to Westinghouse-Hanford, where the test site geology is composed of multiple layers of semi-spherical cobbles ranging from baseball to basketball size. These cobbles are closely packed together with loose sand occupying the interstices. An environmentally benign test area between Technical Areas 200-E and 200-W had been prepared for the X-810 tests. Again, a shallow pit was used to launch the boring machine.

It quickly became apparent that regardless of the adequate thrust and torque capabilities of the $X-810$, the geology would dominate the drilling process. Because the formation was geologically uncemented, there was no stability when penetrated with push points or drill bits. Instead, the cobbles and sand formed a loose mix of material that was similar to drilling into a box of marbles and billiard balls; i.e., the drill bit could not get a bite on anything, it could only move material aside. Since steering control of the X-810 is based on a wedge face being positioned to direct a reaction force, establishing steering control was impossible because the formation had no stability. The result of several attempts to bore or thrust and steer in the formation was that the downhole assembly immediately would tend to rise toward the surface. This tendency to self steer was caused by loose material falling to the bottom of the hole, building up, and causing the downhole assembly to ride up over the debris and to rise, regardless of the position of the wedge-shaped bit face.

The boring machine took a considerable amount of mechanical abuse in this test due to the extreme forces needed for even a small amount of forward progress and the severe bending stress applied to the drill string by the formation. After several attempts and maximum horizontal progress of approximately $60^{\prime}$, the tests were terminated with the conclusion that this technology is not a candidate for the Hanford site as currently configured. Figure 15 shows the winter drilling activity at Hanford and Figure 16 the typical excavated geology.

The effectiveness of a 4" diameter Pierce-Airrow pneumatic hammer was tested at the site by free launching it into the sidewall of the X-810 launch pit at depth of 5'. After approximately three hours the hammer had penetrated horizontally approximately 50'. The hammer was recovered by excavation at a depth comparable to the launch depth. After this relatively successful penetration, adapting a hammer tool to the X-810 was considered, but not attempted. The combination of high thrust machinery, a pneumatic hammer tool, and a method of casing advance may still be viable, but will remain untested unless specific funding for continued development testing can be obtained. The Pierce-Airrow is shown at Hanford in Figure 17.

The suite of test equipment taken to Hanford also included a commercial P-80 hydraulic rod pusher manufactured by CMW. Testing of this equipment was performed at an old gravel pit site near the site where the other equipment had been tested. The rod pusher was mounted in a trench box, placed in a shallow excavation, and used for several penetration, steering control and soil sampling tests. The small diameter (2") push point and the 1.75" diameter push rod had some success in penetrating and sampling the formation. These tests used steering control to maintain a relatively straight trajectory for approximately 100' from the launch pit to a surface target area. The sampler used was a commercial soil mechanics type, modified for horizontal use by SNL. The sampler/rod pusher combination was able to obtain a sample of the loose sand in the sand/cobble soil. 


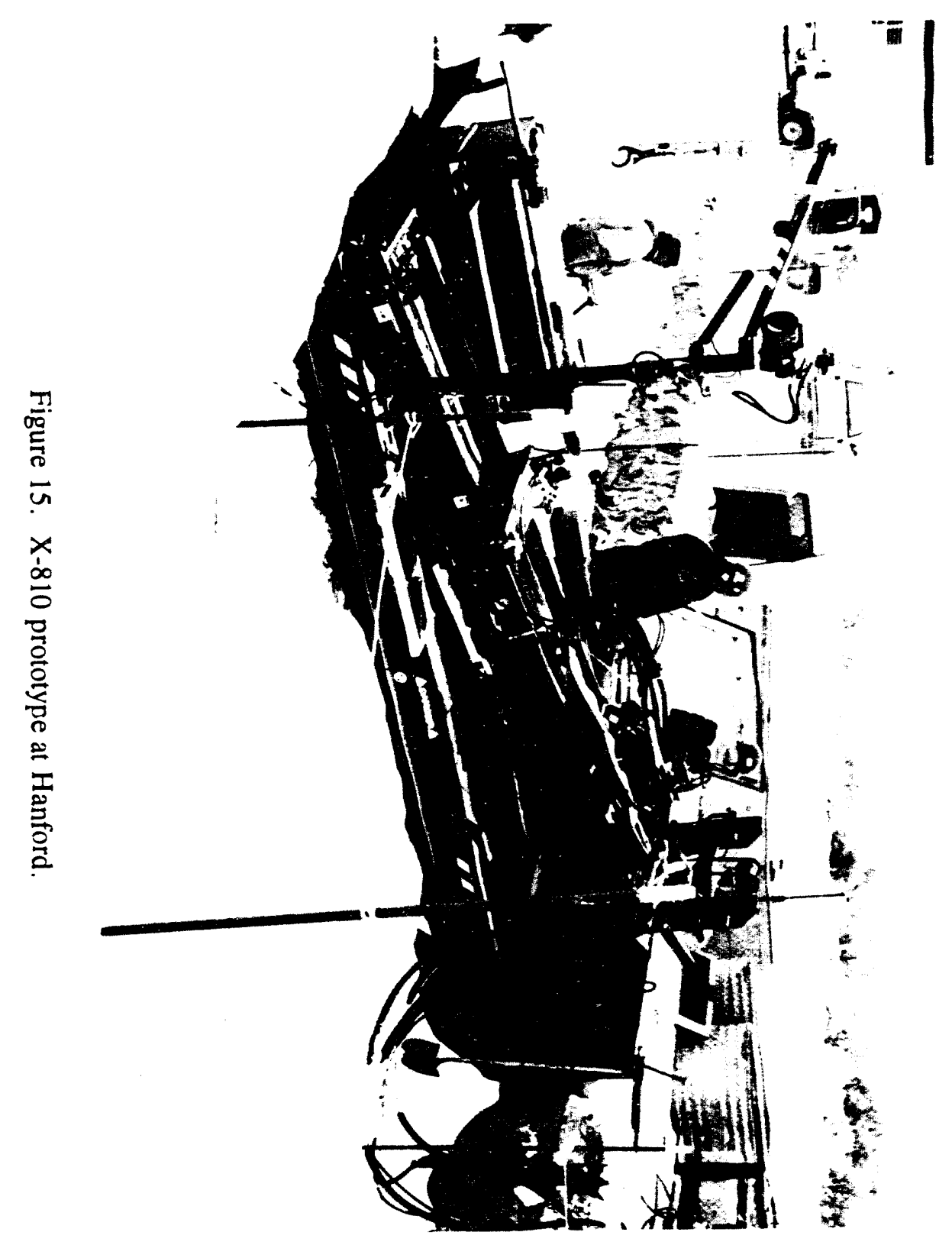




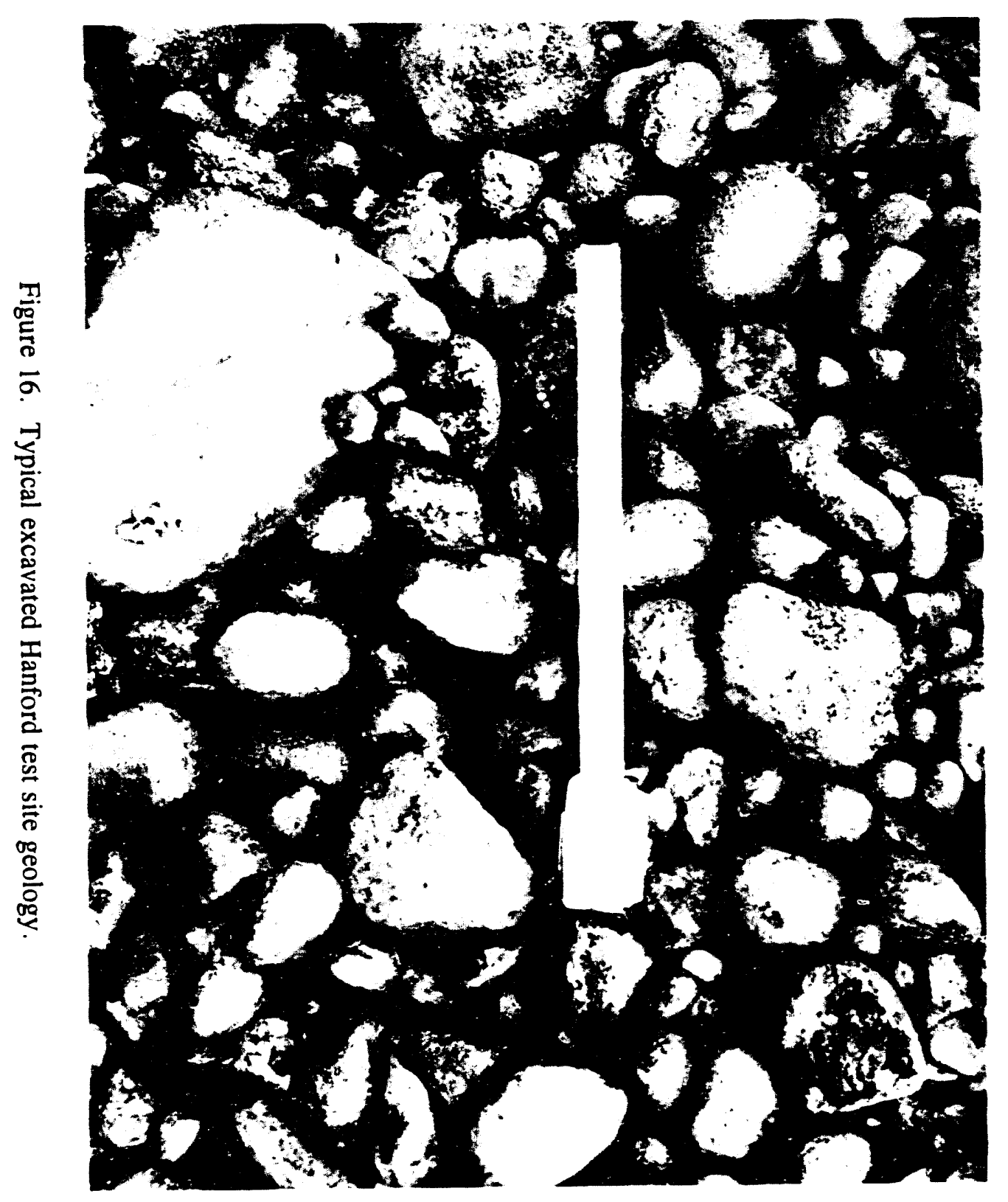




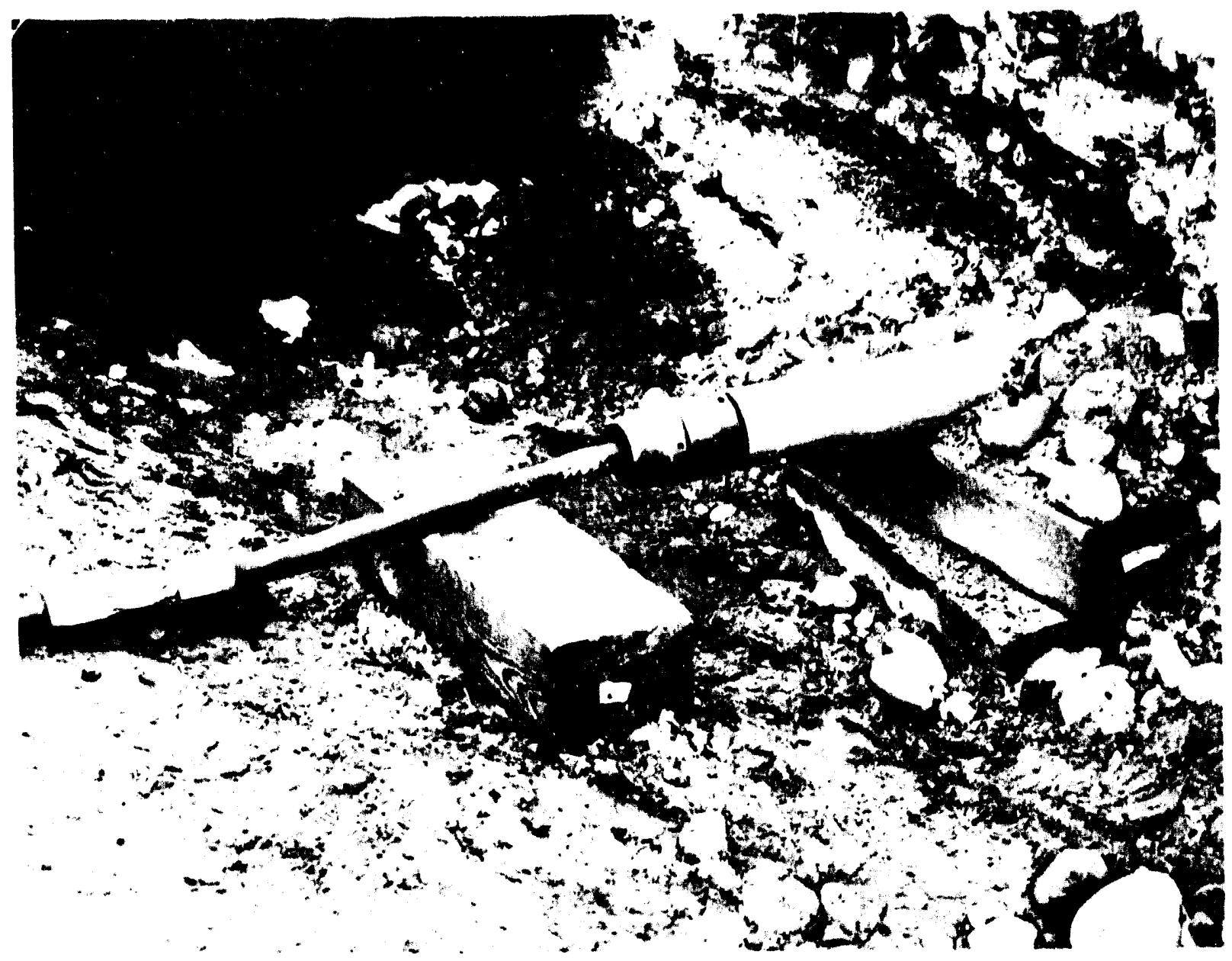

Figure 17. Pierce-Airrow penetrating Hanford test site geology. 
Refer to Appendix A for more detailed information regarding the Hanford testing.

\subsubsection{RB-11 Environmental Site Testing at KAFB}

In May FY 93, the first environmental test well emplacement at the KAFB RB-11 site was attempted. The well was planned for a $410^{\prime}$ length with a maximum depth in the horizontal section of 33'. The borehole was completed with some difficulty. Downhole breakage of hardware and subsequent excavation outside the boundaries of the potentially contaminated zone were necessary. Several iterations of hardware repair and redesign were made. The hole was reamed twice to try to improve the chances of a successful casing pull. The casing used was the same fiberglass material used in the successful installation at SRS in FY 92. The casing pull in this hole was not successful. The casing broke approximately $100^{\prime}$ into the hole from the exit portal, near a transition zone from slant angle to horizontal. Major efforts in time, manpower, and funding were expended in trying to save the hole, but after approximately six weeks of work the hole was abandoned. The X-810 was moved to the SNL DBTR for additional testing in rocky soils. This testing ended in August FY 93. Refer to Appendix A for more detailed information regarding this test.

In September FY 93, the second attempt to drill the RB-11 site was begun. The planned trajectory of this hole was changed to be parallel to the first hole and the entry portal was offset approximately 80" east in the same launch pit. The depth of this hole was planned for 27', thus if any lateral deviations in the trajectory occurred, the vertical separation of the two boreholes would still be approximately 6'. The boring operation proceeded with some difficulty at several rocky and sandy zones but required only one trip out of the hole to change bits. The bits used in this hole were of two different designs, somewhat different than the bits used in the June attempt at this site. The exit portal was approximately $15^{\prime}$ away from the target point. Penetration of a very rocky zone at approximately $20^{\prime}$ depth at this site on both the entry and the exit ends was a real challenge for machinery and operators. This zone corresponds to the points in the trajectory where a transition from slant to horizontal occurs and maximum steering control is required. This was the zone that had caused hardware breakage that contributed to the earlier hole being abandoned.

The first reaming pass was very difficult and breakage of the drill string occurred behind the reamer when the first transition zone near the exit portal was encountered. Approximately 90 ' of the broken drill string was pulled out of the exit portal with a winch line from a truck. The unbroken drill string with the reamer still attached was then pushed/drilled back to the exit portal. The broken parts were repaired. This breakage was attributed to combined rotation and flexion stresses on the 3" diameter drill rod that was radially unsupported in the 7" reamed hole.

The second reaming attempt also had difficulties. The reamer was attached to the drill string at the exit portal and prepared for pullback. When the reamer was approximately 2 ' into the portal, the drill string twisted off near the transition zone at the entry end. The reamer was removed and approximately $300^{\circ}$ of drill rod was removed from the exit portal by pulling with a backhoe. The remaining drill rod was pulled to the entry portal.

This breakage of the drill rod at very low mechanical loading, when considered with the prior breakage, indicated that all of the drill rod should be nondestructively tested before another reaming pass was attempted. A local inspection lab performed this inspection using ultrasonic techniques and found 12 rods that were suspect. These rods were marked and set aside for further testing.

The third reaming pass attempt progressed very well until the transition zone at the entry end was encountered. The drill string again broke, but this time at a weld ahead of the reamer, not in the drill 
rod. Excavation in the transition zone, but outside the boundary of the waste site, was required to recover the reamer and pull the remaining drill string to the entry portal. Again, hardware was repaired and replaced.

The casing pull was then begun with the reamer ahead of and spaced by one drill rod joint from a heavy duty crane swivel adapted to a soft link made from several links of heavy duty chain. The opposite end of the chain was secured to a pulling plug attached to a different type of heavy duty fiberglass casing/screen material. This casing/screen material was basically casing that had been perforated with 0.25 " diameter holes in certain zones to correspond to gas sampling ports required by the SEAMIST ${ }^{\text {TW }}$ experiment liner. Post-drilling installation of the liner would permit vapor sampling in the general area of the burial trenches at the site. The concept for this particular configuration of downhole hardware was that the reamer needed to be free to rotate, and everything behind it would not be rotating due to the swivel placement. The soft link of heavy chain was needed to prevent compression loading of the trailing casing in case some limited reversal was needed to clear the reamer cutting face of packed debris.

The pullback of this hardware/casing/screen string progressed very well until the reamer again began the transition near the entry portal end of the trajectory. A zone of loose debris was encountered in the hole, additional pullback force was required, and the downhole assembly broke at the front adapter near the swivel assembly. Again, excavation outside the boundary of the waste site was necessary to recover the downhole hardware, but the casing pull was completed during this recovery process. After several days, the casing was swabbed to remove any fluid, natural mud, or debris that had entered the casing during pullback and only 38 gallons (approximately $15 \%$ of casing volume) of material was found and removed. A second swab run was made the following day and only 1-2 gallons of fluid were recovered. Riser sections of casing were added to the entry and exit ends of the casing string to complete the well to the desired above ground height. Refer to Appendix A for detailed information regarding this test.

This completed well is to be used for follow-on experiments with the SEAMIST pneumatically deployed liner, a gamma spectrometer from PNL, and other characterization technologies.

It is recognized that further development, testing, and improvement of downhole hardware is necessary before this class of equipment could be specified for commercial applications in difficult geologies similar to this site.

\subsubsection{Cuttings Containment System Development}

As mentioned previously in FY 91 activity, air operated downhole motors or hammer tools may have application at certain sites in geologies that are very rocky. Also, air returning to an entry portal carrying potentially contaminated cuttings and suspended contaminants must be contained and filtered prior to the air being released to the atmosphere.

SNL considered enhancing an existing ambient pressure prototype cuttings containment box that had been developed at Hanford, but the estimated costs of that approach were considerable and could have resulted in a somewhat marginal overall system.

A new containment system concept for handling exhaust air at a slightly negative pressure as is done in glove boxes in radiological laboratories was proposed by SNL project staff and was intellectually supported by Hanford personnel. This concept had significant merit when the consequences of a potential ambient or positive pressure system breach was considered from a standpoint of personnel 
contamination, decontamination of surrounding equipment, and releasing hazardous material to the atmosphere.

The market was surveyed to find large vacuum machines that were being used in the asbestos remediation industry. A machine manufactured by GUZZLER Corp. in Birmingham, AL was found to be a close match to the requirements. After discussions with GUZZLER Corp., a contract was issued to GUZZLER to build a prototype machine capable of a $1700 \mathrm{cfm}$ flow rate with a negative pressure capability of 12.8 inches of mercury. This machine would have parallel banks of absolute filters, charcoal filters for organic vapors, special controls and readouts for differential pressures at several points, and bear an ASME qualification stamp for the design and testing of the cyclone separator and bag house vessels. The contract permitted SNL to lease the machine for six months for test and evaluation. A purchase option was included after the lease period. SNL would need to design the diverter box to adapt the machine to a drill rig. This design work would require system overpressure protection and flow control hardware.

The machine was tested at the SNL DBTR from March through August FY 93 with different kinds of sands, gravels, bentonite clays, etc. to determine separation efficiencies and filter effectiveness. Final testing of the machine was accomplished with a True Trac boring machine coupled to the GUZZLER via an innovative diversion box designed and built at SNL. The diversion box attached to a surface casing, permitted the drill rod to be inserted through positive seals with adjustable clamping force, and routed the uphole drilling debris and air to the GUZZLER. In a final test, a hole was bored in soil at the DBTR that encompassed a variety of caliche, sand, gravel, and cobble materials. The prototype machine was found to be suitable for the intended purpose. A separate report for this test activity is in preparation. Figure 18 shows the GUZZLER machine at SNL and Table 3 lists the test phases.

The Guzzler is scheduled for testing at Hanford in FY94 with funding by Hanford. SNL staff will support these field tests.

\subsubsection{Sampler Development Activity}

Because of other commitments and problems encountered in field operations, sampling did not get much emphasis. However, the latch modifications that permitted standard samplers to operate in a horizontal geometry without the gravity assist were refined and tried several times. A sampler with a larger volume was designed and fabricated by CMW. The multiple sample concept was taken one step further at SNL by fabrication of second generation hardware with a larger capacity. No field testing of this hardware was attempted due to time and manpower constraints. 


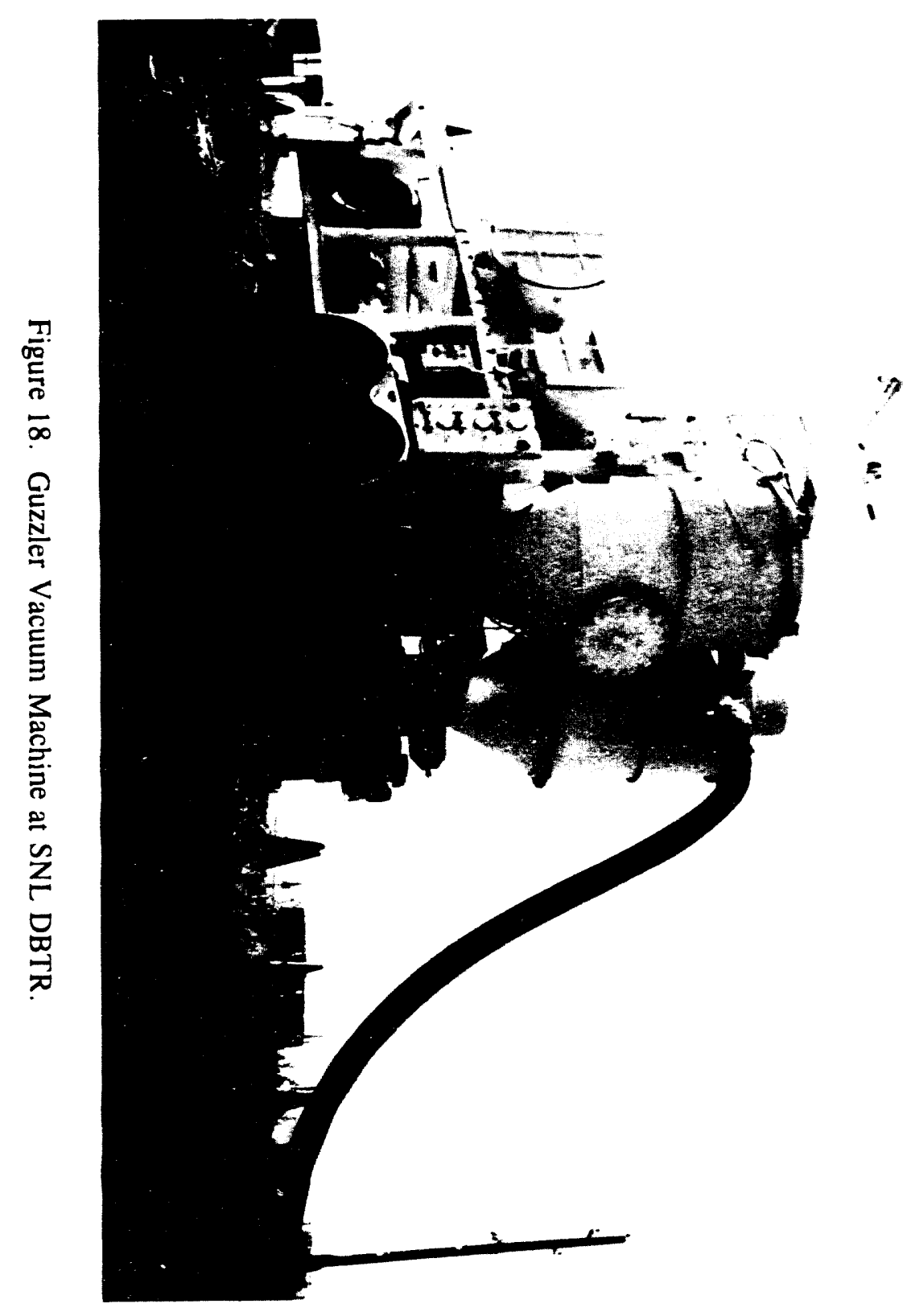


Table 3. Four Test Phases for the Drill Cuttings Containment System

Phase I - Shakedown of the Guzzler Unit using commercial crushed stone and sand as test samples.

Phase II - Operating the Guzzler Unit with Wellhead Diverter Box, using commercial crushed stone, sand, and bentonite powder as test samples.

Phase III - Operating the Guzzler Unit with Wellhead diverter box and Air Compressor to test system flow parameters.

Phase IV - Operating the Guzzler Unit with Wellhead Diverter Box, Air Compressor, and Drilling Rig during actual drilling operations. 


\subsection{PROBLEM AREAS}

The machinery, downhole hardware, casing/screen materials, strategies and techniques developed to date in this project have been relatively successful. However, there are several technical problem areas that remain. These are discussed in the following paragraphs as distinct issues, but it must be recognized that there are interdependencies.

\subsection{Geology Dependency}

There are several issues related to the geology dependency of either success or failure while directional boring with this class of equipment. Equipment that cuts and compacts the cuttings works best in soils that are homogeneous without rocks and cobbles. These soils are typically clays and cemented sand/gravel formations. Soils of this type are relatively easy to penetrate, sometimes without actual cutting of chips, but rather by displacing material. Formations containing very wet sands or fine dry non-cemented sands are easy to penetrate, but provide very little wall stability for buttressing, steering control forces. These formations tend to collapse on the drill string and prevent any forward or rearward movement. Drill string bend radii are necessarily greater in these soils than for the clays and cemented sands/gravels. Also, more aggressive steering head geometry is required.

Widely heterogeneous formations such as alluvial fills with caliche, sand, gravel, cobbles and boulders are very difficult to penetrate/cut and to control steering. The shallow slant angle of penetration, natural dips of the formation, zones where compaction of cuttings is not possible, the tendency for reamers to walk around a boulder or cobble rather than grind through it, and the very abrasive environment for the bits and reamers as well as casing to be pulled through all affect the drilling operation. Again, wall stability, either naturally occurring or compacted by the boring head, plays a large role in success or failure of a boring operation.

The glacial till geology found at the Hanford site was the most difficult formation encountered during development testing. This previously described "box of rocks," an extremely unstable formation, provided no opportunities for success in cutting, compaction, steering and casing emplacement with the current configuration of the X-810 prototype machine.

\subsection{Onboard Position Locating Electronics}

The oil/gas, geothermal, and river crossing drilling industries use very precise, and very expensive $(\$ 50 \mathrm{~K}-\$ 100 \mathrm{~K})$, olivoard electronics position locating or "survey" systems. These systems are very good and have sophisticated software capabilities and comparative data features that are capable of displaying a variety of information. The tools, installed in their housings, are typically $10^{\prime}$ in length and $3 "$ in diameter. Standard operating practice requires that two survey tools be available at a drill site to assure that drilling will not be held up by the failure of one electronic package. Companies doing business in these industries use large expensive drilling rigs, have drilling costs ranging from $\$ 75$ to $\$ 350$ per foot, and can drill much deeper and farther than the class of machinery being developed in this project.

Some of these sophisticated, magnetometer based systems also use an electrically driven grid on the surface surrounding the borehole trajectory to create an artificial magnetic field that is used as a 
reference in place of the weaker field of the earth. This is particularly important if the drilling trajectory parallels nearby metallic objects (pipe, tanks, electrical equipment, etc.) as might be the case in the river crossing industry.

The drilling machinery in this development project class might typically sell for $\$ 150 \mathrm{~K}-\$ 300 \mathrm{~K}$. Contractors buying this type of machinery for shallow environmental work may not be willing or able to spend an amount equal to the drill rig cost to have two spare electronic locating packages, especially if competitive drilling costs are approximately $\$ 25$ to $\$ 75$ per foot. A fundamental goal of this project was to purchase, develop or adapt onboard electronic locating packages in the $\$ 10 \mathrm{~K}$ to $\$ 20 \mathrm{~K}$ range that would have sufficient accuracy to drill to 80' depths and emplace boreholes up to $1000^{\prime}$ in length. Because of size and cost constraints, the choice of electronics in this project was somewhat limited to two-axis magnetometer-based instruments, approximately 2 ' in length and less than $2^{\prime \prime}$ in diameter.

The directional survey tool used to date in this project was obtained from a small company in California and costs approximately $\$ 12 \mathrm{~K}$. SNL and CMW each purchased a tool so that a spare would be available. The tool is based on a two-axis magnetometer detector system with an inclinometer. Most of the project development drilling has been at locations where site geometry dictated that the borehole trajectory was slightly off of magnetic north. As expected, the azimuth data from this tool was less than optimum under these physical conditions of shallow angle intersection of the earth's magnetic field.

The tool design limits may have been exceeded while drilling, also contributing some inaccuracies. The tool was subjected to some abuse by the torsional and longitudinal vibrations and impact caused by the drilling operation. Also, frictional heating of the downhole hardware as a result of penetration and compaction forces on the drill bit and by the uphole drill rod rubbing on the borehole wall at trajectory deviations contributed to some electronic failures. There are several improvements to steering tool technology that have been identified and work is ongoing.

\subsection{Bits and Steering Faces}

Bits and steering face geometries of the development hardware were severely tested in the evaluations to date. Many types of experimental bits were tried. Some worked in one soil, but not in other soils. Some showed extreme wear afier use. Some worked very well when boring but would not steer effectively. These geometries will not be discussed in further detail due to their currently proprietary nature with CMW. A key improvement in cutting, compacting, steering, and borehole stability was attained when a small amount of water (2-5 gallons/minute) was added to cool and lubricate the bit/drill string, cool the locating electronics, and aid in compaction of the cuttings on the borehole wall. This small amount of potable water should be acceptable at many environmental sites.

\subsection{Wellbore Completion Hardware}

After the wellbore is drilled at some nominal diameter ( $3 "-5 ")$, the wellbore is typically reamed to a larger diameter (6") to accommodate the pullback of $4.5^{\prime \prime}$ diameter casing/screen string. Each reaming pass from exit portal to entry portal can take as long as the original boring operation. The reamers must enlarge the borehole diameter, then compact and stabilize the cuttings in the borehole wall. This operation may require as much as 10 gallons/minute (typically $5 \mathrm{gpm}$ ) of potable water. Several reamer passes may be required in alluvial type soils similar to the soil at SNL. After the 
reaming is completed, a pullback hardware string is assembled for the casing pull. This hardware string is typically composed of the reamer in front, followed by a swivel, a slip or soft link, a pulling plug, and the casing. This is a very critical part of the well emplacement, fraught with potential problems.

The RB-11 operation helped to define acceptable, but not optimal, reamer designs for shallow directional boring. Several iterations caused by reamer hardware wear and breakage permitted project personnel to try new geometries and materials on the reamers which ultimately proved successful at RB-11. The SNL designed swivel hardware used at RB-11 was rated at 50T and was obtained from heavy construction crane technology. The bearings and seals in the swivel held up but the hardware adapting the swivel to the drill string failed. The pulling plug designed and assembled at SNL held up until the last directional transition zone was encountered. A weld between the swivel adapter and drill pipe failed and caused problems with continued casing emplacement. Additional design work, testing, and evaluation of this hardware is needed.

\subsection{Casing and Screen Materials}

Casing/screen materials of various types are commercially available for use in vertical environmental wells. The casing of a vertical well must be strong enough to carry the weight of the remainder of the downhole casing/screen, but this casing is not subjected to any appreciable torsion or flexion loads. When this material is used in directional wells, the combined stresses, mechanical loading and abrasive environment are much different and more severe than encountered in vertical wells. Project testing contains a component of casing/screen evaluation that to date has been reactionary in nature to solve a real-time problem. The cost of strong casing materials must be proactively lowered through design, testing and innovation. Materials being considered for casing in horizontal boreholes comprise a cost spectrum from \$4/foot HDPE utilities conduit on 500' rolls to aluminum electrical conduit at $\$ 5 /$ foot in $10^{\prime}$ lengths, to $\$ 20 /$ foot high strength fiberglass tubing in $30^{\prime}$ lengths. Screen materials can be more expensive due to the slots, perforations or gravel packs sometimes required. The project advocates using the most cost effective material for an application without overkill, keeping in mind that there must be an educational process for the ER professionals and regulators that will ultimately lower costs. An example of this situation is to propose using standard HDPE utility tubing with custom perforations, added in the field, at environmental sites where vapor or liquid pumping from a well is needed.

A series of casing tests in adjacent wells, as nearly identical as possible, is needed to assess the various casing/screen materials such as fiberglass, aluminum, HDPE, PVC, etc. Instrumentation of these tests to measure critical loads while each material is being installed is important. Planning for these tests is currently underway. 


\subsection{TECHNOLOGY TRANSFER TO USER INDUSTRIES AND REGULATORS}

Information about the project and the evolving machinery, hardware, drilling strategies, and casing material options continues to be shared with sponsors, ER professionals, and at technology workshops with the user industries and the few regulators that attend. For the most part, the user industry representatives are convinced that this technology has much promise for future environmental drilling. The technical personnel at several regional EPA labs are also intrigued by the technology and innovative methods.

The barriers that have not been breached, and in all fairness have yet to receive major emphasis, are the actual regulatory bodies. Since the current regulations do not cover directional work, the work plans for the SRS operation and the Hanford operation had to bridge to the respective state drilling regulations for vertical monitoring wells and discuss differences of the directional work with entry and exit portals. Solid assurance was required that the directional work would take care to protect the groundwater while drilling, that only approved vertical drilling fluids, if any, or potable water would be used, and that well completions would be constructed in such a way as to protect against surface water infiltration around the casing. In each case, however, approval was obtained to perform the drilling test. Testing at SNL has not encountered any regulatory barriers. The AF and the SNL MWL-ID prepared the appropriate requests and predrilling documentation for the work at the RB-11 site on KAFB.

A strategy used in the project since its inception is to include the ultimate users in information sharing as early as appropriate. This is a standard procedure used by CMW to get feedback on a new product. Typically, pre-production prototype hardware is placed in the hands of selected customers/contractors with histories of being innovative and interested in new developments. These evaluators then provide product feedback from the day to day user perspective. This same strategy was followed with the X-810 through CMW involving the S \& S Harris Co. in a field test. S\&SH is a small, innovative company that had previously contracted with a refinery to emplace an underground monitoring grid of directional boreholes. S\&SH has successfully adapted existing commercial utilities machinery to emplace the boreholes at a shallow depth in a narrow sand layer. There are also other contractors in the utilities installation industry that are capable and innovative, and could easily expand their business to include low cost horizontal environmental boring. 


\subsection{TYPICAL GOVERNMENT, COMMERCIAL AND PRIVATE SECTOR APPLICATIONS}

The DOE certainly has a variety of environmental problem sites where this technology could be applied. Applications of the technology benefit from lower costs than larger directional rigs at depths to 80', much less fluid added while boring, very little if any secondary waste generation, minimal site disturbance, and shorter mobilization and demobilization time.

Likewise, the DOD has similar sites with additional potential hazards such as buried ordnance, fuel storage, de-icing pads, etc but without the volume of radiological material that DOE sites have.

Most major industries in the USA have environmental problem sites that may or may not be unique to an industry. Steel, aluminum, petrochemical refining, fertilizer, plastics, heavy and light

manufacturing, etc industries all use or have used and disposed of by-product materials. The accepted disposal practices of the past are now under scrutiny, and the burden-of-proof and the cost of cleanup are now on individual companies under the current EPA regulations. The number of private industry sites that will require characterization and, ultimately remediation in the country is staggering. Also, municipal entities have operated landfills, some of which will eventually benefit from this technology.

The costs associated with the characterization and remediation of private sector sites could have a severe impact on financial markets, individual company survival, and stock holder earnings.

Fuel storage and small fuel distribution sites such as the local gas station will be required to prove whether their tanks are or are not leaking. Remediation of some of these sites has already begun with a "muck and truck" philosophy. Costs can be lowered by applying new technologies that permit in situ sampling. Some of these sites may not need immediate remediation, but instead may be monitored for any contaminant plume migration.

Natural radon gas problems are being encountered in certain regions of the country and lending institutions are hesitant to arrange loans for properties with this pre-existing condition. This directional boring technology has potential application in characterization and remediation without major excavation and reconstruction of buildings. 



\subsection{FY 94 PLANNING}

Milestones for FY 94 include this interim report, a test plan, a commercialization plan, a final field test activity, and a final report. The strategy for the remaining development and testing to support the milestones will primarily consist of joint SNL/CMW testing at the CMW test range in Oklahoma and potentially a final test activity at SNL. Technical issues to be addressed in FY 94 are downhole hardware design and reliability, casing/screen materials and installation methods, steering tool improvements, and limited work on sampling methods.

The GUZZLER vacuum system developed and tested in FY 93 has been returned to the factory for some modifications and then will be moved to Hanford for field testing at benign sites. SNL project staff have received supplemental funding from Hanford to support this field testing.

Working relationships with other agencies such as DOD and NASA are being pursued. Testing at other sites to identify future applications of the technology is a possibility to encourage commercial contractor characterization and remediation of these sites. 



\subsection{SUMMARY}

The primary goals of the project to provide high quality access beneath waste sites in a cost-effective manner while minimizing site impact are being met by iterative technology development and testing. Two major successful tests at the SRS M-Area and at the SNL/KAFB RB-11 sites have demonstrated that this hybrid technology developed and adapted from the underground utilities industry has many potential applications for environmental work. A major test at Hanford was not successful and demonstrated that this technology will not be applicable to all geologies. Conversely, testing at SRS and SNL/KAFB sites has demonstrated that the technology can be usable and cost effective.

The SNL industry partner, Charles Machine Works, has made a corporate decision to formally enter the environmental boring machinery market. Agencies other than DOE are interested in the technology. Private industry has shown considerable interest in applying the technology. The project has involved some potential user companies in evaluating the technology and prototype machinery.

FY 94 is the last planned year for this project; however, there are tasks in sampler development, boring hardware refinement, and technology transfer to the private sector that could benefit from funding from other sponsors. Charles Machine Works will continue to develop the technology to a commercial product level with private capital.

An important remaining goal is to approach regulatory agencies to explain the developed technology, address concerns and hopefully get concurrence that the technology is valid. Specification of the new technology in the near future will require bridging documentation from the intent of current regulations. Ultimately, changing or adding to the current drilling regulations to recognize and allow directional boring as an optional technology for environmental site characterization, monitoring, and remediation will be required. 


\section{APPENDIX A: TEST PLANS, TRAJECTORY PLOTS, AND EDITED FIELD NOTES}




\section{CONTENTS FOR APPENDIX A}

Drilling Activities at SRS $6 / 16 / 92$ to $6 / 29 / 92 \ldots \ldots \ldots \ldots \ldots \ldots \ldots$

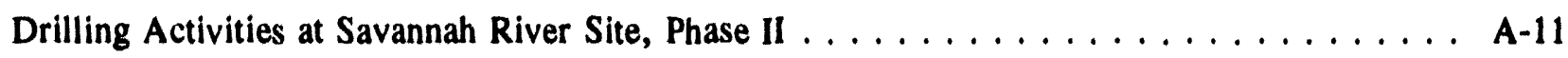

Drilling Activities at Hanford Washington, $3 / 1 / 93$ to $3 / 6 / 93 \ldots \ldots \ldots \ldots$. . . . . . . A

Drilling Activities at RB-11 Site, September to October $1993 \ldots \ldots \ldots \ldots$. . . . . . . . A-29 


\section{Drilling Activities at SRS $6 / 16 / 92$ to $6 / 29 / 92$}

This is a description of the activities at SRS to drill horizontal wells at the M-Area and at the TNX site during June 1992. The drilling at M-Area was attempted first and would occupy most of the allotted time. It was determined early to try this bore first in case it became necessary to dig a pit for the drill to be used at this location. The TNX drilling could then be done while the drill pit was dug. The CMW personnel were required to attend a site orientation course before they could start to work. The SNL staff were not required to attend so they started to unpack and checkout the steering tools and other equipment. Most of Monday 6/15 was taken up with the unloading and spotting of the various pieces of drilling equipment. Drilling plans and plots of the bores made for both M-Area and TNX are included as attachments.

\section{6/16/92 Tue.}

Continue to checkout the CMW survey tool by placing the survey tool on a survey tape stretched between the entry stake and the $200 \mathrm{ft}$. stake. The system seems to function and gave a heading of $338 \mathrm{deg}$. This value was obtained by rotating two turns and taking Az data at $90 \mathrm{deg}$. increments of roll. Inclination was not changed during these readings. At the start of the drilling actual survey data of the bore heading was not available so there was no means of checking the survey tool heading.

During test of the SNL survey tool it was noticed that the system had a lot of hysteresis error in the azimuth readings. After working with this unit for some time it became apparent that this error was observed in the north/south orientation and was not seen when the unit was used east/west. These anomalies were first thought to be associated with the SNL tool that had just been repaired and may have had a sensor problem. After using the CMW system in a similar manner, the same behavior was seen in that tool, so it was obvious that the problem was generic to these tools. These azimuth errors were $+1-5$ deg which was not acceptable. The two units were tested using several techniques and it was determined that by rolling the survey tool at least one revolution between $\mathrm{Az}$ readings an acceptable set of values could be obtained.

Pre drilling rod tally: 140 ea. $5 \mathrm{ft}$. steel

4 ea. Non-Magnetic @ $5 \mathrm{ft}$.

BHA - Bit, Housing, Flex sub @ $5 \mathrm{ft}$.

1420 - Starting to drill, entry angle $-19.3 \mathrm{deg}$.

1430 - A hydraulic hose broke on the drill power pack - most of the oil was contained on the plastic sheet which had been placed under the system. Approximately $4 \mathrm{gal}$. of oil was collected in a bucket and with absorbent. SRS was notified and they seemed satisfied with the result. The bit had gone only about $2 \mathrm{ft}$. when the hose broke.

1600 - Back to drilling but could not make up the flex sub to the first non-mag section - cross threaded. Shutting down to disassemble and take the damaged parts to a machine shop for repair.

EOD - end of day.

6/17/92 Wed.

0845 - Started drilling without the flex sub as the plan called for $50^{\circ}$ of straight hole at $20^{\circ}$ before the steering was to begin.

0920 - At $20^{\prime}$ in the hole began tripping out to check the bit temperature.

0937 - Bit very hot to the touch, hard pack clay on the bit. Setting up to use water assist to cool the steering tool and lubricate the drill string. The water will be supplied by the Jet Trac pumping system through a water swivel and packoff for the survey tool signal wire.

1250 - Installed BHA with flex sub and 15' non-mag rod, will add water as required to aid drilling and hold the temperature down. Flow rate of the water was 1 to $3 \mathrm{gpm}$ at 350 to $450 \mathrm{psi}$. 
1315 - Starting water flow, slow drilling.

1330 - Still slow drilling.

1345 - Tripping out to install a carbide bit, survey tool temperature OK with water in the string.

1508 - Starting to drill again.

1555 - $35^{\prime}$ in the hole, inc. 17.5 , h 33.3 , MSL 345.1

1605 - Some water/clay returning to entry pit. We are monitoring with $\mathrm{HNu}$ and Mass Spec., neither show any significant effluent from the well. Very hard drilling $h=33^{\prime}$ to $38^{\prime}$, depth 11 '.

1640 - Survey tool will not talk to us! It may have gotten too hot.

1645 - Installed wiper and break out tools to come out of hole. M.S. and HNu did pick up trace indications, HNu barely observable meter deflection, the M.S. peaks were $166 \mathrm{amu}$ (PCE), $130 \mathrm{amu}$ (TCE), and $97 \mathrm{amu}$ (DCE?). Came out of hole, survey tool no good, it would give some data intermittently, water in connector, and loose parts inside, will send it to the manufacturer for repair.

EOD

6/18/92 Thur.

Starting in the hole using the SNL survey tool (4th attempt) BHA large S.S. bit, survey tool with housing, flex sub, and 15' of non-mag rod. Will use water assist as before, returns if any will be collected for disposal. This survey tool has a much different inclination - removed survey tool for calibration.

$\begin{array}{ccc}\text { Cal. w/tool face at } 0^{\circ} & \text { Inclinometer } & \text { Survey Tool } \\ 0.0 & +0.3 \\ 5.0 & 5.5 \\ 10.0 & 11.3 \\ 15.0 & 17.4 \\ 20.0 & 23.1 \\ -20.0 & -23.8 \\ -15.0 & -18.0 \\ -10.0 & -12.3 \\ -5.0 & -6.3 \\ 0.0 & +0.3\end{array}$

1053 - Starting to drill with compensation applied to the inclinometer readings.

1143 - New hole starting with rod \#9, adding water, no returns.

1208 - Checked the azimuth sensitivity at rod \#10 by parking the water truck over the bore, at a depth of $15^{\prime}$ the truck induced an error of $+1^{\circ}$.

1353 - We now have 90' of rod in the hole and are starting to lose angle form $-19.2^{\circ}$.

1721 - The Jet Trac power unit quit, cannot add water, $175^{\prime}$ of rod, nearly level at $319.1 \mathrm{MSL}$, 36.9' deep.

1743 - Drilled ahead to $185^{\prime}$, will remove one rod and park in mid travel and leave 180' of rod in the ground overnight.

EOD

6/19/92 Fri.

0800 - Jet Trac pump now working, it had a loose connection on the fuel cutoff solenoid. Also repaired a small leak on the drill power pack.

0945 - Safety meeting. 
1000 - Drilling again - almost lost the signal wire down the string.

1102 - Hit some hard drilling at $\sim 195^{\prime}$ and MSL of 319', 37' deep.

1153 - Hard drilling again at $\sim 215^{\prime}$ and $36.6^{\prime}$ deep.

1235 - Drilling still tough, all drilling done with water pump on.

1248 - Tripping out - the drill bit water outlet may be plugged. Rod length 230', 319.6' MSL.

1438 - Trip out complete, filling the hole with water.

1458 - Jet mostly plugged, carbides good.

1530 - Starting back in, will take data every 10'.

1555 - A wire splice came loose, tripping from 30'.

1615 - Lightning shut down operations off and on until $1700 \mathrm{hrs}$. Decided to pull out from 30' and calibrate the survey tool. The survey tool reads $\sim 333^{\circ}$ in the ground and $338^{\circ}$ on the surface, this could cause a $\sim 55^{\prime}$ error in exit location.

1731 - Checked out the survey tool on the surface at $0^{\circ}$ and $180^{\circ}$, the average heading was $338^{\circ}$; on the drill string it varies $330^{\circ}$ to $335^{\circ}$. This survey tool (SNL) agrees with the heading obtained when using CMW's unit. It would appear that we are drilling at $\sim 332^{\circ}$ and should be at $338^{\circ}$. Tomorrow we will survey the bore using the Subsite and Jet Trac rod to provide an indication of the actual heading.

6/20/92 Sat.

0730 - Started to check out the bore heading using the Subsite, while this was going on we ran another calibration of the inclinometer.

$\begin{array}{rccc}\text { Inc. } & \text { Survey Tool } & \text { Inc. } & \text { Survey Tool } \\ 0 & +0.2 & 0 & 0.0 \\ -1 & -1.0 & 1 & +1.0 \\ -2 & -2.3 & 2 & +2.1 \\ -3 & -3.5 & 3 & +3.1 \\ -4 & -4.7 & 4 & +4.5 \\ -6 & -7.0 & 6 & +6.9 \\ -8 & -9.5 & 8 & +9.3 \\ -10 & -11.8 & 10 & +11.6 \\ -12 & -14.3 & 12 & +13.9 \\ -14 & -16.7 & 14 & +16.4 \\ -16 & -19.2 & 16 & +18.8 \\ -18 & -21.6 & 18 & +21.1 \\ -20 & -24.0 & 20 & +23.6\end{array}$

Hysteresis $\sim 0.1^{\circ}$

Ran the Subsite in the hole to check the heading and depth calculations.

$h$

31 ,

$35^{\prime}$

$39^{\prime}$

$43^{\prime}$

$47^{\prime}$

51 '

$55^{\prime}$

?

?

63.5
Depth

9'4"

$10^{\prime} 8$

13 '5"

$14^{\prime} 11 "$

$15^{\prime} 11^{\prime \prime}$

18 '1"

17 '"

20'5"

22 ' 5 "

$>22^{\prime}$
The line established was about $1 \mathrm{ft}$. west and parallel to a tape stretched between the drill and the 200' stake. 
0946 - Starting in the hole with the BHA.

1130 - At 175' the survey tool stopped transmitting Az data.

1230 - Drilling ahead, the survey tool gives Az data sometimes.

1310 - End of old hole, drilling ahead, the survey tool gives AZ data most of the time.

1400 - Status $\mathrm{h}=255^{\prime}, \mathrm{D}=37^{\prime}$.

1423 - Hit a hard spot $h=269.9^{\prime}$, MSL $-319.2^{\prime}$.

1526 - Drill bit jet plugged!

1535 - Hard to pull back 4 rods and pumped about 1 " of water from the tank, we now have flow to the bit and will drill ahead.

1800 - Added 1.5 rods and the jet plugged again.

1816 - Removed two rods and parked at mid travel.

\section{EOD}

6/21/92 Sun.

0800 - Safety and planning meeting. The plan of attack is to trip out, replace this bit with a new bit using a larger jet to help cut the clays, lubricate the drill string to reduce the heat generation the SRS people suggest the clay layer may be altered due to the remediation already done in this area.

0917 - Starting out of the hole.

1527 - Installed new bit with a 5.5 jet in place of the $1 / 8$ pipe check that was used up to now.

1537 - Held up by lightning.

1553 - Back in operation.

1928 - Status, $\mathrm{h}=300$ ', pulled back to 288 .

EOD

6/22/92 Mon.

0800 - Started drilling again, rod length $305^{\prime} ; \mathrm{h}=299.1 ; \mathrm{MSL}=321.6^{\prime}$

0946 - During the interval between 310' and 340 the Az indicated that the bore was turning slightly left. We did not use any correction and it soon came back to previous values.

0952 - So far the chemical sensing systems have seen only trace amounts of chemicals - there is only slight evidence that these "shows" came from the hole in progress. There are several vertical wells in this area which are said to vent as the barometric pressure changes and the wind may blow from several different directions during the day. In addition, the sensing system sometimes picks up a stronger indication above grade than they do in the entry cellar.

1053 - No signal from the survey tool, a wire had broken during the last rod make up, all OK.

1307 - At $h=399^{\prime}$ started to steer up.

1510 - Anchors real loose, $h=468^{\prime}, \mathrm{MSL}=331$ '.

1630 - Anchors too loose to hold the drill, will shut down and prepare to set the anchors tomorrow AM.

1640 - Status as of now rod length $480^{\prime}, \mathrm{h}=473, \mathrm{MSL}=332^{\prime}$.

EOD

6/23/92 Tue.

0715 - Waited on the back hoe until 1045 to set the anchors.

1138 - Original four anchors reset and two new anchors installed down the center of the drill frame. Coupling up the drill again.

1221 - Casing inventory; 420' x 3" PVC, 260' x 3" PTFE. 
1330 - Anchors loose, waiting on the back hoe, which will be used to secure the drill frame.

1427 - Drilling again, $\mathrm{h}=501.9, \mathrm{MSL}=342.2^{\prime}$.

1601 - Came to surface - $\sim 22^{\prime}$ west of centerline, the calculated $h=545.6, \mathrm{MSL}=366$.

1900 - Started to pull back casing, schedule 160' solid PVC, 260' slotted PTFE, 125' solid PVC. The first part of the casing (160' PVC) pull went very smoothly, when the first joint of Teflon was attached it was noticed that the box had opened up due to the slight radius required to make the entry into the whole. The upset was bad enough that it was felt by all that there was no chance that the casing would remain intact for the pullback. Status $150^{\prime}$ of PVC in the hole, 10" at ground level, 0 PTFE.

\section{EOD}

\section{6/24/92 Wed.}

The SRS staff is working on the PTFE casing problem. They are looking at welding or otherwise bonding the pin and box. As it stands now they can be screwed together and the box can be flared open and stripped by hand with very little effort. The shop that has the equipment to weld Teflon could not generate enough heat to weld this material so that idea is out. There are as many ideas as people on how to fix this problem. The most practical and expedient one is to support the box with cloth tape applied in 18" strips axially over the joint which is then held in place with a spiral over wrap. After a "bench test" in which two sturdy lads could not generate any upset by hand it was decided to try to install the casing using this technique.

Started pulling casing with the Teflon joints taped for support. Pulled four casing joints and the system parted down hole. Started a push back and achieved 110' (no casing) when the cable that had been used to apply compression to the casing jammed. Pulled the wire rope until it parted. Pushed until the rig was too loose and quit.

\section{EOD}

6/25/92 Thur.

1730 - Started tripping out, the survey tool is working.

1000 - Casing inventory PTFE 210' ×3", 3" PVC 260', 4' PVC 200'.

1113 - Started back in hole with the same BHA as 6/22 .

1651 - Drilling good until rod $\# 102, \mathrm{~h}=284, \mathrm{MSL}=337$ '; had some hard drilling with this rod.

1630 - Came out right along side the existing casing left in the hole yesterday.

\section{EOD}

6/26/92 Fri.

Casing schedule $180^{\prime} \times 4^{\prime \prime}$ PVC, $10^{\prime} \times 3^{\prime}$ PVC, $210^{\prime} \times 3^{\prime \prime}$ PVC, $160^{\prime} \times 3^{\prime}$ PVC. Each threaded joint of PVC pipe will be cemented using PVC cement and made up as tight as possible by hand. The 4" to 3" transition was made using a 4" slip coupling and a 3" slip reducer. These were cemented up about an hour prior to use. The threaded joints of the remaining 4" casing were primed and cemented as they were added to the pullback string.

1220 - Started pull back. All went very well with the PVC and startled adding the PTFE, water was added to the casing entry pit to keep lubrication on the casing. Since the PTFE was slotted it allowed the solid casing to fill up with water. The casing parted after during the 10th PTFE joint. Started pull back and recovered one 10' piece of PVC which had failed at the root of 
the pin, (the casing was installed pin to the north) with a circumferential tear which was very smooth and regular. Status of casing; $180^{\prime} \times 4^{\prime \prime}, 10^{\prime} \times 3^{\prime \prime}$ PVC plus 100' of PTFE. The entry end has one 10' piece of 4" PVC to keep the entry hole open. Removed all of the cable used to apply tension to the casing.

This ended the effort at M-Area.

6/27/92 Sat.

Started moving the drilling equipment to the TNX area and were ready to drill about noon.

1245 - Started drilling at the test well location, went about $40^{\prime}$ with a good penetration rate, depth 7.3'. The drilling got real hard and by $50^{\prime}$ the penetration rate was poor. There was also some trouble steering and the system was above the desired trajectory until rod $\# 3$ (30') it then took a dive adding to the problem. Drilled in part of rod $\# 6$ and the drill essentially stalled. Decided to run a sampler to try and find out what we were in. The sampler was installed and ran to the end of the hole where it became very hard to advance, the operator rotated to aide the penetration. The sampler was then set pushed and recovered. The cone point had been sheared off and jammed in between the push rod and the sampler. The material was a very coarse, saturated, angular grained sand called "running sand" by one of the drilling crew and extremely difficult to drill with the equipment that was in place.

6/28/92 Sun.

Part of Sunday was used to collect and organize equipment and data in preparation for either drilling or demobilization. All personnel took at least a half day off.

6/29/92 Mon.

It appeared that there was very little chance of drilling the TNX area so the equipment was moved back to the M-Area and prepared for transport.

\section{CRITIQUE}

M-AREA

Drill Performance: The experimental X-810 performed very well with only minor problems that may require engineering attention. There were some problems associated with the breakout wrenching system. The power pack needs an integral catch basin to contain hydraulic fluid in case of a leak. The anchoring system gave the most problems but launching from a pit eliminates most of these, the rest can be solved with some modification to the anchor and the driving system.

Steering Tool: As noted the survey tool steering tool performance requires some attention as it was not nearly as good as it could be. The tool clearly needs an onboard temperature sensor as this was the third temperature related failure this year. The manufacture is working on this problem and has a design that increases the tool temperature rating from $85^{\circ} \mathrm{C}$ to $125^{\circ} \mathrm{C}$ and also supply internal temperature data to the surface panel. It is not clear at this time if the azimuth resolution can be improved and some investigation is planned. The inclination system needs some work, there should be much better accuracy than was experienced with the SNL tool. Each tool needs as thorough calibration check prior to use at each site. A system to do that will be developed. There is also a strong need for better software to plan a bore trajectory and to handle the acquired data while drilling. This software is nearly complete as of this date. The development of a serial link between the surface panel and a portable computer is very desirable. Signal wire handling while somewhat time consuming especially with the pack off required during fluid injection went 
rather smoothly. This system could be improved with the addition of a split seal to eliminate the task of feeding it over the wire each time a rod is changed out.

Geology: There were no unexpected problems with the geology except that the temperature of the BHA got too hot to drill without water assist. Water aided the cutting process, cools the steering tool and lubricates the drill string. At no time was enough water added to generate "returns."

Casing/Well Completion: There were significant problems with the casing and this issue is at the top of the list for attention for directionally drilled off vertical wells. A much better understanding of casing characteristics and attention to detail is required to successfully complete these wells. The casing failure in the first pull back attempt was most likely caused by the overnight settling of the formation securing the inhole casing in place. It is not known whether the PVC or the PTFE portion parted. There is speculation that the second attempt failed due to the PVC filling with water in a hole that provided little or no buoyancy. Other alternatives exist, that the casing just failed at the point of highest stress, the first joint pin possibly at the O-ring groove. Other possibilities are a flaw or as a result of softening from the application of solvent type cement. Another look at the tensioning and pull back hardware may also be beneficial.

\section{TNX AREA}

Drilling: The drilling operation at TNX did not go well at all. The Jet Trac had some hydraulic problem that reduced its capability. This however did not prevent drilling had the soil conditions permitted drilling. The coarse saturated sands encountered at the depth of interest were extremely difficult to drill without heavy mud to stabilize the hole both for drilling and for pull back.

Tracking: Due to constraints of the placement of the drill the entry point was about 12 ' in front of the survey stake form which the bore trajectory was calculated. Since this well was to be tracked with a walk over system on uneven terrain a significant shift in the $h$ vs. depth values occurred. While not difficult to correct it does require a significant amount of time when using a hand calculator. This situation is also being corrected by writing software for both planning and steering control of walk over tracked wells.

General: The separate oversight person supplied by CDM Federal Programs Corp., under contract to SRS worked very well. This person provided H\&S monitoring, bookkeeping, conducted daily safety meetings. This was a valued, non intrusive contribution to the project. 
흠

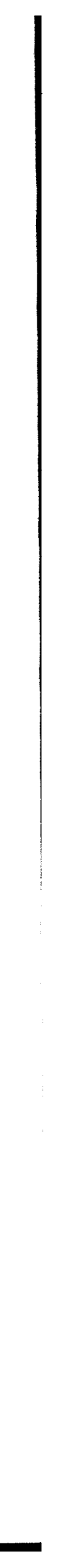




\title{
Drilling Activities at Savannah River Site, Phase II 9/21/92 to 9/24/92
}

\author{
SRS M-Area September 1992 (See Figs. A-1 and A-2)
}

The activity described here is the second attempt to provide a cased horizontal bore hole at the Non-Arid Integrated Demonstration project located at the Savannah River Site M-Area. The target parameters are a surface to surface length of $550 \mathrm{ft}$., and a depth of between $35 \mathrm{ft}$. and $45 \mathrm{ft}$. deep. This cased hole is to be used for an RF heating demonstration to test this method of remediation at this location. Because of the intent to heat the formation around the hole, high temperature nonmetallic casing is a requirement and the reason that the first attempt used Teflon as the casing material for the horizontal portion. Since there was so much difficulty in dealing with both the PVC and PTFE a different type of material was chosen for this installation. The casing procured was a fiberglass reinforced epoxy, type CEN-800 in 3 in. pipe size supplied by ENCO of Austin, Texas. A total of 20 pieces $30 \mathrm{ft}$. long were ordered, $300 \mathrm{ft}$. of solid and $300 \mathrm{ft}$. with 3 rows of 0.01 in. $\times 1.75 \mathrm{in}$. long slots for use as screen. This casing wall has a much higher tensile strength than the PVC or PTFE and has a bell upset for both box and pin end to increase the strength of the joints as well.

The launch point is from a $5 \mathrm{ft}$. deep pit such that the drill frame can use the pit walls to accommodate the reaction forces. The pit was to be located $5 \mathrm{ft}$. east and just forward of the position used in June. The drill and associated equipment is nearly the same as that used in June.

\section{Monday $9 / 21 / 92$}

The objectives for this day were to inspect the launch pit, establish the bore line and heading, calibrate the steering tools and prepare the drill for operation. The X-810 would be spotted, lined up to the bore and two anchors set at the entry end, all interconnects made and pre-drilling operational check completed. The drilling system has been modified as follows: a new rod break out system installed, the power pac has an integral base/catch basin to control any fluid leaks, the water supply system now consists of a hydraulically controlled and powered Bean pump which will use the water truck as a supply source, the casing pulling plug has been redesigned to make it easier to install and reduce the point loading on the casing.

The HP Total Station and the transit were set up on the line established by SRS which was to be parallel to and about $5 \mathrm{ft}$. east and forward of the bore made in June. The measured azimuth of this line was $343 \mathrm{deg}$. magnetic. Declination at this location is $4 \mathrm{deg} .21 \mathrm{~min}$. west but was not needed to set up the steering tools. Both survey tools, $\# 114$ (CMW) and $\# 123$ (SNL) were checked in roll, inclination and azimuth sensing modes. Roll and inclination were in very good shape and as before (6/92) most of the attention was directed to understanding the azimuth response. Azimuth data was taken at seven locations out to $150 \mathrm{~m}$ along the bore line. Survey tool \#123 was selected for the drilling as it gave both the most consistent and closest readings to the measured heading of 343 deg. Readings for this unit were in 333 to $343 \mathrm{deg}$. range. Survey tool \#114 started out reading in the 331 to 339 range but after using at several locations the output improved, indicating 336 to $340 \mathrm{deg}$. with less scatter in the data. Both of the steering tools had recently been to the factory for repair and calibration.

The launch pit that had been prepared was in very good shape to receive the X-810. The floor was sloped at about $3 \mathrm{deg}$. instead of $5 \mathrm{deg}$. but presented no problem. The drill was set in place, oriented using the HP Total Station. The south wall of the pit was reinforced with a 1 in. thick steel plate and some sheets of $3 / 4$ in. plywood to increase the bearing surface area, the rams extended and the two front anchors installed. When the carriage was raised to the $15 \mathrm{deg}$. stop the rod angle was 18.2 deg., the choice at this point was to go up $5 \mathrm{deg}$. to $23.2 \mathrm{deg}$. which made rod handling more difficult or leave it at $18 \mathrm{deg}$. Since the entry angle during Phase I was 17.9 this was an 
acceptable position. The drill, power pac and water systems were all connected and made ready for work Tuesday. EOD

\section{Tuesday $9 / 22 / 92$}

Installed survey tool \#123 on the bit and checked this assembly for Az error, all OK. Assembled the bit to the steering tool housing and this assembly to the flex sub. The system had to be torqued in for the last turn. A check of the survey tool indicated inclination and azimuth $\mathrm{OK}$ but tool face was off by 15 to $30 \mathrm{deg}$. Disassembled the BHA and found that the pin of the flex sub had been screwed into the top of the survey tool and had upset and rotated the connector and pressure barrel. Installed $\# 114$ with a different adapter sub at the bit, assembled the BHA and all was working properly.

Early in the drilling, about $30 \mathrm{ft}$. the bore took a slight turn left and by $60 \mathrm{ft}$. it was apparent that we were in the old bore hole. Very little effort was required to push or rotate, no steering capability, most of the push was done with tool face down, the data from the steering nearly matched that from the 6/21 - 6/22 data. After consultation with CDM and SRS we decided to proceed and try to get a bite and steer out of the old hole during the level part of the bore. If that was not successful to go through or along side the old casing. Either of these results would be satisfactory for the experimenter and not compromise the testing to be performed in this bore. The old rear anchor points were discovered to be in line and $11 \mathrm{ft}$. to the south of the drill. It appears that we encountered the grout plug about the third rod and drilled through it.

0900 - Safety meeting by Dave Wilson (CDM) and Dawn Kaback (SRS).

1000 - Started drilling, first inclination value $15.7 \mathrm{deg}$. It is not unusual for the drill to trace an upward kick on entry.

1100 - With $30 \mathrm{ft}$. of rod in the hole the Az took a turn left and the inclination down, the drill has probably intercepted the bore made in June.

1120 - Rod length $45 \mathrm{ft}$., very easy drilling without water, push only-definitely in the old bore since there is a very close match on the trajectories.

1303 - Rod length now $110 \mathrm{ft}$., progress very easy push only.

1400 - Rod length $170 \mathrm{ft}$.

1458 - Rod length $250 \mathrm{ft}$.

1605 - Rod length $290 \mathrm{ft}$. Checked the water system, little or no flow through the bit. Should be in the 4 in. PVC installed in June, the steering tool data correlates, there is a $1.4 \mathrm{ft}$. discrepancy in the depth data.

1657 - Rod length $360 \mathrm{ft}$.

1715 - EOD, Rod length $370 \mathrm{ft} . \mathrm{h}=366 \mathrm{ft} . \mathrm{MSL}=366 \mathrm{ft}$.

Wednesday $9 / 23 / 92$

0725 - Advancing the bore, push only.

0730 - Filling the bore hole with water from the entry end.

0803 - Rod length $440 \mathrm{ft}$., MSL - $326.8 \mathrm{ft}$., depth $29.2 \mathrm{ft}$. Coming up now and changing angle at about $1 \mathrm{deg}$. each rod.

0830 - Bore hole now full of water.

0855 - Hit the grout seal plug and used the back hoe to remove the plug and dig a small pit for the exit. Rod length $520 \mathrm{ft}$. MSL $-353.2 \mathrm{ft}$.

1045 - Worked out the casing pull back schedule with Tim Jarosch (SRS). There is $300 \mathrm{ft}$. each of solid and slotted on hand, each $3 \mathrm{in} . \times 30 \mathrm{ft}$. long. One of the solid pieces had $2 \mathrm{ft}$. of the box end removed to make up the pulling plug to the casing adapter. The casing will be pulled north to south pin toward the drill and the last piece added will not have a threaded end above ground level. 
Schedule: $\quad 4$ pieces of solid $-120 \mathrm{ft}$.

10 pieces of slotted $-300 \mathrm{ft}$.

5 pieces of solid $-150 \mathrm{ft}$.

The pulling plug will be removed with the pin end of the casing flush with the pit wall and the remaining solid piece will be added after the drill is removed from the pit. The pit can then be filled in and the surface seal set. The casing will be pulled back with a 1/4 in. wire rope installed but tension will not be applied to the cable during installation.

1000 - BHA at the surface, rod length $550 \mathrm{ft}$., horizontal $-535.9 \mathrm{ft}$., MSL $369.3 \mathrm{ft}$. (the BHA is above grade to provide access for disassembly). The bit came to surface right along side a piece of the 3 in. PTFE left behind during the June effort.

1130 - The pullback string assembly is complete, 6.5 in. diameter expander, pulling plug, casing and pull cable.

1143 - Started the casing installation.

1155 - A portion of the rod breakout system failed and had to be removed, this will slow down the process but have no other affect. Entry pit $\mathrm{HNu}$ readings, surface background - $2 \mathrm{ppm}$, in the pit $-2 \mathrm{ppm}$ at the bore hole $-3 \mathrm{ppm}$.

1420 - With about $60 \mathrm{ft}$. of casing in the hole the pull back was stopped as it would be after dark before it could be completed. Up to this point the pull had been smooth but required considerable force. The amount of force to move the heavy rods around the two curves in the bore hole accounted for some of this and also there was a considerable amount of old casing in the region. The force values were expected to decrease as the expander end reached the level section and cleared this portion of the bore hole.

1530 - EOD

Thursday $9 / 24 / 92$

0745 - Resumed the casing pull without difficulty and the load reduced steadily as the rods were removed. The water added to the bore hole yesterday in addition to that added during pull back may have softened the formation allowing the expander to move material aside without the high force values experienced $9 / 23$.

1056 - Pulling plug at the pit wall.

1140 - Removed all of the pulling assembly and capped the casing. Starting rig down and site clean up.

CASING DETAILS:

Centron ${ }^{\text {mw: }}$ CEN-800 Fiberglass Reinforced Epoxy, Integral Joint Line Pipe

3 in. nom. pipe size $\times 30 \mathrm{ft}$.

I.D. 3.35 in. $\quad$ O.D. 3.57 in.

Box O.D. 4.49 in. Wt. $1.4 \mathrm{lb} / \mathrm{ft}$.

Service Temperature Rating $200 \mathrm{deg}$. F. $(93.3 \mathrm{C})$

INSTALLATION

Grade at entry $356 \mathrm{ft}$. MSL

From the pit wall $-120 \mathrm{ft}$. of solid, 0 to $120 \mathrm{ft}$.

Entry MSL $\quad 351.3 \mathrm{ft}$

Horizontal $\quad 116.2 \mathrm{ft}$.

MSL $\quad 321.6 \mathrm{ft}$.

Depth $\quad 34.4 \mathrm{ft}$. (relative to grade at entry)

$300 \mathrm{ft}$. slotted, $120 \mathrm{ft}$. to $420 \mathrm{ft}$.

Horizontal $116.2 \mathrm{ft}$. to $415.9 \mathrm{ft}$.

MSL $\quad 321.6 \mathrm{ft}$. to $324.5 \mathrm{ft}$. 
Depth Start $34.4 \mathrm{ft}$. (relative to grade at entry)

End $31.5 \mathrm{ft}$.

$148 \mathrm{ft}$. solid, $420 \mathrm{ft}$. to $568 \mathrm{ft}$.
Horizontal
$415.9 \mathrm{ft}$. to $536 \mathrm{ft}$. - at surface
MSL
$364 \mathrm{ft}$. (grade at exit)

Coordinates (Plant)

South end (entry)

North end (exit)

East 48604.04 North 102209.05

East 48719.33 North 102758.78

Distance between casing end points at the surface $561.7 \mathrm{ft}$.

Plant North is $36 \mathrm{deg} .22 \mathrm{~min}$. west of True North

Declination is $4 \mathrm{deg} .21 \mathrm{~min}$. west

\section{CRITIQUE}

Drill Performance: The X-810 experimental boring unit had undergone only slight modifications since its use at $M-A$ rea at this same location in June. These changes primarily involved the water injection and the breakout systems. The only problem encountered were some slight damage to the survey tool during assembly and the drive end breakout system got fouled with rod grease causing it to fail. Each of these items are easily corrected.

The launch pit worked very well. Because of the intercept of the old well and the subsequent fact of having to deal with the casing from the June attempt the forces required of the drill were higher than those observed in June. The drill frame held its position very well and only slight motion occurred and it did not require extra attention to the anchor system. The only pit associated problem was the water which accumulated during the heavy rain on Thursday. The rain also caused the west bank of the pit to become unstable and it is recommended that if possible the sides not used by the drill be sloped to provide better access to each side of the machinery.

Steering Tool: The steering tools were the same ones that had been used before and worked well except as before the azimuth produced some inconsistent readings at this near north heading. Since the bit was in the old hole from $R 1=25 \mathrm{ft}$. the steering tool depth data was compared with that acquired in June. The only real difference was in depth where a portion of the new track appeared to be about $1 \mathrm{ft}$. deeper this time. This is not surprising since the inclination calibration was off and all calculations were done by hand during the first attempt. All readings from the newly calibrated survey tool were entered in a laptop computer which kept track of all the data and did a running plot which improved the steering bookkeeping.

Casing: The casing performed very well with no difficulties during assembly or pull back. The only disadvantage encountered was the $30 \mathrm{ft}$. joints made the two ends of the casing terminate without threaded ends. If a couple of $10 \mathrm{ft}$. lengths had been available the surface completion would have been a little easier. Samples of the casing material have been provided to Sandia Org. 1723 for analysis of the temperature driven off gas by-products to $150 \mathrm{deg}$. C. This work is now (Nov. 1992) in progress and will be reported separately. 


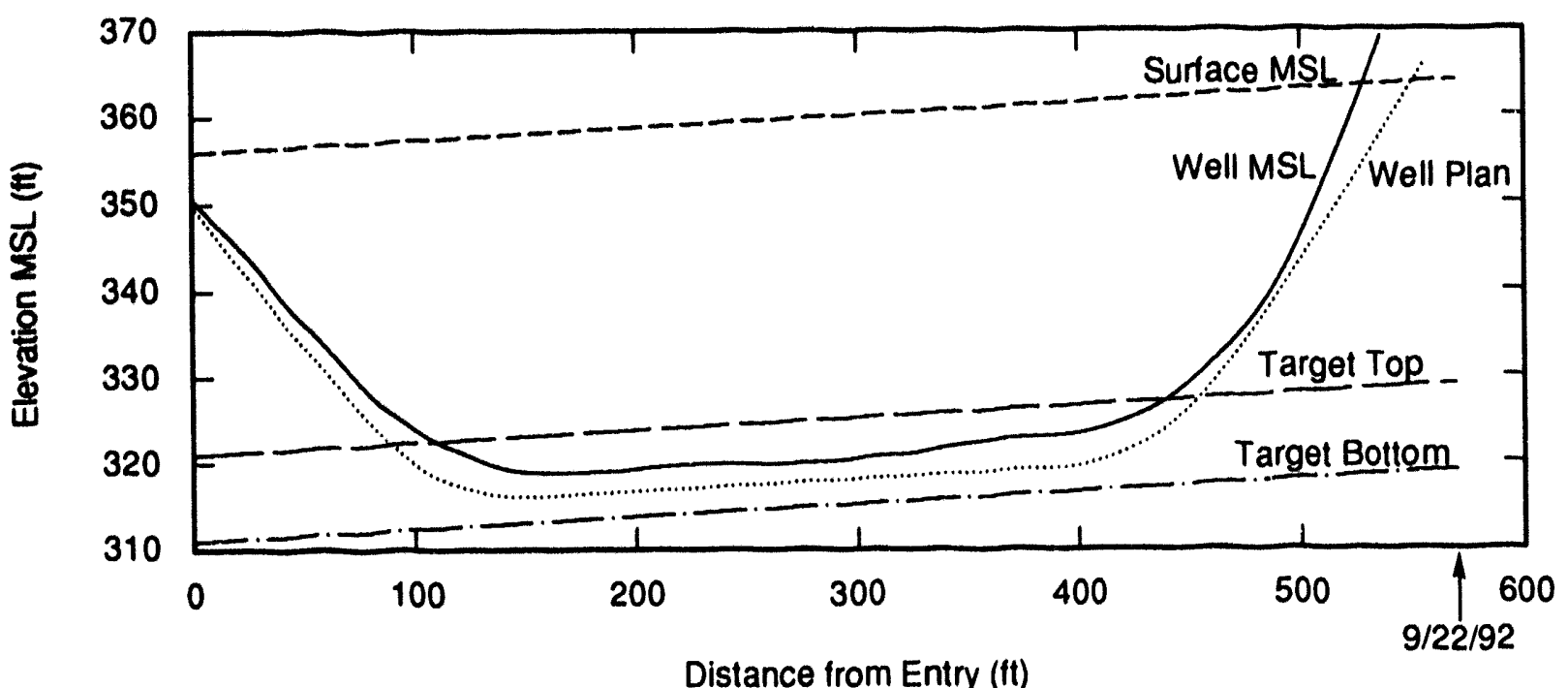

TA1.6111.13.0

Figure A-1. Savannah River Site M-Area Phase II. 

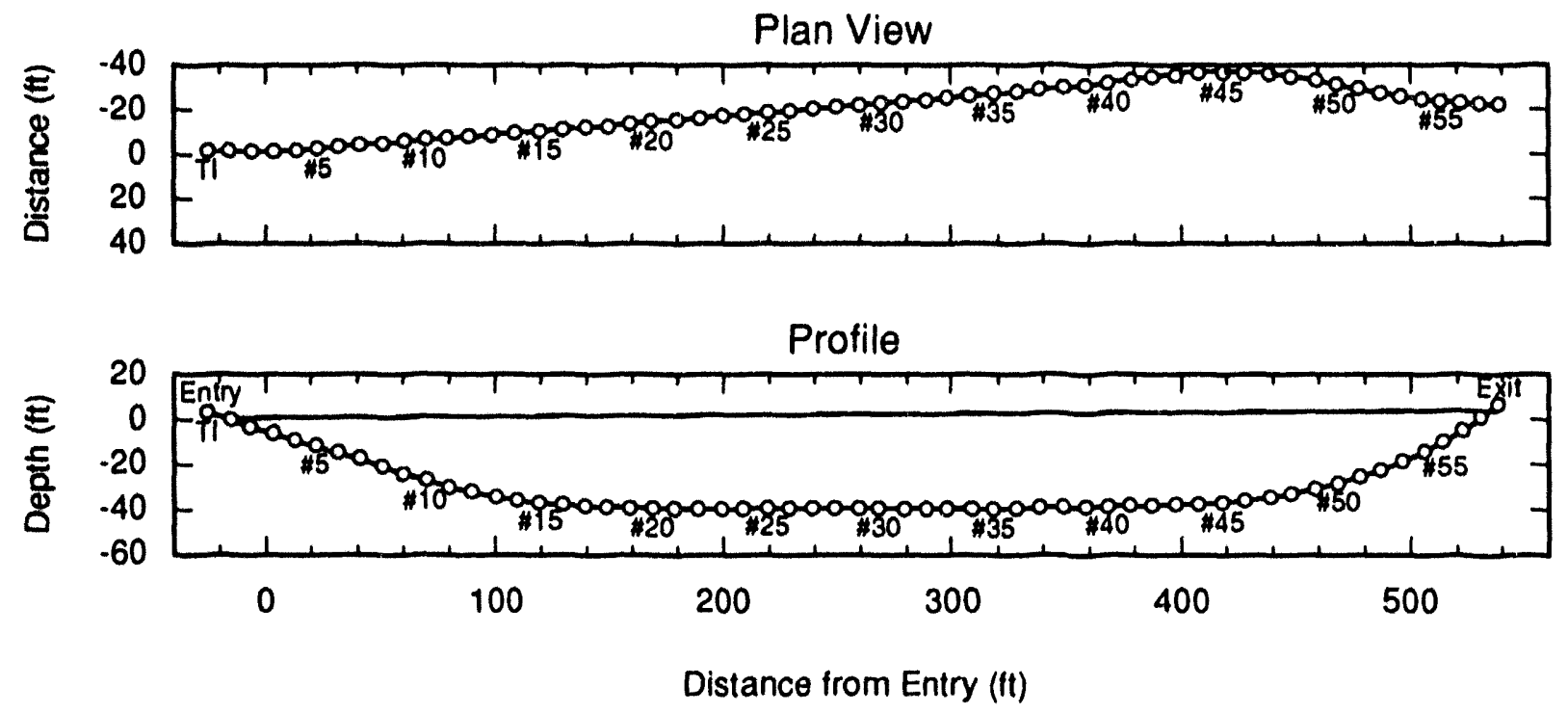

Sharewell, Inc

Sandia National Laboratories Savannah River Site

Figure A-2. Savannah River Site M-Area Phase II. 


\title{
Drilling Activities at Hanford Washington Drilling Tests $3 / 1 / 93$ to $3 / 6 / 93$
}

\author{
Feasibility testing using the X-810, P-80 and the Pierce Airrow (See HAN/PLN.XLS)
}

During 1992 it was decided to try using the X-810 and the P-80 boring systems at the Hanford, VOC-Arrid I.D. site in Washington State to complement the testing already done at Perry, OK, Albuquerque, NM and Savannah River Site, SC. Test and logistics plans were formulated for testing to be done in March 1993.

The test areas selected were between 200 east and 200 west. The location for the X-810 test was about $1000 \mathrm{ft}$. NW of the 200 Area Fire Station and the P-80 tests were done at the gravel pit about a 1/2 mile due east of that. The original plan called for two bores. S1-1 and S1-2 with the X810; and sampling experiments and bore attempts, S1-3, to be done at the gravel pit. In addition two Pierce Airrow machines, a 4 in and a 6 in. were available to try should time permit. For a description of the operation of the X-810 and the P-80 see Test Plan WHC-SD-EN-TP-020, Ben Volk Environmental Field Services, WHC. The Pierce Airrow is a cylindrical air powered in-hole hammer system which produces a hole by compaction. Air is supplied through a connecting hose. The direction (forward or reverse) can be changed while in the hole by turning the hose about 10 turns $\mathrm{CCW}$ (to reverse); the system is, however, not steerable.

The preliminary plan (Nov. 1992) for drilling S1-1 was to use an entry angle of $10^{\circ}$, target depth of $12 \mathrm{ft}$. and a length of $200 \mathrm{ft}$. with a level section $45 \mathrm{ft}$. long. Bore S1-2 was planned to start at $15^{\circ}$, boring straight for $45 \mathrm{ft}$. then at a constant radius of $250 \mathrm{ft}$. until $\mathrm{R} 1=195$ (rod length) and inclination of $20^{\circ}$ then straight to the exit at $200 \mathrm{ft}$. horizontal distance. Each of these holes were to be cased with 4 in. CEN-800 fiberglass casing. The first portion of the bore establishes a section to allow the drill string to work against to turn or steer from, the exit angle of $20^{\circ}$ or so is the preferred angle for casing installation. The above drilling plans were modified in the field to account for the actual entry angle of the drill as measured in the launch pit.

WHC provided a set of engineered reaction plates for the front and back of the drill frame to distribute the load along the launch pit walls and reduce the damage done to those walls during the drilling and casing pull back. Also provided was a buried anchor which consisted of $10 \mathrm{ft}$. long steel rods attached to a piece of 8 in. casing and set to a depth which allowed an eye on the rod to be just above the pit floor. Both of these systems were major improvements over previous methods and will be incorporated in future drilling where possible.

The site chosen to test the X-810 was the same as had previously been used for the WHCsponsored Dual Wall Percussion Hammer and the Cone Penetrometer Tests. The location is flat and the top soil is about $2 \mathrm{ft}$. of sandy soil over gravel. The gravel is unconsolidated mixed oval stones of all sizes mainly 1 in. to 4 in. some as large as 12 in. and occasionally larger. The remainder is made up of both fine and coarse loose sand. This area is said to be typical of most of the Hanford site, neither the toughest or the easiest to drill.

The following is a description of the drilling activities for each of the machines. 


\section{Monday 3/1/93}

Part of the day was spent clearing security, along with a small amount of site-required training. The truck carrying the shipment arrived on schedule and the X-810, P-80 and support equipment was unloaded by crane using site personnel. The X-810 drill power pack, drill rods, and equipment boxes were spotted, hook up of the hydraulics and drill set to the $10^{\circ}$ stop. Actual angle was $12.4^{\circ}$ due to a $\sim 2.5^{\circ}$ slope of the pit floor. The bore line was surveyed in use a measuring tape and Brunton compass, the bore azimuth $102.5^{\circ} \mathrm{mag}$. The steering tool was checked out and found to be operating satisfactorily.

Tuesday 3/2/93

0900 - Preparing to drill S1-1, air temperature $\sim 20^{\circ} \mathrm{F}$, the survey tool will not respond in azimuth and it is probably too cold, it may be OK by the time we get it all assembled.

Bottom Hole Assembly (BHA)

Subsite and housing

Survey tool and housing

P-80 style bit

The flex sub, survey tool housing and P-80 style bit are $\sim 5 \mathrm{ft}$. long. It should be noted that the steering tool, a survey tool, mounts to the back side of the bit and thus provides excellent data on bit reaction, azimuth, inclination and tool face (rotation) can be taken at any time during drilling, except while rotating. The BHA is followed by four $5 \mathrm{ft}$. long non-magnetic drill rod sections.

1120 - Inclinometer angle reading $12.4^{\circ}$, starting to drill. The survey tool is responding to both $\mathrm{Az}$ and inclination although the $180^{\circ}$ inclination reading is very noisy.

1124 - Lost $\sim 2^{\circ}$ angle during the first $5 \mathrm{ft}$.

$1136-\mathrm{R} 1=10 \mathrm{ft}$. held $\sim 10^{\circ}$ for this rod, attempting to steer down. $(\mathrm{R} 1=$ total rod length including BHA)

$1202-\mathrm{R} 1=20 \mathrm{ft}$., inc. now $\sim 9.7^{\circ}$. (inc. $=$ inclination)

1208 - Redrill (push only) this rod steering down; angle now $-11.6^{\circ}, \mathrm{Az} 101^{\circ}$; very rocky, the drill string bucks and jumps as torque is applied, very difficult to maintain down angle even with no rotation. Angle now $-11.4^{\circ}$. Water flow rate $1.6 \mathrm{gpm}$.

$1320-\mathrm{R} 1=25 \mathrm{ft}$. inc. $-4^{\circ}, \mathrm{Az} 95^{\circ}$; the bit deviated up and to the right. Swabbed this rod with tool face down, inc. now $-4.8^{\circ}$.

$1329-\mathrm{R} 1=30 \mathrm{ft}$. inc. now $-5.6^{\circ}$. The Subsite tracking also indicates that the bit is leveling off.

$1347-\mathrm{R} 1=35 \mathrm{ft}$. inc. now $-0.6^{\circ}$. Decided to pull back 4 rods and read inclination.

$\mathrm{R} 1=15 \mathrm{ft}$. inc. $-7.7^{\circ} /-6.3^{\circ}\left(0^{\circ}\right.$ and $\left.180^{\circ}\right)$.

$\mathrm{R} 1=10 \mathrm{ft}$. inc. $-8.6^{\circ} /-7.5^{\circ}$.

Pulled all the way back, there is now a discrepancy between the tool face reading of the survey tool and the Subsite, also the flex sub is bent $\sim 2^{\circ}$ (eyeball).

1515 - Making up the BHA without the flex sub. It will be taken to town to a machine shop to be straightened. Realigned the survey tool and subsite to give proper tool face and will drill with a stiff assembly.

Attempt \#2 S1-1

1610 - Ready to drill, BHA is the Subsite housing. Survey tool housing and bit. Surface inc. $12.2^{\circ} /-12.2^{\circ}$. Drilled fairly smoothly to $\mathrm{R} 1=20 \mathrm{ft}$. The angle held much better than before.

$1639-\mathrm{R} 1=20 \mathrm{ft}$. inc. $-12.5^{\circ} / 11.6^{\circ}$. Slight turn to the right to $\sim 95^{\circ}$. At $22 \mathrm{ft}$. we apparently hit a large rock, started to rotate and drilled the rest of the rod.

$1648-\mathrm{R} 1=25 \mathrm{ft}$. Hard thrust, tool face down with some rotation, inc. $-12.4^{\circ} /-11.2^{\circ}$, water flow rate $\sim 3 \mathrm{gpm}$. 
1656 - During the drilling of this rod (\#6) an attempt was made to swab and steer down as the bit apparently rode up and over a rock to an angle of $-6^{\circ}$. The hole was then worked until 1705 trying to build down angle.

$1705-\mathrm{R} 1=30 \mathrm{ft}$. inc. $-10.3^{\circ} / 8.2^{\circ}, \mathrm{Az} 92^{\circ} / 93^{\circ}$. Added one more rod which encountered big rocks and required lots of force.

$1712-\mathrm{R} 1=35 \mathrm{ft}$. inc. $-8.4^{\circ} /-7.5^{\circ} \mathrm{Az} 90^{\circ} / 92^{\circ}$. Difficult down push.

$1750-\mathrm{R} 1=40 \mathrm{ft}$. inc. $-4.5^{\circ} /-4.9^{\circ}, \mathrm{Az} 90^{\circ} / 90^{\circ}$.

EOD (end of day) $3 / 2 / 92$

$3 / 3 / 93$

0845 - Removed one rod, inc. $-8.4^{\circ} /-7.5^{\circ} @ \mathrm{R} 1=35 \mathrm{ft}$.

0900 - Drilled rod $\# 8$ back in, inc. $-2.3^{\circ} /-2.0^{\circ}, \mathrm{Az} 85^{\circ} / 87^{\circ} @ \mathrm{R} 1=40 \mathrm{ft}$.

$0915-\mathrm{R} 1=45 \mathrm{ft}$. inc. $+1.3^{\circ} /+1.9^{\circ}, \mathrm{Az} 86^{\circ} / 85^{\circ}$. The bit is turning right with a hard up.

$0930-\mathrm{R} 1=49 \mathrm{ft}$. inc. $+3.9^{\circ}, \mathrm{Az} 84^{\circ}$ tool face $0^{\circ}$. Cannot steer, the bit jet is now plugged, tripping out!

\section{Attempt \#3}

The drill frame was raised to the $20^{\circ}$ stop in preparation for starting a new hole under the old one. In addition the Subsite and housing have been removed, the BHA now consists of just the bit, survey tool and housing. The drill bit water jet has been replaced.

1100 - Starting to drill with inclination $-22.0^{\circ}$.

$1111-\mathrm{R} 1=5 \mathrm{ft}$. push down and rotate, inc. $-22.7^{\circ} /-22.1^{\circ}, \mathrm{Az} 41^{\circ} / 41^{\circ}$. Note that the Azimuth readings are affected by the drill frame.

$1119-\mathrm{R} 1=10 \mathrm{ft}$. push down and rotate, inc. $-25.8^{\circ} / 24.9^{\circ}, \mathrm{Az} 109^{\circ} / 106^{\circ}$.

$1129-\mathrm{R} 1=15 \mathrm{ft}$. push down and rotate, inc. $-22.1^{\circ} /-21.0^{\circ}, \mathrm{Az} 106^{\circ} / 103^{\circ}$.

$1141-\mathrm{R} 1=20 \mathrm{ft}$. push down and rotate, very hard drilling of this rod from $17 \mathrm{ft}$. to $20 \mathrm{ft}$. inc. $12.2^{\circ} /-11.2^{\circ}$. Az $100^{\circ} / 99^{\circ}$. Obviously the bit rode over the top of a large rock.

$1256-\mathrm{R} 1=25$ inc. $-2.0^{\circ} /-1.5^{\circ}, \mathrm{Az} 93^{\circ} / 95^{\circ}$. Cannot hold water pressure with flow rate at 10 $\mathrm{gpm}$, looks as if the drill string has twisted off, tripping out of the hole.

Retrieved 3 rods from the hole leaving one non-mag section and the BHA for the backhoe to dig up. The two bottom non-mag rods both had belled box sections and were no longer usable. Upon retrieval of the remaining rod and BHA the box on this rod was also damaged and unusable. The drill bit was still in relatively good condition although did show some wear. This ended the effort to drill with the X-810.

The remainder of this day was spent preparing the X-810 for shipping, cleaning up the drilling area and conducting a test of the Pierce Arrow. At the gravel pit the P-80 trench box was placed in the pit for the sampling and boring test to follow.

\section{Conclusions X-810 Boring System Performance}

This machine is designed and intended to be used where conditions permit compaction by displacement of the soil along the bore path. The choice of the P-80 style bit which has no provisions for cutting was felt to give the best chance of accomplishing the compaction process. This bit it was felt would move material to the side and compress it enough to stabilize the bore walls. An aggressive cutting bit by contrast would create more fine material and dislodge rock and sand in an already unconsolidated media thus reducing wall stability. It appeared during the drilling that as the bore was swabbed, the fine material would build up under the nearly horizontal drill string causing it to ride on top and lose angle. Since the string turns clockwise looking down hole the deviations to the right may have been caused by the same effect, that is fine material building both under and the left side of the string. It was also apparent that some rather severe deflections occurred as a result of some of the larger rocks in the formation. This eventually caused failure due to bending the drill rod 
on too short a radius. There may be a bit design in the middle that would cut the larger stone, a more aggressive steering surface while still providing substantial compaction capability. Bit design and testing would involve a rather extensive development program. effectively.

There may be some locations at the Hanford site where the existing system could be used the ground.

The rest of the systems performed very well, in particular the method of anchoring the drill to

\section{Pierce Airrow Tests 3/3/93; R.P. Wemple, SNL Org. 6111}

The purpose of this experiment was to qualitatively test the effectiveness of percussion hammer type tools in the Hanford geology. The device used was a standard 4 in. diameter Pierce Airrow using threaded anvil nose piece and a tapered tailpiece. The X-810 and other Ditch Witch equipment is adaptable to similar hammer devices which are steerable when coupled to a bent sub. Also, the Pierce Airrow has been used in the Southeastern Washington area by utilities contractors with some success.

This experiment was performed after the completion of the X-810 tests and used the east pit wall about $5 \mathrm{ft}$. south of that location. The Pierce Airrow was launched horizontally about $4 \mathrm{ft}$. below grade in an intermediate zone of sand and small gravel (up to 3/4 in. dia.) that was confined above and below by cobble zones with material up to 2 in. dia. The tool was supported on timbers for the launch. The air hose attached to the rear of the tool was marked at $1 \mathrm{ft}$. intervals to monitor rate and distance.

Initial penetration was surprisingly easy ( $\sim 1 \mathrm{ft} . / \mathrm{min}$. for $30 \mathrm{~min}$.) but forward progress gradually slowed as drag on the air supply hose increased. The drag was caused by partial collapse of the borehole on the hose. Penetration rate also varied due to the type of rocks and cobbles encountered along its path.

After approximately $90 \mathrm{~min}$. forward progress had ceased. The tool was allowed to hammer the impediment for an additional $90 \mathrm{~min}$. to see if it could break through, it was then shut down and retrieved with a backhoe. It was found at depth of $8 \mathrm{ft}$. in a zone of rather large cobble and had traveled about $52 \mathrm{ft}$. The supply hose was disconnected from the tool and pulled out from the entry end with some difficulty, indicating that progress had been stopped by the hole collapsing on the hose.

\section{Conclusions From The Pierce Airrow Test}

This test demonstrated that small hammer tools may be applicable in the Hanford geology. The particular type of free-launched, non-steerable tool used in this test would not be recommended for emplacing very long boreholes. It may be necessary to advance casing while drilling because of the poor borehole stability as the formation may be too loose to rely on compaction to maintain stability. A similar hammer tool is being considered for use with the X-810 prototype machine at Hanford during FY 94.

\section{P-80 Sampling and Boring}

Friday 3/5/93

The launch pit for P-80 Trench Box was located about $100 \mathrm{ft}$. west of the gravel pit and up near the original grade level. The top soil here is mainly fine sand about $1.5 \mathrm{ft}$. thick overlaying beds of small gravel most of which was less than 2 in. The gravel pit wall is about $30 \mathrm{ft}$. tall and displays numerous beds of gravel and large rocks at various depths. The launch pit was about $9 \mathrm{ft} . \times 9 \mathrm{ft}$. $\times$ $4 \mathrm{ft}$. deep, the walls below the top soil somewhat unstable and some minor sluffing of the gravel layer had occurred. The launch direction was to the north under a slight rise in the grade. The trench box was placed in the pit and the two ends shored in with timbers. 
Set up to pre-bore for the sampler using the $13 / 4$ in. conical non-steerable point. The first sample attempt was to be at $10 \mathrm{ft}$. so the bore was made to $8 \mathrm{ft}$. without difficulty, the rods tripped out and the sampler with transmitter housing attached. The tracking system was used at the end of each rod to set a flag and obtain a depth reading. The sampler was then pushed to $10 \mathrm{ft}$. cocked (withdrawn) with $1 / 2$ rod then driven in 1 full rod $(4 \mathrm{ft}$.). It appeared from the tracking data that the bore path was at an upward angle, possibly due to the sluffing of the gravel at the entry point causing the rod to deflect upward at entry. Also, there was considerable difficulty with the P-80 cylinder dragging on the rod during both forward and reverse cylinder travel. The gravel seems to have a very loose grip on the rods. The sampler was recovered but did not contain a sample. The entry to sampler was packed with a clay-like material with a small hole in the center and an internal shape conforming to the cone rod point. Apparently, the cone rod had retracted but not far enough to latch up until withdrawal. The second attempt was a $20 \mathrm{ft}$., the bore was made to $18 \mathrm{ft}$. with the conical point as before. This time the rods were withdrawn $3 \mathrm{ft}$. for cocking and then inserted $6 \mathrm{ft}$. to obtain the sample. The sampler again came out without a sample. For the third attempt the hole was predrilled for 7 rods $(28 \mathrm{ft}$.), the sampler installed for an attempt at $30 \mathrm{ft}$. For this attempt a full rod was used to set the sampler latch and this rod plus an additional rod to take the sample. During the second rod a loud pop was heard. This was not unusual as similar sounds are made frequently during the pre bore with the cone point. However, in this case, the sampler had broken off at the cone rod thread where it screws into the rod adapter. The surface was flagged over the point where the sampler had broken off to enable it to be recovered using a backhoe.

The fourth try was done as before with the sample target at $39 \mathrm{ft}$. The sampler was set with 3 cylinder strokes $(\sim 30$ in.) then two additional strokes used to get a sample. This time the sampler performed normally, the sample tube was packed with dry white sand. The sample tube was capped, dated and presented to WHC.

\section{Conclusions From The Sampler Testing}

The Hanford geology presents several problems to the punch/core type devices typically used with soil mechanics-type testing equipment for which the device used here was designed. The locations of interest usually contain high ratios of rock to sand. The rocks are of very little interest analytically so in order to have a viable sample you must recover the fine materials in which the contaminants are trapped. To accomplish this in a gravel bed the push distance with the sampler in the cocked position is necessarily longer than it would be for soil. This, of course, increases the risk to the cone rod which has been recognized as vulnerable to breakage as it has happened before.

However, the system did work and it did get a sample. There is a need to increase both the strength and sample volume of this sampler and to also make an attempt to somehow prevent the opening from plugging off with stones. The other more serious problem of the cone rod breakage may be a simple matter of increasing the diameter and/or the heat treat of the rod. It is planned at this time (April 1993) to look into reducing the cone rod vulnerability and to design and build a prototype sampler of on the order of 2.25 in O.D. for the P-80 and possibly a 3 in. version for the X-810.

A later attempt to retrieve the broken sample was unsuccessful, the hole dug continued to fall in and they could not find it (Ben Volk, WHC).

\section{Using The P-80 To Bore A Pit To Surface Hole (See HAN3TRK1.XLS and Fig. 4) Saturday $3 / 6 / 93$}

With the trench box set up as for the sampling a 2 in. steering head and transmitter were installed to bore a pit to surface hole under the hill and to the surface in a flat area about $120 \mathrm{ft}$. away. The first attempt entered the same hole as that used for sampling. Seven rods $(28 \mathrm{ft}$.) were pushed and it was determined the upward trajectory precluded doing an experiment to see if we could steer the hole. We then tripped out and started a new hole with a level trajectory. The tracking sonde used for this type of drilling transmits through the earth to a surface walkover receiver which 
indicates tool face and depth. Surface elevation change along the bore path were shot using a transit and level rod as the surface tracking data was taken. This data was entered into tracking software in a compuier which then plots surface and bore elevations. The MSL values are arbitrary.

1003 to 1020 - Steering down to maintain level path. $\mathrm{R} 1=16 \mathrm{ft}$.

1020 to 1042 - Steering down with some rotation. $\mathrm{R} 1=36 \mathrm{ft}$.

1042 to 1142 - Rotating the rods in to steer straight. $\mathrm{R} 1=60 \mathrm{ft}$.

Lunch break

1247 to 1324 - Rotating to steer straight. $\mathrm{R} 1=82 \mathrm{ft}$.

1323 to 1344 - Turning up for exit trajectory. $\mathrm{R} 1=94 \mathrm{ft}$.

1344 to 1410 - Coming up at about $0.8 \mathrm{ft} / \mathrm{rod}$

1410 - Surface at $\mathrm{R} 1=114 \mathrm{ft}$.

The rods were then tripped out of the hole without an expander due to the poor condition of the pit wall in front of the trench box. The concern was that the trench box would slide forward under the large forces required with the use of an expander and up on the gravel that had sluffed in the bore entry area. This would put the rod in a bind and make removal very difficult. During the boring operation there was a fair amount of popping as the boring head was pushed forward and either broke or pushed rocks out of its way. This was energetic enough to be easily felt on the surface.

\section{Conclusions From The P-80 Boring Tests}

The P-80 can be used to make a bore in at least the zones of smaller gravel, the holes produced may stay open for short periods of time. At no time were the forces required either during the sampling or drilling near the capacity of the machine. It may be appropriate to do a more extensive set of tests with the P-80 to determine what the limits are in unconsolidated gravels for sampling, boring and casing installation. 
HAN1PLN.XLS

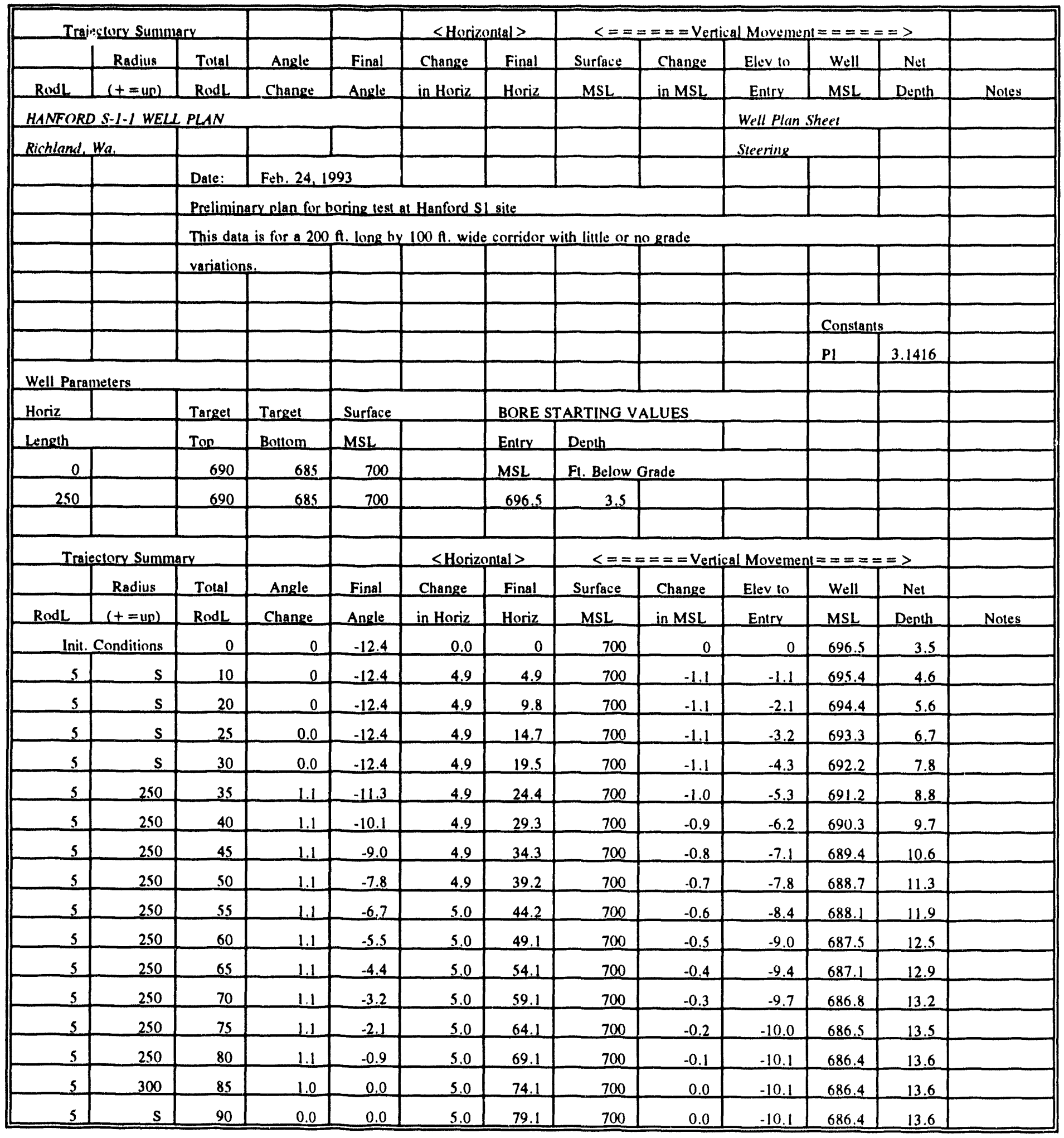


HANIPLN.XLS

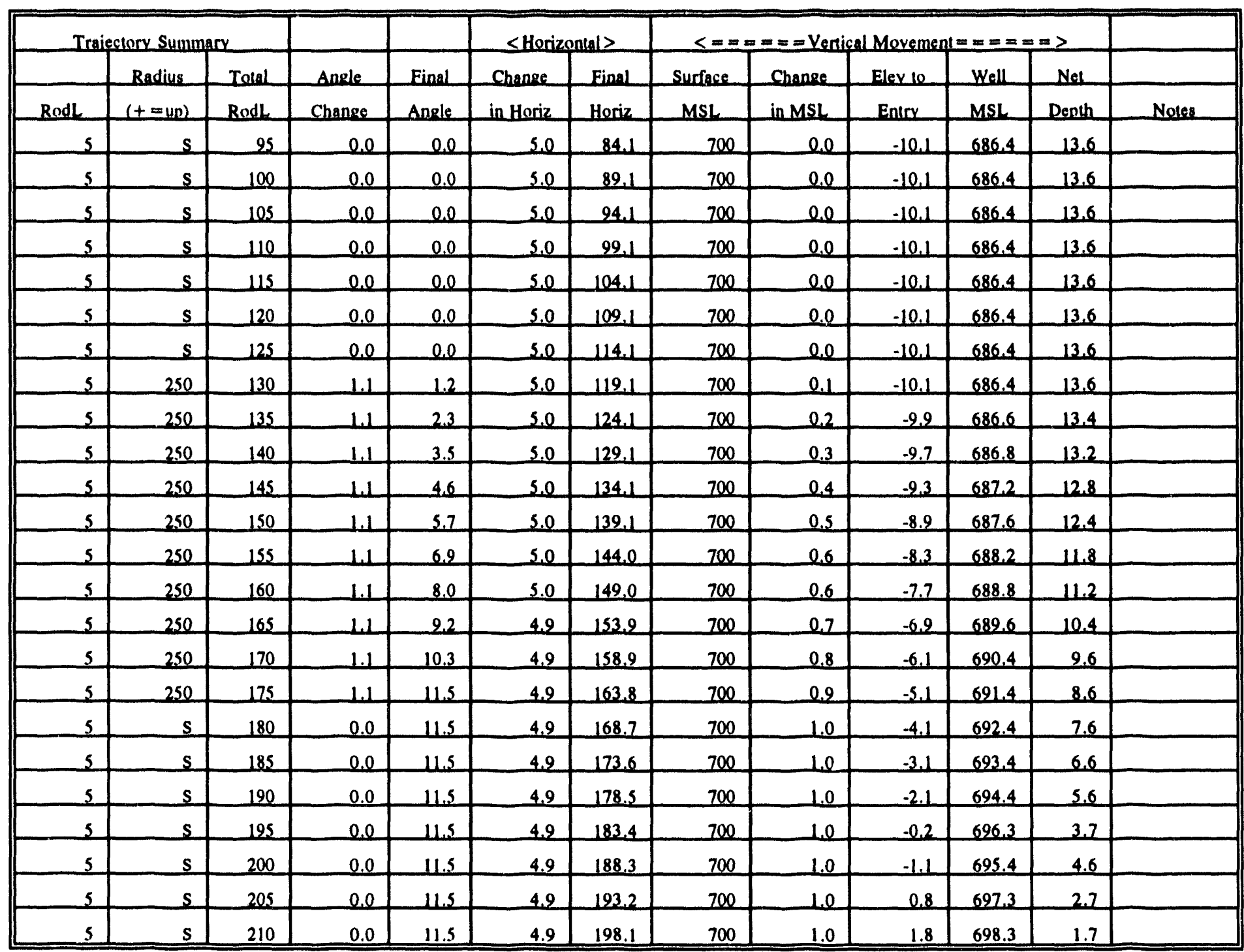




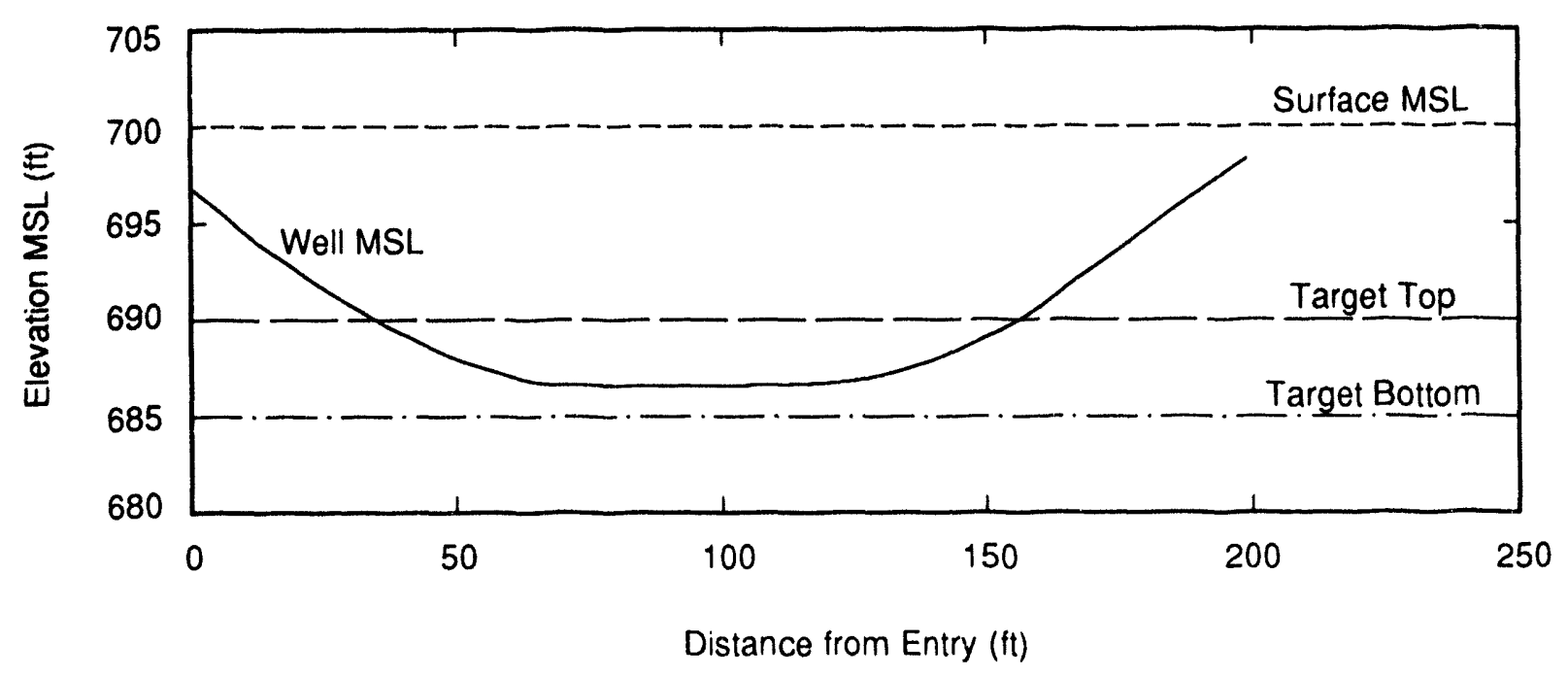

TRI.6111-18.0

Figure A-3. Hanford S-1-1 well plan. 


\section{HAN3TRK1.XLS}

\begin{tabular}{|c|c|c|c|c|c|c|}
\hline \multicolumn{7}{|c|}{ Traiectory Summary } \\
\hline & Red & surface & Depth & Bore & & \\
\hline TOR & Leneth & MSL & Readine & MSL & Depth & Notes \\
\hline \multicolumn{3}{|c|}{ P 80 Drill Hole HSL -3} & & & & Trackine Form \\
\hline \multicolumn{2}{|l|}{ Hanford Wa } & & & & & \\
\hline & Datei & 6-Mar-93 & & & & \\
\hline & \multicolumn{3}{|c|}{ P 80 oush with steerine head } & & & \\
\hline & \multicolumn{3}{|c|}{ Reenter sameling hole } & & & \\
\hline & \multicolumn{3}{|c|}{ Second tor al sleering down } & & & \\
\hline & \multicolumn{2}{|c|}{ First reenter went uo } & & & & \\
\hline & & & & & & \\
\hline & & & & & & \\
\hline & & & & & & \\
\hline & & & & & & \\
\hline & & & & & & \\
\hline & & & & & & \\
\hline & & & & \multicolumn{3}{|c|}{ MSL Values Are Ariirrary } \\
\hline \multicolumn{2}{|l|}{ Plot Parameters } & & & & & \\
\hline & & Tarres & Target & & & \\
\hline Dissance & & Ton & Bottom & & & \\
\hline & & 688 & 690 & & & \\
\hline 125 & & 688 & 690 & & & \\
\hline & & & & \multicolumn{3}{|c|}{ Bore MSL $=$ Ave of 1 wo values } \\
\hline \multicolumn{7}{|c|}{ Traiectory Summary } \\
\hline & $\operatorname{Rad}$ & Surface & Depth & Bore & & \\
\hline TOD & Lengeh & MSL & Readine & MSL & Depth & Noles \\
\hline Inil_cond. & 0 & 691.8 & 2.8 & 688.9 & 2.8 & Time PST \\
\hline 1003 & 4 & 691.8 & 2.9 & 688.9 & 2.9 & Steer down \\
\hline 1012 & 8 & 691.8 & 2.8 & 688.9 & 2.8 & Steer down \\
\hline 1018 & 12 & 693.9 & 4.8 & 689.0 & 4.8 & Steer down \\
\hline 1020 & 16 & 694.3 & 4.8 & 689.3 & 4.8 & Steer down \\
\hline 1026 & 20 & 695.3 & 5.9 & 689.3 & 5.9 & Rolate \\
\hline 1028 & 24 & 695.3 & 5.7 & 689.5 & 5.7 & Steer down \\
\hline 1032 & 28 & 695.7 & 5.7 & 789.8 & 5,7 & Steer down \\
\hline 1035 & 32 & 696.3 & 6.3 & 689.9 & 6.3 & Sleer down \\
\hline 1042 & 36 & 696.5 & 6.4 & 690.0 & 6.4 & Steer down \\
\hline 1046 & 40 & 696.6 & 7.6 & 689.5 & 7.6 & Rotale \\
\hline 1053 & 44 & 697.0 & 7.8 & 689.4 & 2.8 & Rolate \\
\hline 1056 & 48 & 697.3 & 8.2 & 689.2 & 8.2 & Rotate \\
\hline 1058 & 52 & 697.6 & 8.8 & 689.1 & 8.8 & Rotate \\
\hline 1102 & 56 & 698.0 & 9.3 & 688.9 & 9.3 & Rotale \\
\hline 1247 & 60 & 698.2 & 10.8 & 688.1 & 10.8 & Lunch-Rotate \\
\hline & 64 & 698.3 & 10.8 & 687.8 & 10.8 & Fudged data \\
\hline
\end{tabular}




\section{HAN3TRK1.XLS}

\begin{tabular}{|c|c|c|c|c|c|c|}
\hline \multicolumn{7}{|c|}{ Triecilory Summary } \\
\hline & Rod & Surfuce & Denih & Bore & & \\
\hline TOR & Leneth & MSL & Readine & MSL & Depeth & Notes. \\
\hline 1304 & 68 & 698.4 & 10.7 & 6878 & 10.7 & \\
\hline 1307 & 72. & 698.8 & 10.4 & 688.1 & 10.4 & Pushup \\
\hline 1313 & 76 & 698.8 & 10.9 & 688.0 & 10.9 & \\
\hline 1321 & 78 & 698.2 & 9.4 & 688.4 & 2.4 & \\
\hline 1324 & 82 & 698.1 & 9.8 & 688.3 & 9.8 & Route \\
\hline 1332 & 86 & 697.4 & 8.9 & 688.4 & 8.9 & Push Un \\
\hline 1338 & 90 & 965.7 & 7.9 & 688.1 & 7.9 & Push Uo \\
\hline 1344 & 24 & 694.6 & 6.1 & 688.3 & 6.1 & Push Us \\
\hline 1348 & 98 & 692.9 & 3.5 & 688.9 & 3.5 & Rotate \\
\hline 1351 & 102 & 692.7 & 2.3 & 689.6 & 2.3 & Rotate \\
\hline 1356 & 106 & 692.7 & 1.5 & 690.4 & 1.5 & Rotale \\
\hline 1403 & 10 & 692.7 & 0.8 & 691.1 & 0.8 & Rotale \\
\hline 1410 & 114 & 692.7 & 0.1 & 691.8 & 0.1 & Rotale-S \\
\hline
\end{tabular}




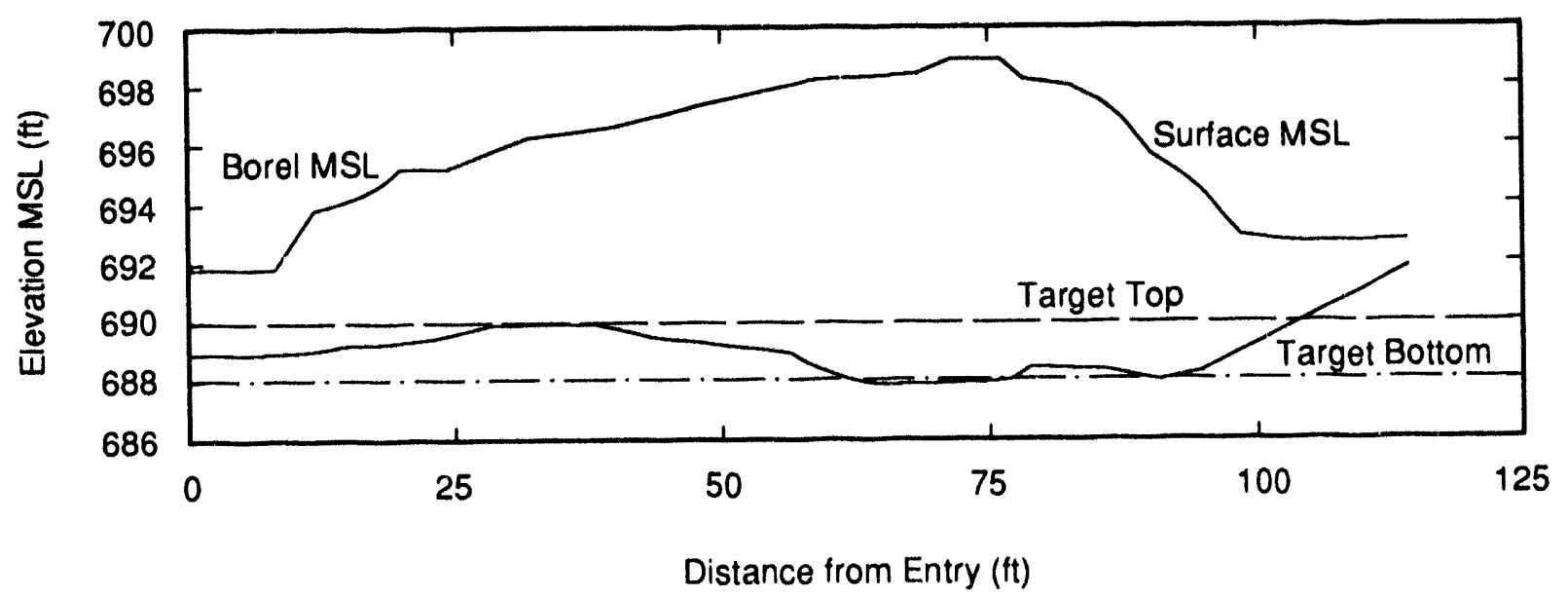

TR1.6111.20-0

Figure A-4. P-80 drill hole H S1-3. 


\section{Drilling Activities at RB-11 Site-September to October 1993}

(See RB11-4.XLS and Fig. A-6 and A-7)

Horizontal drilling at the RB-11 Site was done under the Sandia Mixed Waste Landfill Integrated Demo Program. There were two attempts to provide a cased borehole below six of the 10 burial pits located at this site. The initial attempt ended in June 1993 when the casing parted during installation. This casing, Centron" CEN-800 4 in size with 0.145 wall was a combination of solid and slotted sections. The slotted casing had 4 rows of slots, $0.010 \times 1.5 \mathrm{in.}$ on $0.125 \mathrm{in}$. spacing. At the time of the failure there were three $30 \mathrm{ft}$. lengths each of solid and slotted in the exit end of the borehole. After the casing parted three lengths less about $7 \mathrm{ft}$. of the slotted casing was recovered from the exit end of the hole. The casing was found to have parted at the first row of slots behind the sections of solid casing. An attempt to pull the remainder of the casing to the entry end was started to try and salvage the hole. During this effort the connection between the reamer and the pulling plug failed $45 \mathrm{ft}$. out from the entry point and only the reamer was recovered. A borehole TV camera was used to "log" as much of the hole as possible before attempting to retrieve any of the parts still in the borehole. About $75 \mathrm{ft}$. of the exit end and $43 \mathrm{ft}$. of the entry end was logged before encountering mud and obstructions. The bore was quite irregular with rocks protruding out from the walls as if the reamer had "walked" around rather than cutting in a straight line, none of the abandoned equipment was seen with the TV system. The pulling plug was subsequently recovered by digging and it appeared that a bearing had seized twisting the casing off and then the shaft between the reamer and the pulling plug also failed. None of the casing was close $(5 \mathrm{ft}$.) to the pulling plug and its location is unknown. The trench at each end of this bore were then filled with the excavated soil and abandoned.

Clearly there persists some problems in the bore reaming, casing pulling hardware and in the casing selection. A second attempt to bore and install casing under the six southern most pits was planned for September. During the July-August interval, improvements were made to the reamer, the pulling assembly and a stronger casing was located and ordered. In addition, the drill bit and steering tools still require some development but are not as limiting to the program as the reaming and casing problems. The alluvial geology in the Kirtland area presents a significant challenge to the drilling process and once solved for this location, technology application to a major share of sites across the country would become much easier.

The RB-11 Phase II drilling started Sept. 9. This well plan called for the bore to be roughly parallel to and $6 \mathrm{ft}$. shallower than the previous hole. The same launch pit would be used with the entry point 80 in. to the east. The target depth was $27 \mathrm{ft}$. below grade under the six southern most pits and about $15 \mathrm{ft}$. east of pit \#7. The exit target was the same. Because of the shallower target depth the entry angle was to be $-17 \mathrm{deg}$. instead of the $-22 \mathrm{deg}$. used previously. The drill frame has $5 \mathrm{deg}$. stops for setting the entry angle and the pit had a $2 \mathrm{deg}$. slope built in to control drainage. The reamer had been improved by adding length to the body, two new pulling assemblies were available each having very heavy duty bearings. The casing selected was again Centron but type DH-2000, with a wall thickness of 0.385 in. and was selectively perforated with 0.25 in. drilled holes rather than slotted. These holes were located only in the regions required to accommodate the SEAMIST sampling system.

The drilling operation was complete on $9 / 21$, the reaming $10 / 12$ and the casing was installed 10/13. The well was turned over to the first experiments on $10 / 25$. A portion of the interval between $9 / 21$ and $10 / 12$ was used to repair or modify parts of the drilling system but there was a period where not enough qualified personnel were available due to year end vacations and when some out of town field tests and meetings were conducted. 
An estimate of the time required to complete the operations of drilling, reaming and casing installation was made from the field notes. This estimate is made on the basis of a mature drilling system which would require less experimentation, modification and repair than prototype equipment made of piece parts still in the development phase. Based on this premise, a $400 \mathrm{ft}$. bore, at this location, drilling time of $16 \mathrm{hrs}$, , about $25 \mathrm{ft}$. per hr., with a possible trip to change the bit an additional $8 \mathrm{hrs}$. Reaming for the first pass about $12 \mathrm{hrs}$, average $35 \mathrm{ft}$. per hr., the second pass about $8 \mathrm{hrs}$., $55 \mathrm{ft}$. per hr. The casing pull back about $6 \mathrm{hrs}$. or $65 \mathrm{ft}$. per hr. Water consumption while drilling 1 to $4 \mathrm{gpm}$ and while reaming and pull back, 3 to $8 \mathrm{gpm}$. The recommended crew size is 4 people for the actual drilling, and does not include any additional support such as oversight which should remain a separate function from the drilling operation.

One environmental drill contractor with horizontal experience was contacted and stated that they normally use a crew of five at a labor only cost rate of $\$ 1800$ for a $10 \mathrm{hr}$. day. They also stated that the rate of progress of the drilling at this location was probably somewhat slower than most locations that they had drilled. 


\begin{tabular}{|c|c|c|c|c|c|c|c|c|c|c|}
\hline \multicolumn{11}{|c|}{ Traigitocy Summary } \\
\hline TOD & Badl & Aze & A2/80 & $\operatorname{lnce}$ & $\operatorname{lnc} 180$ & Av lnc & Horiz Dist & MSL & Deolh & Notes \\
\hline \multicolumn{6}{|c|}{ KURTLAND AER RB-UTEST AREA BORE } & & & \multicolumn{3}{|c|}{ Steering Fiorm } \\
\hline \multicolumn{11}{|c|}{ Albusucreme NQS } \\
\hline & Dale: & \multicolumn{2}{|c|}{ D.4. 8. 1992} & & & & & & & \\
\hline & \multicolumn{9}{|c|}{ The well nlan for the RB-11 Sile Test area was 10 hore a (see RB-11 PLN.XLS) } & \\
\hline & \multicolumn{9}{|c|}{$350 \mathrm{fl}$. lone $35 \mathrm{fl}$ deen well with o $50 \mathrm{f}$ long straight section at the $35 \mathrm{fl}$ denth } & \\
\hline & \multicolumn{7}{|c|}{ Entry was from s 5 fe deen nit with a heading of 0221 deg mag } & & & \\
\hline & \multicolumn{8}{|c|}{ The MSL is 5460 n. and is nol enoush grade to reauire gomnensation. } & & \\
\hline \multicolumn{11}{|c|}{ Bore Completion Descrintion: } \\
\hline & \multicolumn{9}{|c|}{ During the drilling censiderable difficulle occur ad to maintain the desired down } & \\
\hline & \multicolumn{9}{|c|}{ ande. This nroblem was due to the very gravely nature of the formation which } & \\
\hline & \multicolumn{10}{|c|}{ caused the traiectory to be slighuly higher than desired resulting in a depth of $33.4 \mathrm{fl}$} \\
\hline & \multicolumn{10}{|c|}{ and a sliphily shoner (20 fl.) than nlanned. The well was to be cased with 4 in. PVC } \\
\hline & \multicolumn{10}{|c|}{ slotled casing. This casing tyne was considered to he of high risk of casing failure } \\
\hline & \multicolumn{9}{|c|}{ but it was all that was on hand. A tolal of $80 \mathrm{n}$. of casing was installed when } & \\
\hline & \multicolumn{3}{|c|}{ cosing failure occurred. } & & & & & & & \\
\hline \multirow[t]{5}{*}{ Bore Valus } & & & & & & & & & & \\
\hline & \multicolumn{2}{|c|}{ Length: $330 \mathrm{Al}$} & & & & Casing: & \multicolumn{4}{|c|}{4 in with 0.01 in slots 0.125 spacing } \\
\hline & \multicolumn{4}{|c|}{ Horizontal nit wall te exit: $321,2 \mathrm{ft}$} & & & \multicolumn{4}{|c|}{$\operatorname{Sch} 40-1.0 .4 .026$ in. O.D. $4.5 \mathrm{in}$} \\
\hline & \multicolumn{3}{|c|}{ Maximum depth $33,4 \mathrm{~A}$} & MSL S4 & $2.6 \mathrm{An}$ & & Start $R 1=$ & 50 An. H & $=245.4$ & \\
\hline & & & & & & & $M S L=546$ & exil. de & th 24.91 & $S L=5435.1$ \\
\hline Ploc Param & tens & & & & & BORES & $A R T I N G$ VA & UES & & \\
\hline $\operatorname{Rod} 1$ & & & & & & & & & & \\
\hline Rad & & Tareet & Target & Surface & & Entry & Denth & & & \\
\hline Length & & Top & Bottom & MSL & & $\underset{\mathrm{F}}{\mathrm{MSL}}$ & Ft. Below G & ade & & \\
\hline 0 & & .5430 .0 & 5420.0 & 5460.0 & & 5455 & 5 & & & \\
\hline 350 & & 5430.0 & 5420.0 & 5460.0 & & & & & & \\
\hline Traiectory & Summan & & & & & & & & & \\
\hline TOD & $\operatorname{Rod} L$ & $A=0$ & $A=180$ & Ince & $\operatorname{lnc} 180$ & Avlnc & Horiz Dist & MSL & Depth & Notes \\
\hline Init. Con & 0 & 154.0 & 152.0 & -21.7 & -22.3 & -22.0 & 0.0 & 5455.0 & 5.0 & $12 / 8 / 92$ \\
\hline 1058 & 5 & 209.0 & 211.0 & -22.7 & -22.4 & -22.6 & 4.6 & 5453.1 & 6.9 & \\
\hline 1104 & 10 & 209.0 & 218.0 & -22.5 & -22.0 & -22.3 & 9.2 & 5451.2 & 8.8 & \\
\hline 109 & 15 & 219.0 & N.D. & -22.5 & -212 & -22.1 & 13.9 & 5449.3 & 10.7 & \\
\hline 1113 & 20 & 219.0 & 220.0 & -22.0 & -21.4 & -21.7 & 18.5 & 5447.5 & 12.5 & \\
\hline 1117 & 25 & 219.0 & 220.0 & .21 .4 & -20.7 & -21.1 & 23.2 & 5445.7 & 14.3 & \\
\hline 1122 & 30 & 217.0 & 217.0 & -19.1 & -18.4 & -18.8 & 27.9 & 5444.1 & 15.9 & Hard Drilling \\
\hline 1336 & 35 & 221.0 & 221.0 & -16.3 & -15.5 & -15.9 & 32.7 & 5442.7 & 173 & Vry Hard Drilling \\
\hline 1624 & 40 & 215.0 & 216.0 & -172 & -15.5 & -16.6 & 37.5 & .5441 .3 & 18.7 & Hard Drilling \\
\hline 1633 & 45 & 216.0 & 216.0 & -12.6 & -12.4 & -12.5 & 42.4 & 5440.2 & 19.8 & \\
\hline 16.52 & 50 & 213.0 & 223.0 & -15.5 & -13.5 & -14.5 & 47.2 & 5438.9 & 21.1 & \\
\hline
\end{tabular}


RB_TST2.XLS

\begin{tabular}{|c|c|c|c|c|c|c|c|c|c|c|}
\hline \multicolumn{11}{|c|}{ Traiectory Summary } \\
\hline TOD & $\operatorname{Rad} L$ & $A=0$ & $A=180$ & Incel & Inc 180 & dv lnc & HorizDist & MSL & Depth & Noces \\
\hline 1702 & 55 & 22.1 .0 & 2.12 .0 & -15.6 & -13.8 & -14.7 & 52.1 & 54377 & 22.3 & \\
\hline 1722 & 60 & 223.0 & 224.0 & -16.1 & -14.4 & -15.3 & 56.9 & 5436.3 & 23.7 & \\
\hline 0730 & 65 & 220.0 & 220.0 & -14.3 & -12.4 & -13.4 & 61.8 & 5435.2 & 24.8 & $12 / 9 / 92$ \\
\hline 0741 & 70 & 221.0 & 211.0 & -14.3 & -11.9 & -13.1 & 66.6 & 5434.1 & 25.9 & Rotate \\
\hline 0748 & 75 & 213.0 & 212.0 & -12.4 & -11.5 & -12.0 & 21.5 & 5433.0 & 27.0 & Dn/Rotate \\
\hline 0755 & 80 & 215.0 & 219.0 & -12.4 & -11.5 & -12.0 & 76.4 & 5432.0 & 28.0 & 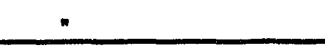 \\
\hline 0805 & 85 & 223.0 & 222.0 & -10.7 & -9.9 & -10.3 & 81.3 & 5431.1 & 28.9 & $n$ \\
\hline 0811 & 90 & 223.0 & 221.0 & -8.6 & -7.9 & -8.3 & 86.3 & 5430.4 & 29.6 & " \\
\hline 0816 & 95 & 224.0 & 223.0 & -8.8 & -6.2 & -7.8 & 912 & 5429.7 & 30.3 & \\
\hline 0825 & 100 & 222.0 & 222.0 & -8.3 & -7.2 & -7.8 & 96.2 & 5429.0 & 31.0 & \\
\hline 0834 & 105 & 222.0 & 224.0 & -7.0 & -5.7 & -6.4 & 1012 & 5428.5 & 31.5 & \\
\hline 0841 & 110 & 215.0 & 222.0 & -5.9 & -4.8 & -5.4 & 106.1 & 5428.0 & 32.0 & \\
\hline 0848 & 115 & 225.0 & 223.0 & -5.1 & -4.3 & -4.7 & & 5427.6 & 32,4 & \\
\hline 0856 & 120 & 222.0 & 225.0 & -4.6 & -3.3 & -4.0 & 116.1 & 5427.2 & 32.8 & \\
\hline 0906 & 125 & 225.0 & 225.0 & -4.0 & -2.5 & -3.3 & 121.1 & 5427.0 & 33.0 & \\
\hline 0917 & 130 & 225.0 & 226.0 & -1.8 & -0.8 & -1.3 & 126.1 & 5426.9 & 33.1 & \\
\hline 0925 & 135 & 225.0 & 223.0 & -1.4 & -0.5 & -1.0 & 131.1 & 5426.8 & 33.2 & \\
\hline 0933 & 140 & 223.0 & 215.0 & -1.7 & -0.4 & -1.1 & 136.1 & 5426.7 & 33.3 & \\
\hline 0942 & 145 & 222.0 & 223.0 & -0.5 & 0.6 & 0.1 & . & 5426.7 & 33.3 & \\
\hline 0950 & 150 & 226.0 & 225.0 & -0.2 & 1.0 & 0.4 & 146.1 & 5426.7 & 33.3 & \\
\hline 0958 & 155 & 226.0 & 225.0 & -0.2 & 0.6 & -0.2 & L151/ & 5426.7 & 33.3 & \\
\hline 1006 & 160 & 226.0 & 224.0 & -2.2 & 0.2 & -1.0 & 156.1 & 5426.6 & 33.4 & \\
\hline 1016 & 165 & 225.0 & 223.0 & -1.2 & 0.7 & -0.3 & 161.1 & 5426.6 & 33.4 & \\
\hline 1022 & 170 & 224.0 & 223.0 & -0.8 & 0.7 & -0.1 & 166.1 & 5426.6 & 33.4 & \\
\hline 1029 & 175 & 225.0 & 226.0 & -0.4 & 1.2 & 0.4 & 171.1 & 5426.6 & 33.4 & \\
\hline 1038 & 180 & 225.0 & 225.0 & -0.3 & 1.5 & 0.6 & 176.1 & 5426.7 & 33.3 & \\
\hline 1046 & 185 & 223.0 & 225.0 & -0.4 & 1.4 & 0.5 & 181.1 & 5426.7 & 33.3 & \\
\hline 1053 & 190 & 226.0 & 227.0 & 0.0 & 1.5 & 0.8 & 186.1 & 5426.8 & 33.2 & \\
\hline 1105 & 195 & 226.0 & 226.0 & 1.3 & 2.5 & 1.9 & 1911 & 54270 & 33.0 & \\
\hline 1113 & 200 & 226.0 & 224.0 & 2.5 & 3.8 & 3.2 & 196.1 & 5427.2 & 32.8 & \\
\hline 1123 & 205 & 223.0 & 223.0 & 2.7 & 4.1 & 3.4 & 201.1 & 5427.5 & 32.5 & \\
\hline 1145 & 210 & 222.0 & 223.0 & 5.4 & 6.8 & 6.1 & 206.1 & 5428.1 & 31.9 & \\
\hline 1153 & 2.15 & 225.0 & 222.0 & 5.9 & 7.1 & 6.5 & 211.0 & 5428.6 & 31.4 & \\
\hline 1200 & 220 & 225.0 & 225.0 & 7.0 & 8.1 & 7.6 & 216.0 & 5429.3 & 30.7 & \\
\hline 1211 & 225 & 224.0 & 225.0 & 8.3 & 9.4 & 8.9 & 220.9 & 5430.0 & 30.0 & \\
\hline 1222 & 230 & 226.0 & 224.0 & 9.8 & 11.0 & 10.4 & 225.8 & 5430.9 & 29.1 & \\
\hline 1235 & 235 & 226.0 & 225.0 & 10.6 & 12.0 & 11.3 & 230.7 & 5431.9 & 28.1 & \\
\hline 1245 & 240 & 226.0 & 225.0 & 10.1 & 12.1 & 11.1 & 235.7 & 5432.9 & 27.1 & \\
\hline 1300 & 245 & 227.0 & 227.0 & 11.5 & 13.0 & 12.3 & 240.5 & 5434.0 & 26.0 & \\
\hline 1312 & 250 & 227.0 & 226.0 & 12.6 & 14.1 & 13.4 & 245.4 & 5435.1 & 24.9 & \\
\hline 1316 & 255 & 227.0 & 225.0 & 13.4 & 14.6 & 14.0 & 250.3 & 5436.3 & 23.7 & \\
\hline 1330 & 260 & 229.0 & 225.0 & 14.7 & 17.4 & 16.1 & 255.1 & 5437.7 & 22.3 & \\
\hline
\end{tabular}


RB_TST2.XLS

\begin{tabular}{|c|c|c|c|c|c|c|c|c|c|c|}
\hline \multicolumn{3}{|l|}{ Traiectory } & & & & & & & & \\
\hline TOD & $\operatorname{Rod} L$ & Azl & $A=180$ & $\operatorname{lnc} 0$ & $\operatorname{lnc} 180$ & Av lnc & HorizDist & $M S L$ & Depih & Noles \\
\hline 1344 & 265 & 227.0 & 22.7 .0 & 17.4 & 19.4 & 18.4 & 259.8 & 5439.3 & 20.7 & \\
\hline 1406 & 270 & 229.0 & 229.0 & 18.0 & 19.6 & 18.8 & 264.5 & 5440.9 & 19.1 & Hard Drilling \\
\hline 1430 & 273 & 228.0 & 228.0 & 17.3 & 19.0 & 18.2 & 269.3 & 5442.4 & 17.6 & $\checkmark$ Hard Drilling \\
\hline 1511 & 280 & 228.0 & 228.0 & 16.9 & 18.6 & 178 & 274.1 & 5444.0 & 16.0 & $\mathrm{~V}, \mathrm{~V}, \mathrm{Hard}-\mathrm{Bit} ? ?$ \\
\hline 1543 & 285 & 227.0 & 229.0 & 177 & 18.7 & 18.2 & 278.8 & 5445.5 & 14.5 & \\
\hline 1616 & 290 & 228.0 & 228.0 & 17.9 & 18.5 & 18.2 & 283.6 & 5447.1 & 12.9 & \\
\hline 1711 & 295 & 229.0 & 227.0 & 18.2 & 19.3 & 18.8 & 288.3 & 5448.7 & 11.3 & \\
\hline 1752 & 300 & 228.0 & 229.0 & 18.2 & 19.1 & 18.7 & 293.0 & 5450.3 & 9.7 & \\
\hline 1845 & 305 & 227.0 & 226.0 & 17.5 & 18.5 & 18.0 & 297.8 & 5451.8 & 8.2 & \\
\hline 0833 & 310 & 230.0 & 230.0 & 20.0 & 20.8 & 20.4 & 302.5 & 5453.6 & 6.4 & $12 / 10 / 92$ \\
\hline 0841 & 315 & 230.0 & 228.0 & 18.8 & 19.0 & 18.9 & 307.2 & 5455.2 & 4.8 & \\
\hline 0844 & 320 & 230.0 & 230.0 & 20.0 & 20.8 & 20.4 & 311.9 & 5457.0 & 3.0 & \\
\hline 0846 & 325 & 229.0 & 230.0 & 20.8 & 22.1 & 21.5 & 316.5 & 5458.8 & 12 & \\
\hline 0849 & 330 & 227.0 & 230.0 & 21.4 & 21.6 & 21.5 & 321.2 & 5460.6 & -0.6 & SURFACE \\
\hline & & & & & & 0.0 & 321.2 & 5460.6 & -0.6 & \\
\hline & & & & & & 0.0 & 321.2 & 5460.6 & -0.6 & \\
\hline & & & & & & 0.0 & 32.2 & 5460.6 & -0.6 & \\
\hline & & & & & & 0.0 & 321.2 & 5460.6 & -0.6 & \\
\hline & & & & & & 0.0 & 321.2 & 5460.6 & -0.6 & \\
\hline & & & & & & 0.0 & 321.2 & 5460.6 & -0.6 & \\
\hline & & & & & & 0.0 & 321.2 & 5460.6 & -0.6 & \\
\hline & & & & & & 0.0 & 321.2 & 5460.6 & -0.6 & \\
\hline & & & & & & 0.0 & 321.2 & 5460.6 & -0.6 & \\
\hline & & & & & & 0.0 & 321.2 & 5460.6 & -0.6 & \\
\hline & & & & & & 0.0 & 321.2 & 5460.6 & -0.6 & \\
\hline & & & & & & 0.0 & 321.2 & 5460.6 & -0.6 & \\
\hline & & & & & & 0.0 & 321.2 & 5460.6 & -0.6 & \\
\hline & & & & & & 0.0 & 321.2 & 5460.6 & -0.6 & \\
\hline & & & & & & 0.0 & 321.2 & 5460.6 & -0.6 & \\
\hline & & & & & & 0.0 & 321.2 & 5460.6 & -0.6 & \\
\hline & & & & & & 0.0 & 321.2 & 5460.6 & -0.6 & \\
\hline & & & & & & 0.0 & 321.2 & 5460.6 & -0.6 & \\
\hline & & & & & & 0.0 & 321.2 & 5460.6 & -0.6 & \\
\hline & & & & & & 0.0 & 321.2 & 5460.6 & -0.6 & \\
\hline & & & & & & 0.0 & 321.2 & 5460.6 & -0.6 & \\
\hline & & & & & & 0,0 & 321.2 & 5460.6 & -0.6 & \\
\hline & & & & & & 0.0 & 3212 & 5460.6 & -0.6 & \\
\hline & & & & & & 0.0 & 321.2 & 5460.6 & -0.6 & \\
\hline & & & & & & 0.0 & 321.2 & 5460.6 & -0.6 & \\
\hline & & & & & & 0.0 & 321.2 & 5460.6 & -0.6 & \\
\hline & & & & & & 0.0 & 321.2 & .5460 .6 & -0.6 & \\
\hline & & & & & & 0.0 & 321.2 & 5460.6 & -0.6 & \\
\hline
\end{tabular}




\section{RB_TST2.XLS}

\begin{tabular}{|c|c|c|c|c|c|c|c|c|c|c|}
\hline \multicolumn{11}{|c|}{ Traiectory } \\
\hline TOD & $\operatorname{Rod} L$ & $A=0$ & $A=180$ & $\ln c 0$ & $\operatorname{lnc} 180$ & $d v \operatorname{lnc}$ & Horiz Dist & MSL & Depth & Notes \\
\hline & & & & & & 0.0 & 321.2 & 5460.6 & -0.6 & \\
\hline & & & & & & 0.0 & 321.2 & 5460.6 & -0.6 & \\
\hline & & & & & & 0.0 & 321.2 & 5460.6 & -0.6 & \\
\hline & & & & & & 0.0 & 321.2 & 5460.6 & -0.6 & \\
\hline & & & & & & 0.0 & 321.2 & 5460.6 & -0.6 & \\
\hline & & & & & & 0.0 & 321.2 & 5460.6 & -0.6 & \\
\hline & & & & & & 0.0 & 321.2 & 5460.6 & -0.6 & \\
\hline & & & & & & 0.0 & 321.2 & 5460.6 & -0.6 & \\
\hline & & & & & & 0.0 & 321.2 & 5460.6 & -0.6 & \\
\hline & & & & & & 0.0 & 321.2 & 5460.6 & -0.6 & \\
\hline & & & & & & 0.0 & 321.2 & 5460.6 & -0.6 & \\
\hline & & & & & & 0.0 & 321.2 & 5460.6 & -0.6 & \\
\hline & & & & & & 0.0 & 3212 & 5460.6 & .0 .6 & \\
\hline & & & & & & 0.0 & 321.2 & 5460.6 & -0.6 & \\
\hline & & & & & & 0.0 & 321.2 & 5460.6 & -0.6 & \\
\hline & & & & & & 0.0 & 321.2 & 5460.6 & -0.6 & \\
\hline & & & & & & 0.0 & 321.2 & 5460.6 & -0.6 & \\
\hline
\end{tabular}




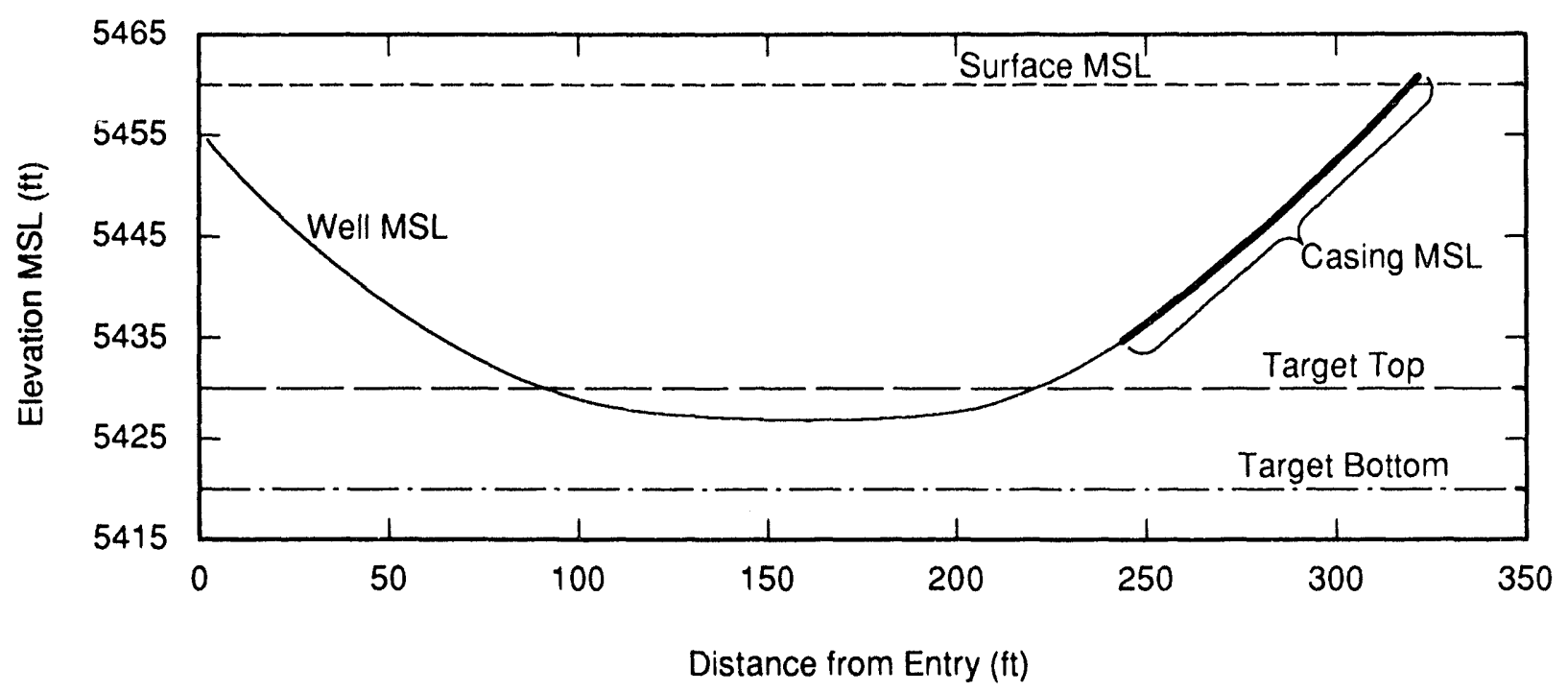

TRI-6111.15-0

Figure A-5. Kirtland AFB RB-11 test area bore. 
RB11_4.XLS

\begin{tabular}{|c|c|c|c|c|c|c|c|c|c|}
\hline & Casing & Casine & Total_RL & Total: & Port & Sample & Perf & & \\
\hline & No. & length & Length & Length & ID & Point & Zone & & \\
\hline & 10 & 291 & 233.7 & 255.4 & & & & & \\
\hline Perf & 11 & 29.1 & 262.8 & 284.5 & $\mathrm{D}$ & 238.2 & $235 / 241$ & D-242.2 & \\
\hline Perf & 12 & 29.1 & 291.9 & 313.6 & E & 277.8 & $275 / 281$ & E-281.8, & \\
\hline \multirow[t]{2}{*}{ Perf } & 13 & 29.1 & 321.0 & 342.7 & $\mathbf{F}$ & 317.5 & $313 / 319$ & F-321.5' & \\
\hline & 14 & 29.1 & 350.1 & 371.8 & & & & & \\
\hline \multirow[t]{2}{*}{ Perf } & 15 & 29.1 & 379.2 & 400.9 & $G$ & 356.9 & $354 / 360$ & G-360.9 & \\
\hline & 16 & 2.5 & 388.7 & 410,4 & & & & & \\
\hline \multicolumn{4}{|c|}{ Total Casing length $\mathrm{t}$. } & 410.4 & & & & & \\
\hline & \multicolumn{8}{|c|}{ Correct positioning of the SEAMUST por system in the casing } & \\
\hline & \multicolumn{8}{|c|}{ requires that it be placed $4 \mathrm{At}$ back from the launch pit wall. } & \\
\hline & & \multicolumn{7}{|c|}{ from a straight line from entry to exit is unknown but is felt to be } & $10 / 29 / 93$ \\
\hline & & not gree & $r$ than that & f the incle & ed plo & & & & $11 / 15 / 93$ \\
\hline
\end{tabular}




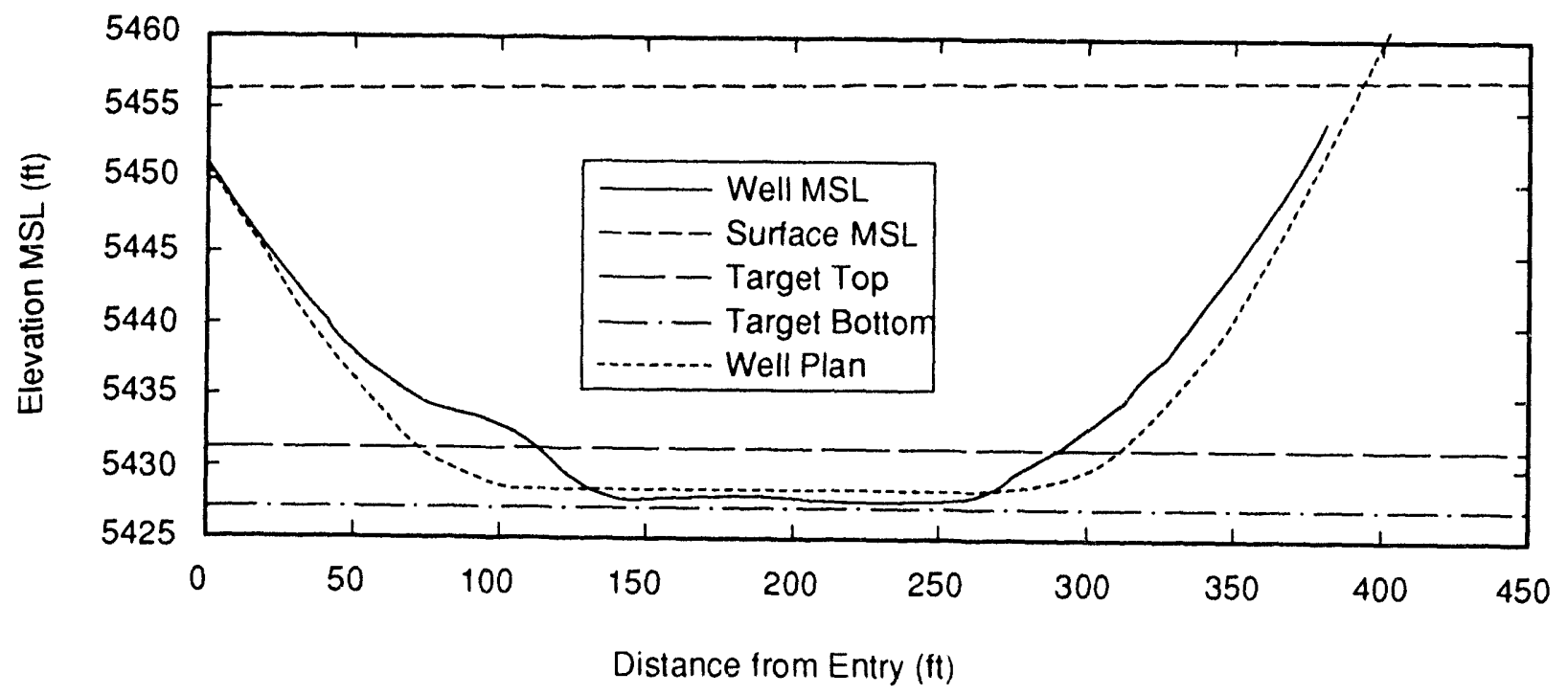

TRI.6111-16.0

Figure A-6. Albuquerque, NM; Kirtland AFB-RB-11 site. 


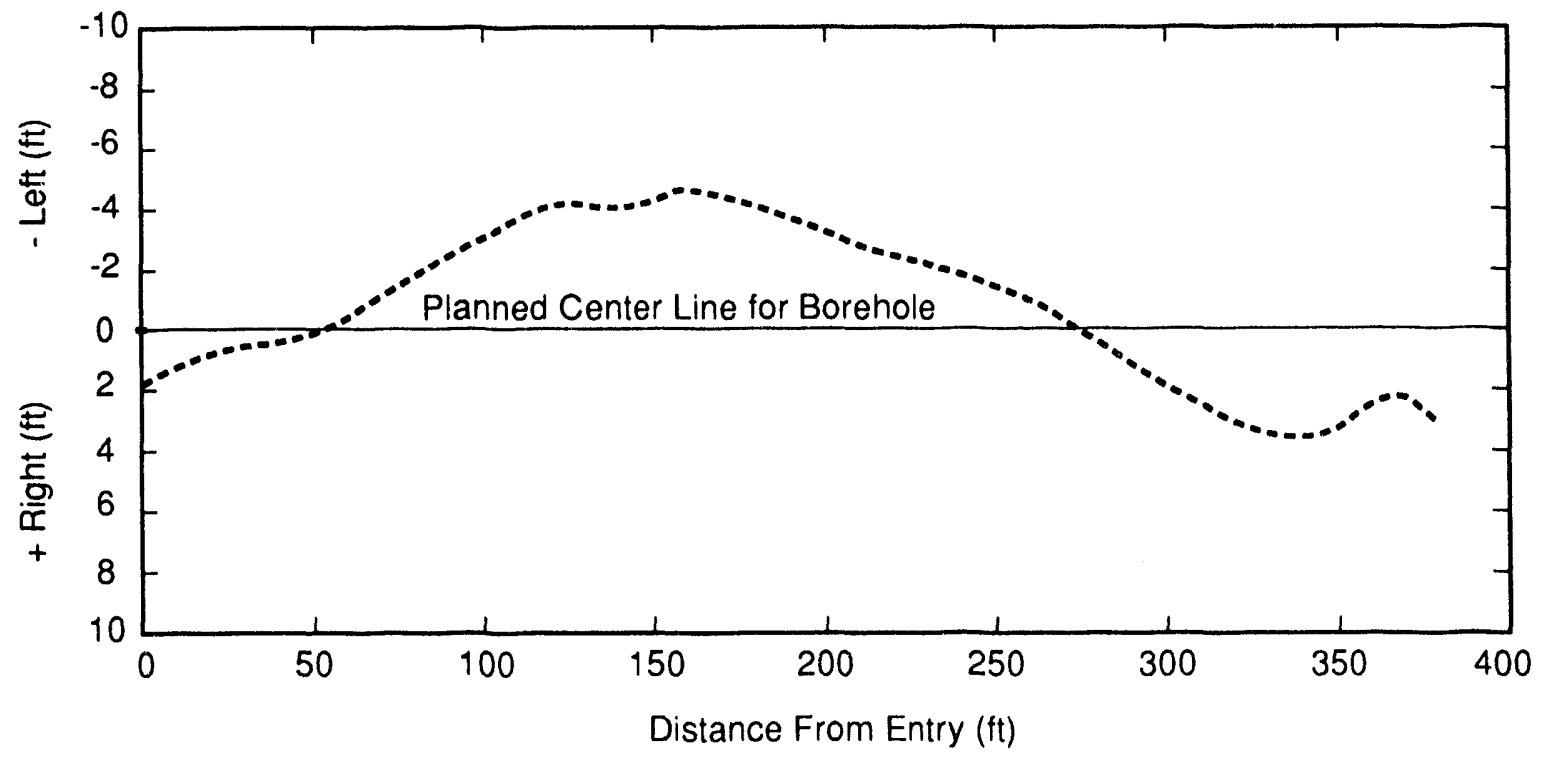

TRI.6111.19.0

Figure A-7. RB-11 Bore 1 plan view. 
A -42 


\section{APPENDIX B: RELATED ACCOMPLISHMENTS}




\section{Publications and Presentations}

FY1990 "Recent Field Trials of Directional Boring Equipment for Emplacing a Borehole Grid Around and Beneath a Simulated Waste Site"; R. P. Wemple, P. J. Lysne, and R. D. Jacobson, SNL; Presentation and Proceedings of DOE Model Conf, Oak Ridge, TN

FY1991 "Continuing Development of Hybrid Directional Boring and Horizontal Logging Technology"; R. P. Wemple, R. D. Meyer, R. D. Jacobson, SNL and R. R. Layne, Charles Machine Works. Inc.; Presentation and Proceedings of DOE Model Conf, Oak Ridge, TN.

FY1992 "Continued Development of Hybrid Directional Boring Technology": R. P. Wemple, R. D. Meyer, R. D. Jacobson, SNL and R. R. Layne, Charles Machine Works Inc.; Presentations and Proceedings of USAF-Hill AFB, EMR Technical Exchange Symposium, Salt Lake City, UT.

"Hybrid Directional Boring Development in the SNL/Charles Machine Works Industrial Partnership"; R. P. Wemple, R. D. Meyer, and R. D. Jacobson, SNL and R. R. Layne, Charles Machine Works Inc.; DOE TIE Workshop, Albuquerque, NM

FY1993 This interim project report.

Project Patent Disclosures

SNL: $\quad$ "Sampler Latch Mechanism," R. D. Meyer, 1992

"Multi-Sample Sampler," R. P. Wemple, 1992

CMW: "Bit and Reamer Designs" (A total of 3 patents applied for in FY 92 and FY 93)

\section{References}

"Industry Survey for Horizontal Wells," D.S. Kaback, Westinghouse Savannah River Co., and D.D. Wilson, CDM Federal Programs Corp., DCN 7901-218-DB-BC4G

"The Use of Horizontal Wells for Subsurface Soil and Aquifer Remediation," D.W. Way, Horizontal Drilling International, Houston, TX. 


\section{CASING OUTGASSING TESTS}

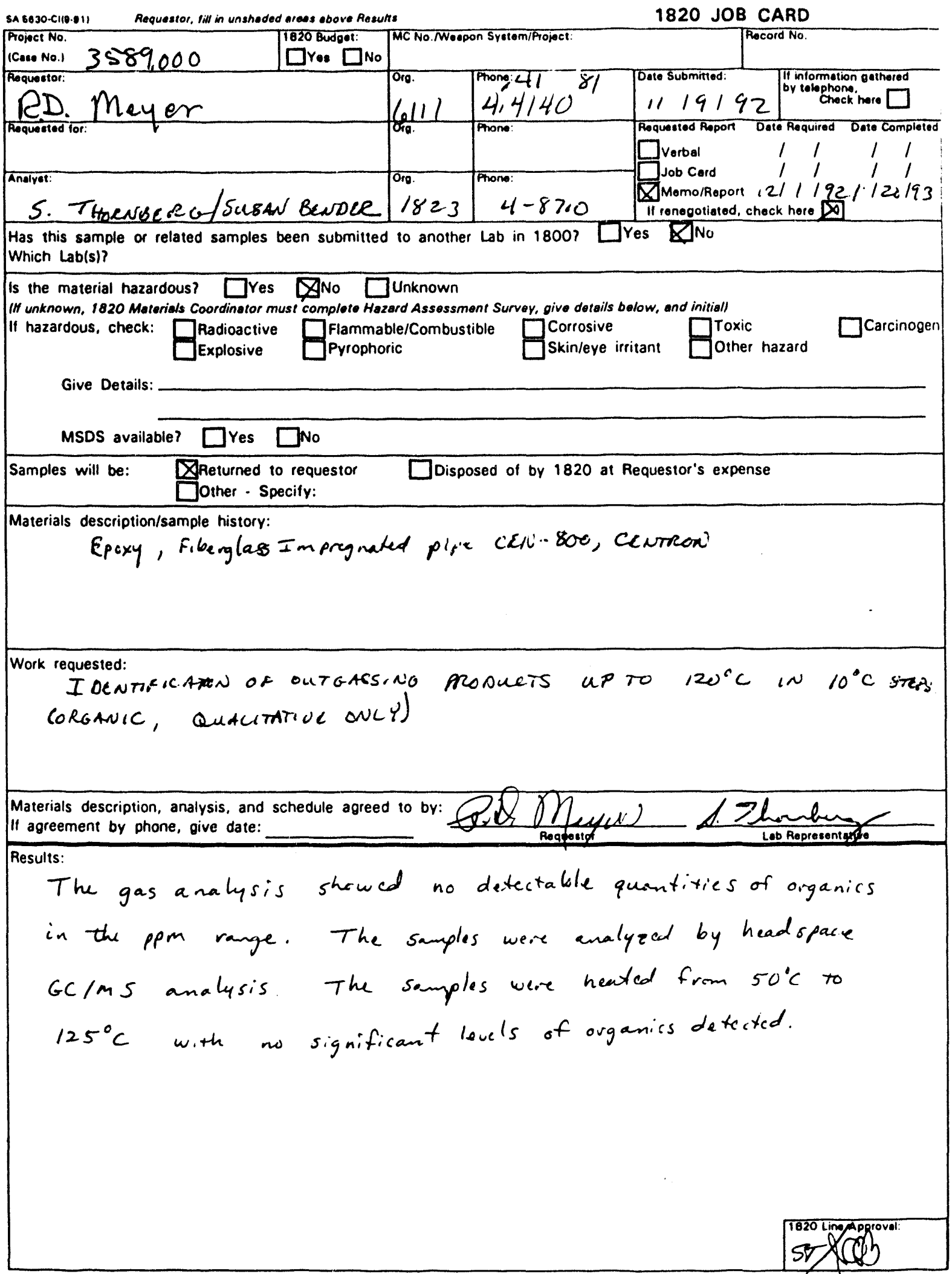




\section{ACCOMPLISHMENTS}

FY 91:

- INITIATED INDUSTRIAL PARTNERSHIP WITH CHARLES MACHINE WORKS, INC. (MAKERS OF DITCH WITCH PRODUCTS)

- TESTED A VARIETY OF EXISTING SHALLOW DIRECTIONAL EQUIPMENT

- TOURED OTHER DOE FACILITIES TO UNDERSTAND NEEDS

FY 92:

- INDUSTRY PARTNER BUILT PROTOTYPE MACHINE FOR TESTING

- ONBOARD POSITIONAL ELECTRONICS ADAPTED FROM RIVER CROSSING INDUSTRY

- DEMONSTRATED CAPABILITIES OF HYBRID HARDWARE

- BUILT CONCEPT HARDWARE FOR MULTI-SAMPLER

- MULTIPLE FIELD TESTS AT SNL DBTR AND INDUSTRY PARTNERSHIP FACILITY

- BORED AND COMPLETED 570', 40' DEPTH WELL AT SRS

- APPLIED FIBERGLASS CASING TO DIRECTIONAL WELLS

- INITIATED DRILL CUTTINGS CONTAINMENT SYSTEM (DCCS) DEVELOPMENT

FY 93:

- BORED TEST WELL AT RB-II SITE

- TESTED BORING AND SAMPLING HARDWARE AT HANFORD

- BORED ENVIRONMENTAL WELL AT RB-II SITE

- CONTINUED DEVELOPMENT OF DCCS DURING LEASE/TEST PHASE

- BUILT SECOND GENERATION PROTOTYPE OF MULTI-SAMPLER 


$$
\text { ( }
$$




\section{DISTRIBUTION LIST}

Sponsors

Westinghouse-SRS

Non-Arid Site Integrated Demonstration

Attn: John Steele, TPM (10)

Miles Denham, Environmental Sciences

P.O. Box 616

Aiken, SC 29802

Westinghouse-Hanford Company

Arid Site Integrated Demonstration

Attn: Environmental Division

Don Moak (10)

Greg McClellan

Ben Volk

Terry Walton

P.O. Box 1970

N3-05

Richland, WA 99352

\section{Other DOE Ofrices}

Allied Signal incorporated

Kansas City Division

P.O. Box 419159

Kansas City, MO 64141-6159

Amarillo Area Office (AAO)

P.O. Box 30030

Amarillo, TX 79120-0030

Dayton Area Office (DAO)

P.O. Box 66

Miamisburg, OH 45343-0066

EG\&G

Mound Applied Technologies

1 Mound Road

P.O. Box 3000

Miamisburg, $\mathrm{OH} \quad 45343-3000$

\section{EG\&G}

Rocky Flats

P.O. Box 464

Golden, CO 80402-0464
Grand Junction Projects Office

P.O. Box 2567

Grand Junction, CO 81502-2567

Kansas City Area Office (KCAO)

P.O. Box 410202

Kansas City, MO 64141-0202

Kirtland Area Office

P.O. Box 5400

Albuquerque, NM 87185-5400

Los Alamos Area Office (LAAO)

528 35th Street

Los Alamos, NM 87544

Los Alamos National Laboratory

P.O. Box 1663

Los Alamos, NM 87545

Lovelace Biomedical and Environmental

Research Institute

Inhalation Toxicology Research Institute (ITRI)

P.O. Box 5890

Albuquerque, NM 87185-5890

Martin Marietta

P.O. Box 2908

Largo, FL 34649

Pinellas Area Office (PAO)

P.O. Box 2900

Largo, FL 34649

DOE Yucca Mit. Project Office

P.O. Box 98608

M.S. 523

Las Vegas, NV 89193-8608

Attn: Roy Long

Other DOE Labs

Ames Laboratory

Iowa State University

106 Spedding Hall

Ames, IA 50011

Attn: Paul Wang 


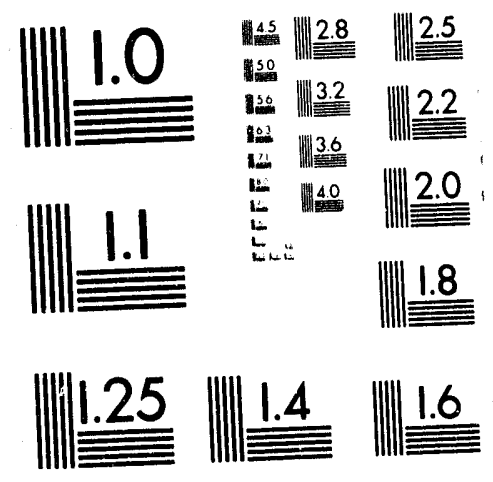



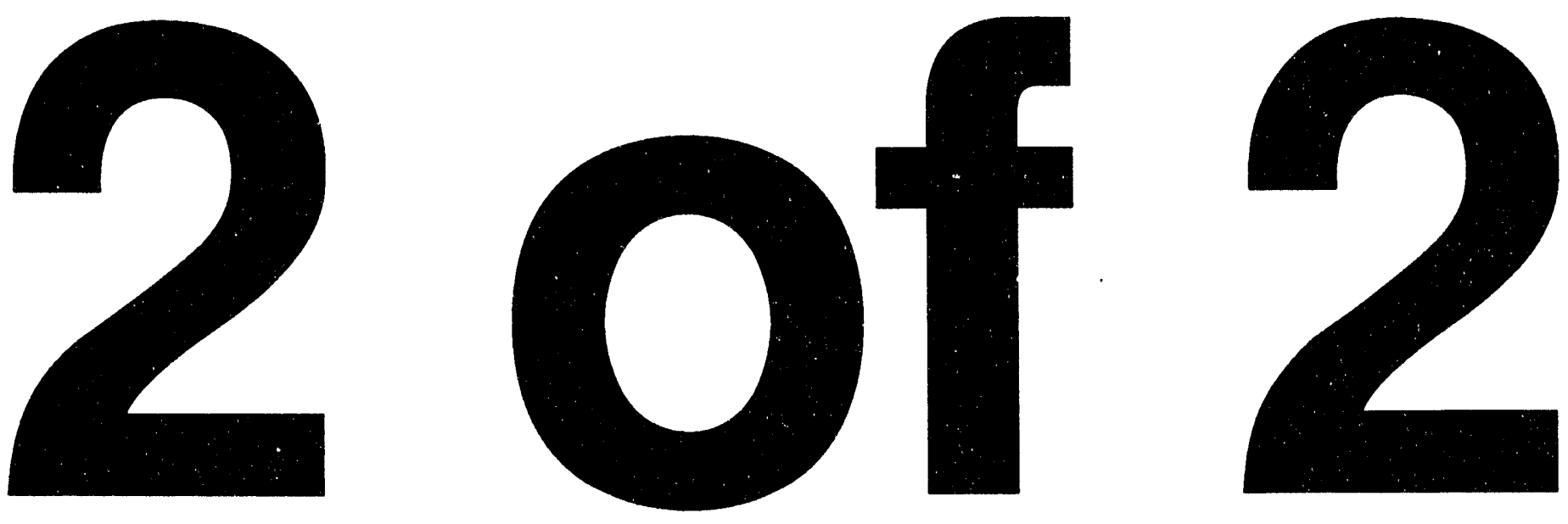
INEL

P.O. Box 1625

Attn: Joel Hubbell (5)

MS 2107

Idaho Falls, ID 83415

GEO Engineering Group

Attn: Sue Goff (5)

EES-4, MS D-443

Los Alamos, NM 87545

Martin-Marietta

ORNL

P.O. Box 2003

Oak Ridge, TN 37831-7172

Attn: R.K. Kibbe

PNL

Attn: F. Blaine Metting

Battelle Boulevard

Richland, WA 99353

Other Government Agencies

\section{Federal}

EPA

Center Hill Solid and Hazardous Waste

Research Facility

Attn: Larry Murdoch

University of Cincinnati

5995 Center Hill Rd.

Cincinnati, $\mathrm{OH} 45224$

Office of Research and Development

Attn: D. A. Carson

26 West Martin Luther King Dr.

Cincinnati, OH 45268

Office of Research and Development

Attn: W. J. Davis-Hoover

Cincinnati, OH 45268

Risk Reduction Engineering Laboratory

Attn: M. H. Roulier

Center Hill Research Facility

5995 Center Hill Ave.

Cincinnati, OH 45224

\section{EPA Regional Offices}

Region 1

U.S. EPA, Region 1 Office

Attn: Pat Meany, Acting Regional Administrator

JFK Federal Bldg.

Boston, MA 02203

Region 2

U.S. EPA, Region 2 Office

Attn: William J. Muszynski, Acting Regional Administrator

26 Federal Plaza

New York, NY 10278

Region 3

U.S. EPA, Region 3 Office

Attn: Stanley L. Laskowski, Acting Regional Administrator

841 Chestnut Street

Philadelphia, PA 19107

R`gion 4

U.S. EPA, Region 4 Office

Attn: John H. Hankinson, Jr., Regional Administrator

345 Courtland Street, NE

Atlanta, GA 30365-2401

Region 5

U.S. EPA, Region 5 Office

Attn: Valdas Adamkus, Regional Administrator

77 West Jackson

Chicago, IL 60604

Region 6

U.S. EPA, Region 6 Office

Attn: Jane N. Saginaw, Regional Administrator

1445 Ross Avenue, 13th floor

Dallas, TX 75202 
Robert S. Kerr Environmental Research Lab

Attn: Clinton Hall, Director

P.O. Box 1198

Kerr Lab Road

Ada, OK 74820

Region 7

U.S. EPA, Region 7 Office

Attn: Dennis Grams

726 Minnesota Avenue

Kansas City, KS 66101

\section{Region 8}

U.S. EPA, Region 8 Office

Attn: Bill Yellowtail, Regional Administrator 999 18th Street

Denver, CO 80202-2405

\section{Region 9}

U.S. EPA, Region 9 Office

Attn: Felicia Marcus, Regional

$$
\text { Administrator }
$$

75 Hawthorne Street

San Francisco, CA 94105

Environmental Monitoring Systems Laboratory Office of the Director

Attn: Wayne Marschant

P.O. Box 93478

Las Vegas, NV 89119

Region 10

U.S. EPA, Region 10 Office

Attn: Gerald Emison, Acting Regional Administrator

1200 Sixth Avenue

Seattle, WA 98101

U.S. Environmental Protection Agency

Environmental Criteria and Assessment Office

Director of Research

26 West Martin Luther King Drive

Cincinnati, OH 45268
U.S. EPA Headquarters

Attn: Director's Office

401 M Street, SW

Washington, DC 20460

U.S.A.F.

Attn: Harry Davidson

Environmental Office

Kirtland AFB

OO-ALC/EM

Environmental Management Directorate

Attn: Daniel Stone

7276 Wardleigh Rd.

Hill AFB, UT 84056-5127

A1/EQW

Attn: Bruce Nielsen

139 Barnes Dr.

Tyndall AFB, FL 32403-5323

\section{NASA}

Martin-Marietta Manned Space Systems

Attn: Marty Rowland

P.O. Box 29304, MS 3141

NASA Michoud Facility

Facilities Environmental Engineering

New Orleans, LA 70189

\section{USGS}

U.S. Geological Survey (2)

Water Resources Division

Attn: R. Livingston

W. Dam

4501 Indian School NE, Suite 200

Albuquerque, NM 87110

USGS

Mail Stop 101 National Center

Attn: Robert M. Hirsch, Acting Director

12201 Sunrise Valley Dr.

Reston, VA 22092

USGS

Mail Stop 911 National Center

Attn: Benjamin Morgan, Chief Geologist 12201 Sunrise Valley Dr.

Reston, VA 22092 
USGS

Director's Representative

Attn: Harry A. Tourtelot

Box 25046

Denver Federal Center

Denver, CO 80225-0046

USGS

Director's Representative

Attn: George Gryc

Bldg. 345 Middlefield Rd.

Menlo Park, CA 94025-3591

USGS

Director's Representative

Attn: Paul Brooks

Grace Hall APU

4230 University Dr.

Anchorage, AK 99508-4664

State

Colorado Center for Environmental Management

Attn: Dawn Kaback

999 18th St., Suite 2750

Denver, CO 80202

Environmental Evaluation Group (3)

Attn: Library

7007 Wyoming NE, Suite F-2

Albuquerque, NM 87109

NM Bureau of Mines and Mineral Resources

Socorro, NM 87801

NM Energy, Minerals, and Natural

Resources Dept.

Attn: Library

2040 S. Pacheco

Santa Fe, NM 87505

NM Environment Department (3)

Attn: J. Espinosa

1190 St. Francis Drive

Santa Fe, NM 87503-0968
Albuquerque Public Works

Attn: Rick Roybal, City Engineer

P.O. Box 1293

Albuquerque, NM 87103

Private Sector

CDM Federal Programs

Attn: Dave Wilson

1626 Cole Blvd., Suite 100

Golden, CO 80401

ALCOA South Carolina, Inc.

Attn: P. H. LeRoy

P.O. Box 819

211 Charles St.

Beaufort, SC 29901

ALCOA Technical Center

100 Technical Dr.

Alcoa Center, PA 15069-0001

FERMCO Restoration Management Corp.

Attn: P. Pettit

4380 Malsbury Rd., Suite 200

Cincinnati, $\mathrm{OH} 45242$

\section{Others}

Western Governors' Association

Attn: James Souby, Executive Director

600 17th St., Suite 1705, South Tower

Denver, CO 80202

Universities/Libraries

Thomas Brannigan Library

Attn: D. Dresp

106 W. Hadley St.

Las Cruces, NM 88001

Government Publications Department

Zimmerman Library

University of New Mexico

Albuquerque, NM 87131

\section{City}


New Mexico Junior College

Pannell Library

Attn: R. Hill

Lovington Highway

Hobbs, NM 88240

New Mexico State Library

Attn: N. McCallan

325 Don Gaspar

Santa Fe, NM 87503

New Mexico Tech

Martin Speers Memorial Library

Campus Street

Socorro, NM 87810

Westinghouse-Savannah River

Technology Center (4)

Attn: N. Bibler

J. Harbour

M. Plodinec

G. Wicks

Aiken, SC 29802

\section{Industry Partner}

The Charles Machine Works, Inc.

Ditch Witch ${ }^{\text {TM }}$

P.O. Box 66

Attn: R.R. Layne, Project Manager (150)

Perry, OK 73077-0066

\section{Drilling Technical Support Group}

Westinghouse-Hanford

Attn: D. Myers

Env. Technology

Westinghouse Hanford (H4-54)

P.O. Box 1970

Richland, WA 99352

University of California-Berkeley

Attn: G. Cooper

Berkeley, CA 94720
University of Missouri-Rolla

Attn: D. Summers

Dept. of Materials Science \& Mineral

Engineering

213 Rock Mechanics Facility

Rolla, MO 65401-0249

Trenchless Technology Center

Department of Civil Engineering

Louisiana Tech. University

P.O. Box 10348

Ruston, LA 71272

Required Distribution

MS 0899 SNL Technical Library, (5), 7141

MS 0619 SNL Technical Publications, 7151

MS 0100 SNL Document Processing, DOE/OSTI (10), 7613-2

MS-9018 SNL Central Technical Files, 8523-2

SNL Sponsors

MS 0728 George Allen, TPM (10), 6602

MS 0719 Jennifer Nelson, IDC (15), 6621

MS 0719 Jim Phelan, 6621

MS 0719 Bob Floran, 6621

MS 0719 Cecilia Williams, 6621

SNL Environmental Groups

MS 1066 R. K. Traeger, 71152

MS 1065 R. W. Rohde, 7254

MS 1061 A. O. Bendure, 7258

MS 1315 T. E. Blejwas, 7500

MS 1309 S. Ward, 7511

MS 1307 J. G. Yeager, 7572

MS 1303 J. R. Guth, 7573

MS 1305 J. D. Fish, 7574

MS 1311 H. S. Hwang, 7575

MS 1347 W. B. Cox, 7581

MS 1347 F. B. Nimick, 7582

MS 1347 J. A. Fernandez, 7583

MS 1347 D. Stermer, 7584

MS 1347 D. Fate, 7585

MS 1045 M. M. Carroll, 7732 
SNL Geoscience/Geotechnology Center Staff

MS 0701 R. W. Lynch, 6100

MS 1033 J. C. Dunn, 6111

MS 1033 J. Gabaldon, 6111

MS 1033 P. J. Cronewald, 6111

MS 1033 R. D. Jacobson, 6111

MS 1033 P. C. Lysne, 6111

MS 1033 R. D. Meyer, (25), 6111

MS 1033 A. R. Sattler, 6111

MS 1033 J. L. Wise, 6111

MS 1033 R. P. Wemple, (50), 6111

MS 1033 J. J. Westmoreland, 6111

MS 0706 D. A. Northrop, 6112

MS 0706 J. K. Linn, 6113

MS 0706 M. W. Scott, 6114

MS 1324 P. B. Davies, 6115

MS 0750 M. C. Walck, 6116

MS 0751 W. R. Wawersik, 6117

MS 0750 H. R. Westrich, 6118

MS 1320 E. J. Nowak, 6119

MS 1322 J. R. Tillerson, 6121 

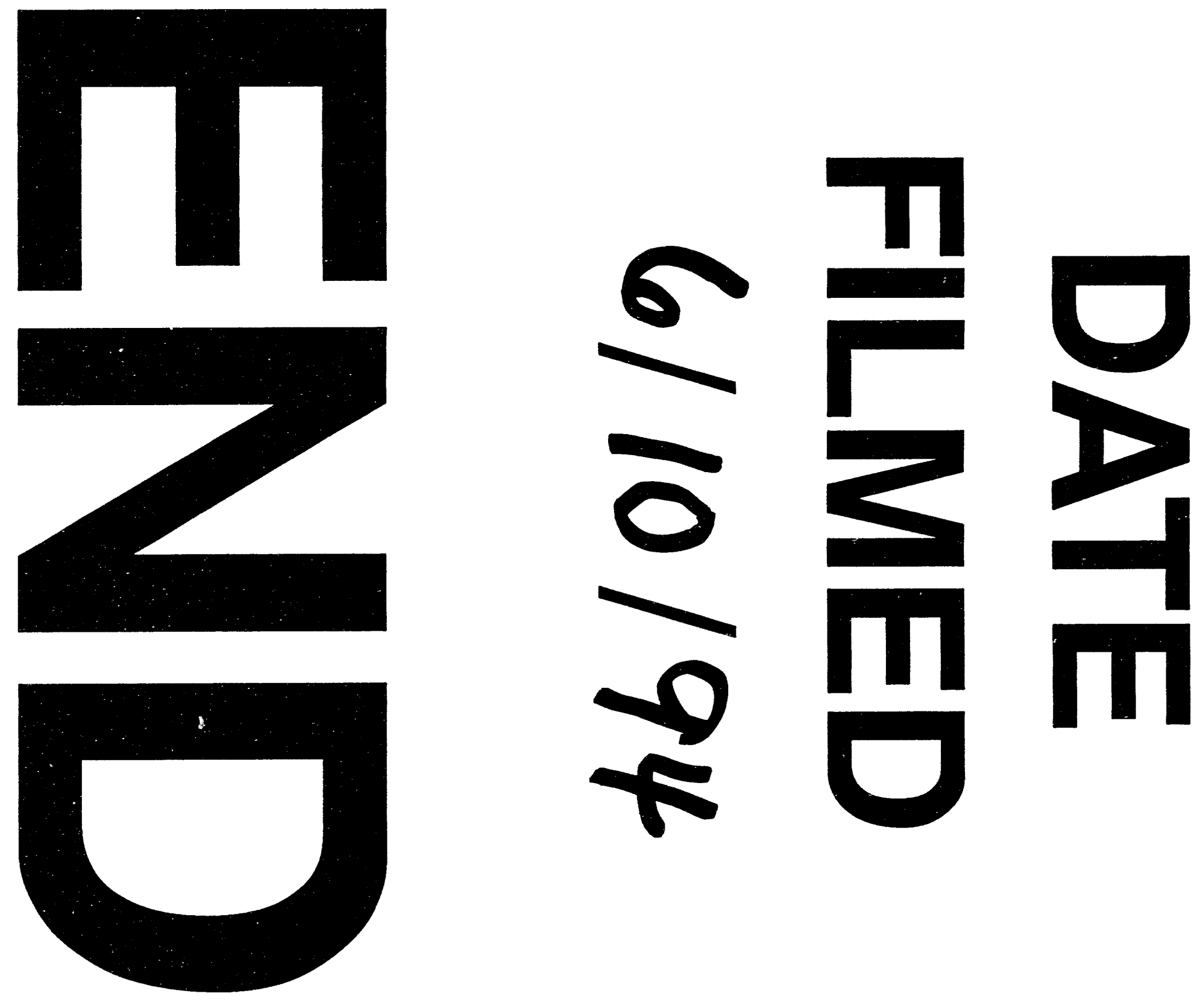
